\title{
ON THE INSEPARABILITY OF GRAMMAR AND THE LEXICON: EVIDENCE FROM ACQUISITION, APHASIA AND REAL-TIME PROCESSING
}

\author{
Elizabeth Bates \\ University of California, San Diego \\ Judith C. Goodman \\ University of Missouri, Columbia
}

\begin{abstract}
Acknowledgments
Support for the work described here has been provided by NIH/NIDCD-R01-DC00216 ("Cross-linguistic studies in aphasia"), NIH-NIDCD P50 DC1289-9351 ("Origins of communication disorders"), NIH/NINDS P50 NS22343 ("Center for the Study of the Neural Bases of Language and Learning"), and by a grant from the John D. and Catherine T. MacArthur Foundation Research Network on Early Childhood Transitions.
\end{abstract}

Please address all correspondence to Elizabeth Bates, Center for Research in Language 0526, University of California at San Diego, La Jolla, CA 92093-0526, or bates@crl.ucsd.edu.

Language and Cognitive Processes, 1997, 12(5/6), 507-584. 


\title{
ON THE INSEPARABILITY OF GRAMMAR AND THE LEXICON: EVIDENCE FROM ACQUISITION, APHASIA AND REAL-TIME PROCESSING
}

\author{
Elizabeth Bates and Judith C. Goodman
}

\begin{abstract}
Within linguistic theory, many phenomena that were previously handled by a separate grammatical component have been moved into the lexicon; in some theories, the contrast between grammar and the lexicon has disappeared altogether. In a review of findings from language development, language breakdown and real-time processing, we conclude that the case for a modular distinction between grammar and the lexicon has been overstated, and that the evidence to date is compatible with a unified lexicalist account. Studies of normal children show that the emergence of grammar is highly dependent upon vocabulary size, a finding confirmed and extended in atypical populations. Studies of language breakdown in older children and adults provide no evidence for a modular dissociation between grammar and the lexicon; some structures are especially vulnerable to brain damage (e.g., function words, noncanonical word orders), but this vulnerability is also observed in neurologically intact individuals under perceptual degradation or cognitive overload. Finally, on-line studies provide evidence for early and intricate interactions between lexical and grammatical information in normal adults. A possible characterization of this unified lexical processor is offered, based on distributed representations in recurrent neural networks.
\end{abstract}

Linguistics is a field that is known for controversy. Consensus and common ground have proven hard to find (Botha, 1989; Harris, 1993; Newmeyer, 1988). One can, however, discern a general trend that has characterized recent proposals in otherwise very diverse theoretical frameworks: more and more of the explanatory work that was previously handled by the grammar has been moved into the lexicon. In some frameworks (e.g., recent versions of Chomsky's generative grammar-Chomsky, 1981, 1995), the grammatical component that remains is an austere, "stripped down" system characterized by a single rule for movement and a set of constraints on the application of that rule. In this theory, the richness and diversity of linguistic forms within any particular language are now captured almost entirely by the lexicon, which includes complex propositional structures and productive rules that govern the way those elements are combined. The trend toward lexicalism is even more apparent in alternative frameworks like Lexical Functional Grammar (Bresnan, 1982, 1996) and Head-Driven Phrase Structure Grammar (Pollard \& Sag, 1994). It reaches its logical conclusion in a framework called Construction Grammar (Fillmore, Kay, \& O'Connor, 1988; Goldberg, 1995), in which the distinction between grammar and the lexicon has disappeared altogether (see also Langacker, 1987). In Goldberg's Construction Grammar, all elements of linguistic form are represented within a heterogeneous lexicon that contains bound morphemes, free-standing content and function words, and complex phrase structures without terminal elements (e.g., the passive). This lexicon can be likened to a large municipal zoo, with many different kinds of animals. To be sure, the animals vary greatly in size, shape, food preference, life style, and the kind of handling they require. But they live together in one compound, under common management. The new lexicalist perspective is quite different from the modular proposals that characterized the first two decades or so of modern generative linguistics, which postulated separate but roughly equal components for semantics (including lexical description), grammar and phonology (e.g., Chomsky, 1957, 1965; Katz \& Postal, 1964).

It is our contention that the fields of psycholinguistics, neurolinguistics and language acquisition have (with some exceptions) not kept up with lexicalist movement in linguistic theory. In their style of argumentation and use of evidence, many investigators within these fields are still firmly rooted in the modular perspective that characterized linguistic theory thirty years ago. In particular, there is still a strong tendency in many quarters to seek (and find) a discrete and discontinuous boundary between grammar and the lexicon, and/or between those lexical items that do grammatical work and those that do not (e.g., the distinction between closed- and open-class words-Garrett, 1992; Neville, Nicol, Barss, Forster, \& Garrett, 1991; the contrast between regular and irregular morphology-Pinker, 1991, 1994). In this paper, we will review evidence relevant to the hypothesized dissociation between grammar and the lexicon, in four areas:

I. First, we will look at recent evidence on the relationship between lexical development and the emergence of grammar in normally developing children between 8-30 months of age. This will include new longitudinal data, from a group of normal infants followed across a crucial phase of language development. The evidence will show that the emergence and elaboration of grammar are highly dependent upon vocabulary size throughout this period, as children make the passage from first words to sentences and go on to gain productive control over the basic morphosyntactic structures of their native language. 
II. Second, we will compare these results for normal children with studies of early language development in several atypical populations, including early talkers, children with focal brain injury, Williams Syndrome and Down Syndrome. Results will show that (a) grammar and vocabulary do not dissociate in early talkers or in children with focal brain injury, at least not within this phase of development, (b) grammatical development never outstrips lexical growth, even in the Williams population (a form of retardation in which linguistic abilities are surprisingly spared in the adult steady state), and (c) grammatical development can fall behind vocabulary in some subgroups (e.g., Down Syndrome), but this apparent dissociation can be ex-plained by limits on auditory processing.

III. Having reviewed the developmental findings in some detail, we will provide a brief critical review of the evidence that has been offered in favor of a double dissociation between grammatical and lexical structures in older children and adults with neurological disorders. We will show that there is no solid evidence for a double dissociation between these putative modules. All aphasic patients with pervasive deficits in grammar also show deficits in some aspect of lexical processing (e.g., the word-finding deficit called "anomia"), and patients with lexical deficits also display limitations in at least some aspect of grammatical processing (receptive, expressive, or both). Despite the absence of a clean double dissociation, it is true that some aspects of grammar appear to be especially vulnerable in aphasia. However, similar patterns of vulnerability are also observed in neurologically intact individuals who are forced to process language under adverse circumstances (e.g., perceptual degradation, cognitive overload), suggesting that specific deficits in grammatical morphology and/or use of complex syntax reflect "weak links in the processing chain." This does not mean that all lexical deficits are alike. Different kinds of lexical impairments have been observed (e.g., in fluent vs. nonfluent aphasic patients), and these lexical contrasts are typically accompanied by different kinds of grammatical breakdown. In other words, our municipal zoo can be damaged in a number of different ways. We will argue, however, that these diverse patterns can be explained within a unified lexicalist account.

IV. Finally, we will present a very brief review of recent on-line processing studies, looking at the early and intricate interactions that have been observed between grammatical and lexical processing in normal adults. We conclude that the evidence is quite compatible with a theory in which grammatical and lexical structures are represented in a common format and processed in an integrated store, following common principles of access and integration (e.g., effects of recency, frequency and priming).

We will conclude that the case for a modular distinction between grammar and the lexicon in acquisition, aphasia and normal processing has been overstated (see also MacDonald, Pearlmutter, \& Seidenberg, 1994). A new look at the evidence shows that the psycholinguistic data are compatible with a radically lexicalist theory of grammar (see also Goldberg, 1995; MacWhinney, in press). This does not mean that grammatical structures don't exist (they do), or that the representations that underlie grammatical phenomena are identical to those that underlie single-content words (they are not). Rather, we are suggesting that the heterogeneous set of linguistic forms that occur in any natural language (i.e., words, morphemes, phrase structure types) may be acquired and processed by a unified processing system, one that obeys a common set of activation and learning principles. There is no need for discontinuous boundaries. A possible characterization of this unified lexical processor is offered, based on distributed representations in recurrent neural networks.

\section{Grammar and the lexicon in normally developing children}

At first glance, the course of early language development seems to provide a prima facie case for linguistic modularity. Children begin their linguistic careers with babble, starting with vowels (somewhere around 3-4 months, on average) and ending with combinations of vowels and consonants of increasing complexity (usually between 6-12 months). Meaningful speech emerges some time between 10-12 months, on average, although word comprehension may begin a few weeks earlier. After this, most children spend many weeks or months producing single-word utterances. At first their rate of vocabulary growth is very slow, but one typically sees a "burst" or acceleration in the rate of vocabulary growth somewhere between 16-20 months. First word combinations usually appear between 18-20 months. At first, these combinations tend to be rather spare and telegraphic (at least in English). Somewhere between 24-30 months, most children show a kind of "second burst", a flowering of morphosyntax that Roger Brown (1973) has characterized as "the ivy coming in between the bricks." By 3-3.5 years of age, most normal children have mastered the basic morphological and syntactic structures of their language (defined by various criteria for productivity, including rulelike extension of grammatical structures to novel words).

This picture of language development in English has been documented extensively (for reviews see Aslin, Jusczyk, \& Pisoni, in press; Bloom, 1991; Fenson et al., 1994; Fletcher \& MacWhinney, 1995; Goodman \& Nusbaum, 1994; Kuhl, 1991; Menn, 1985). Of course this textbook story is not exactly the same in every language (Bates \& Marchman, 1988; MacWhinney \& Bates, 1989; Slobin, 1985, 1992, in press), and perfectly healthy children can vary markedly in rate and style of development through these milestones (for reviews, see Bates, Bretherton, \& Snyder, 1988; Bates, Dale, \& Thal, 1995; Fenson et al., 1994; Shore, 1995). At a global level, however, the passage from sounds to 


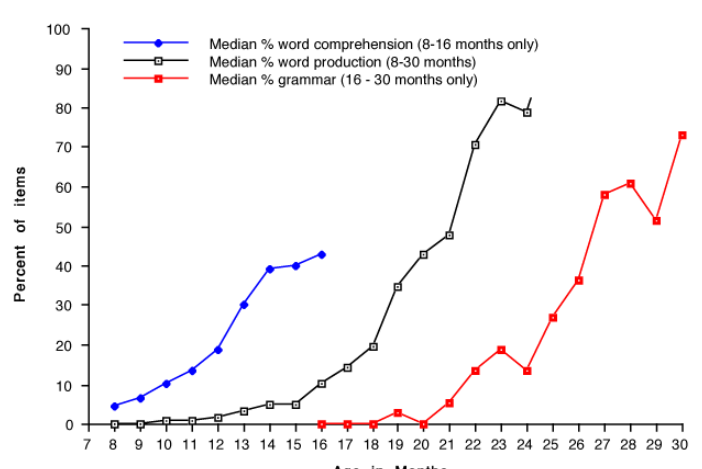

Age in Months

Figure 1. Median growth scores for word comprehension, production and grammar expressed as a percentage of available items (from Goodman, 1995).

words to grammar appears to be a universal of child language development. A quick look at the relative timing and shape of growth in word comprehension, word production and grammar can be seen in Figure 1, taken from our own longitudinal study of language development from 8-30 months (Goodman, 1995). The word comprehension and production estimates are based on the same word checklist, and the grammar estimate is based on a 37-item scale for sentence complexity (note that these comprehension data were only collected from 8-16 months, and measurement of grammar did not begin until 16 months - see below for additional methodological details). Assuming for a moment that we have a right to compare the proportional growth of apples and oranges, this figure shows that all three domains follow a dramatic, nonlinear pattern of growth across this age range. However, the respective "zones of acceleration" for each domain are separated by many weeks or months.

As Fodor (1983) has argued, one of the nine criteria that define a "mental module" is the observance of a "characteristic maturational course" (for a discussion, see Bates et al., 1988; Karmiloff-Smith, 1992). Indeed, it does look as though the basic modules of 1960's generative linguistics emerge on a fixed and orderly schedule: phonology, followed by lexical semantics, with the grammatical component making its first appearance around two years of age. Bickerton (1984) has taken this succession quite seriously. Following Chomsky ${ }^{1}$, he argues that the period of babbling and single-word production prior to two years of age is essentially "pre-linguistic". True, around 2 years of age. Locke (1983, in press) has argued for a similar

\footnotetext{
1“'Observation of early stages of language acquisition may be quite misleading in this regard. It is possible that at an early stage there is use of languagelike expressions, but outside the framework imposed, at a later stage of intellectual maturation, by the faculty of language - much as a dog can be trained to respond to certain commands, though we would not conclude, from this, that it is using language." (Noam Chomsky, Reflections on language (p. 53). New York, Pantheon Books, 1975).
}

discontinuity, albeit in a more subtle form. He suggests that the phase of single-word production (including some formulaic phrases like "I wan' dat" or "Love you") is governed by an "utterance-collecting" mechanism that may be mediated primarily by the right hemisphere. The emergence of productive, lawful grammar between 2-3 years of age reflects the discontinuous emergence of a separate linguistic mechanism, possibly one that is mediated by the left hemisphere. Unlike Bickerton, Locke believes that there is a causal relationship between these two phases. Specifically, if the rule mechanism "turns on" before a critical mass of utterances has been stored, it will not operate properly. However, the two phases are mediated by distinct neural mechanisms, and each matures ("turns on") according to its own genetic timetable (i.e., vocabulary size does not "cause" the grammatical device to mature).

This kind of structural discontinuity in the passage from first words to grammar is reminiscent of Jakobson's proposal for a discontinuity between babble and meaningful speech (1968). Jakobson went so far as to suggest that children fall silent for a brief period between these two stages. Furthermore, he suggested that the phonological content of babble (i.e., the consonants and vowels that children prefer) is quite distinct from the phonological content of first words. These were interesting ideas, but after 30 years of research on child phonology, we now know that Jakobson was wrong on both these points (Goodman \& Nusbaum, 1994; Menn, 1985; Vihman, Ferguson, \& Elbert, 1986; Vihman \& Greenlee, 1987; Vihman, Macken, Miller, Simmons, \& Miller, 1985). There is no silent period, and the specific sounds that individual children prefer in their prelexical babble tend to predominate in the same child's first attempts at meaningful speech. This continuous flow of preferred and avoided phonemes suggests that phonological and lexical development are interwoven. Furthermore, this continuous flow is not unidirectional. Leonard (Leonard, Newhoff, \& Mesalam, 1980; Schwartz, 1978), Vihman et al. (1985) and others have proposed that there is a tight bidirectional relationship between babbling and early lexical development, and that the child's first word templates (probably appearing first in comprehension) serve as targets for complex babble. Furthermore, Werker (1994) and Werker and Tees (1984) have shown that infants begin to home in on the consonant phonemes of their native language between 8 and 12 months of age. They are also beginning to comprehend words at this time suggesting that emerging lexical knowledge may contribute to the development of a phonological system. While the relationship between phonological and lexical development is not the focus of this paper, we bring it up here to illustrate that what appeared at first glance to be an orderly and modular progression from one linguistic component to 
another turns out, after a closer look, to involve bidirectional causality and temporal overlap.

What about the passage from single words to grammar? Is this a discontinuous passage, or does it involve the same kind of messy interchange that has been observed for babbling and first words? We have known for some time that, within individual children, the content, style and patterning of first word combinations is strongly influenced by the content, style and patterning of single-word speech (Bates et al., 1988; Bloom, Lightbown, \& Hood, 1975; Braine, 1976; Horgan, 1978, 1979, 1981). But of course no one has ever proposed (not even Bickerton) that grammar can begin in the absence of words. As Locke notes, any rule-based device is going to have to have a certain amount of lexical material to work on. The real question is: Just how tight are the correlations between lexical and grammatical development in the second and third year of life? Are these components dissociable, and if so, to what extent? How much lexical material is needed to build a grammatical system? Can grammar get off the ground and go its separate way once a minimum number of words is reached (e.g., 50-100 words, the modal vocabulary size when first word combinations appear-Bates et al., 1988; Nelson, 1973; Shore, 1995; Shore, O’Connell, \& Bates, 1984)? Or will we observe a constant and lawful interchange between lexical and grammatical development, of the sort that one would expect if the lexicalist approach to grammar is correct, and grammar does not dissociate from the lexicon at any point in life?

Our reading of the evidence suggests that the latter view is correct. As we shall see, the function that governs the relation between lexical and grammatical growth in this age range is so lawful that it approaches Fechner's law in elegance and power. The successive "bursts" that characterize vocabulary growth and the emergence of morphosyntax can be viewed as different phases of an immense nonlinear wave that starts in the single-word stage and crashes on the shores of grammar a year or so later.

Our first insights into this tight correlation came in a longitudinal study of 27 children who were observed at $10,13,20$ and 28 months of age, using a combination of structured observations (at home and in the laboratory) and parental report (Bates et al., 1988; see also Bretherton, McNew, Snyder, \& Bates, 1983; Snyder, Bates, \& Bretherton, 1981). Among other things, we examined the concurrent and predictive relation between vocabulary size and grammatical status at 20 and 28 months of age. Vocabulary size was assessed with a combination of video observations and parental report (for a discussion of why parental report provides a more faithful estimate of lexical size and content, see Bates, Dale, \& Thal, 1995; Fenson et al., 1994; Marchman \& Bates, 1994). In this study, grammatical development was assessed in a rather standard fashion, calculating mean length of utterance in morphemes (MLU) from
TABLE 1

Relations between Grammatical Development and Vocabulary Size from 20 to 28 Months (from Bates et al., 1998a)

\begin{tabular}{lllll}
\hline & $\begin{array}{l}\text { 20-Month } \\
\text { Vocabulary }\end{array}$ & $\begin{array}{l}\text { 20-Month } \\
\mathrm{MLU}^{1}\end{array}$ & $\begin{array}{l}\text { 28-Month } \\
\text { Vocabulary }\end{array}$ & $\begin{array}{l}\text { 28-Month } \\
\text { MLU }^{1}\end{array}$ \\
\hline $\begin{array}{l}\text { 20-Month } \\
\text { Vocabulary }\end{array}$ & - & & & \\
$\begin{array}{l}\text { 20-Month } \\
\text { MLU }^{1}\end{array}$ & $+.54^{* *}$ & - & & \\
$\begin{array}{l}\text { 28-Month } \\
\text { Vocabulary }\end{array}$ & $+.64^{* *}$ & $+.47^{*}$ & - & \\
$\begin{array}{l}\text { 28-Month } \\
\text { MLU }^{1}\end{array}$ & $+.83^{* *}$ & $+.48^{*}$ & $+.73^{* *}$ & - \\
\hline
\end{tabular}

${ }^{1}$ Mean Length of Utterance in Morphemes. $* \mathrm{p}<.05, * * \mathrm{p}<.01$

speech transcriptions, following the rules outlined by Brown (1973). ${ }^{2}$ Table 1 summarizes the cross-lag correlations that we found between lexical and grammatical development within and across these two age levels. Results were very clear: The single best estimate of grammatical status at 28 months (right in the heart of the "grammar burst") is total vocabulary size at 20 months (measured right in the middle of the "vocabulary burst"). In fact, the correlation coefficient in this and related analyses with other grammatical variables hovered consistently between $+.70-+.84$. Because we know that no measure can correlate with another variable higher than it correlates with itself (i.e., Spearman's Law of Reliability), it is interesting to note that separate samples of MLU at 28 months of age also tend to intercorrelate in the $+.75-+.80$ range. What this means, in essence, is that 20-month vocabulary and 28-month MLU scores are statistically identical; one could be used as a stand-in for the other in predicting a child's rank within his/her group. Of course this kind of correlational finding does not force us to conclude that grammar and vocabulary growth are mediated by the same developmental mechanism. Correlation is not cause. At the very least, however, this powerful correlation suggests that the two have something important in common.

In a more recent series of studies, we have developed a new parental report instrument called the MacArthur Communicative Development Inventory (CDI) to study the relationship between lexical and grammatical development in a much larger sample of 1800 normally developing children, primarily middle class, all growing up in English-speaking households (see Bates, Dale, \& Thal, 1995; Bates, Marchman et al.,

\footnotetext{
${ }^{2}$ We also looked at many other metrics of grammatical development, including propositional complexity and morphological productivity. After all that work we were surprised to find that, at least in this period of development, MLU is so highly correlated with other, more sophisticated measures, that there was no point in using any other estimate of grammar in correlational analyses with other variables; for a discussion of this point, see Bates et al., 1988.
} 
1994; Dale, 1991; Dale, Bates, Reznick, \& Morisset, 1989; Fenson et al., 1993, 1994; Marchman \& Bates, 1994 for review). Because many of the examples we will provide below rely on this instrument, some methodological details are in order.

The CDI relies primarily on a checklist format to assess word comprehension (from 8-16 months), word production (from 8-30 months) and the emergence of grammar (from 16-30 months). The checklists were developed across a 20-year period, in an iterative research program in which modifications were made based on the results of laboratory studies and interviews with parents. Experimenting with various forms of parental report, we learned that parents could provide highly reliable and valid judgments (confirmed in our own laboratory observations) if we (1) restrict our assessment to current behaviors only (no retrospective report), (2) restrict our assessment to behaviors that are just coming in during this period of development (e.g., parents of normally developing children cannot keep track of comprehension after 16 months, and start to lose track of expressive vocabulary after 30 months), and (3) use a format that draws on recognition memory rather than recall. Numerous studies in many different laboratories have shown that these parental-report indices provide a reliable and valid assessment of lexical development from 8-30 months (including both comprehension and production), and grammatical developments in the period from 16-30 months (see Fenson et al., 1994, for a review).

The vocabulary checklist in the CDI contains 680 words that are typically acquired by children exposed to American English from 8-30 months. It was much less obvious how to assess grammar through parent report. Because the set of possible English sentences is infinite (even in this age range), how could we possibly follow the "recognition memory" rule to assess early grammar? Our solution came in several parts. First, we constructed a checklist of 37 sentence pairs, each reflecting a single linguistic contrast that is known to come in across the 16-30-month period (e.g., "KITTY SLEEPING" paired with "KITTY IS SLEEPING"). Parents were asked to indicate (even if their child had not said this particular sentence) which sentence in each pair "sounds more like the way that your child is talking right now." Second, we violated our own recall/recognition rule by asking the parents to write out the three longest sentences that they can remember their child saying in the last couple of weeks (on the grounds that these would be sufficiently recent and striking events to have some validity even in recall mode). Third, we provided a list of irregular nouns and verbs in their correct inflected forms (e.g., teeth; made), as well as a list of regularization errors that are common in young English-speaking children (e.g., tooths; maked). Parents were asked to check whether they had heard their child produce any of these forms. These three different modes of assessing early grammar were all highly



Figure 2. Mean and standard errors for grammatical complexity in children at different vocabulary levels.

correlated in the Fenson et al. study. More importantly still, the three measures correlate very highly with traditional laboratory measures of grammatical complexity (Dale, 1991; Dale et al., 1989), including correlations with MLU up to the statistical ceiling (i.e., as high as MLU correlates with itself in reliability studies). It is thus fair to conclude that these measures constitute a valid and reliable estimate of individual differences in grammatical development across the period from 16-30 months of age. In most of the results that follow, we will concentrate on the relation between vocabulary size and grammar using the 37-item grammatical complexity scale as our primary outcome variable. It is clear from the validation studies, however, that any of these parent report and/or laboratory estimates of gross progress in grammar would yield the same result.

As reported by Fenson et al. (1994), the relationship between grammatical complexity and vocabulary size in their large cross-sectional sample replicates and extends the powerful grammar/vocabulary relationship that had emerged in Bates et al., (1988). Figure 2 (from Fenson et al.) illustrates the relation between performance on the 37-item sentence complexity scale with productive vocabulary size (collapsed over age, with children divided into groups reflecting fewer than 50 words, 50-100 words, 101-200 words, 201-300 words, 301-400 words, 401-500 words, 501-600 words and > 600 words). The linear correlation between these two measures is $+.84(\mathrm{p}<.0001)$, but it is clear from Figure 2 that the function governing this relationship is nonlinear in nature.

Of course there is some individual variation around this function. This is illustrated by the standard error of the mean in Figure 2, and by the separate lines in Figure 3a, which indicate scores for children at the 90th, 75th, 50th, 25th and 10th percentiles for grammar within each vocabulary group. These variance statistics make two points: (1) individual differences around the grammar-on-vocabulary function are relatively small, and (2) the variance is consistent in magnitude at every point along the horizontal axis beyond 50-100 words. 


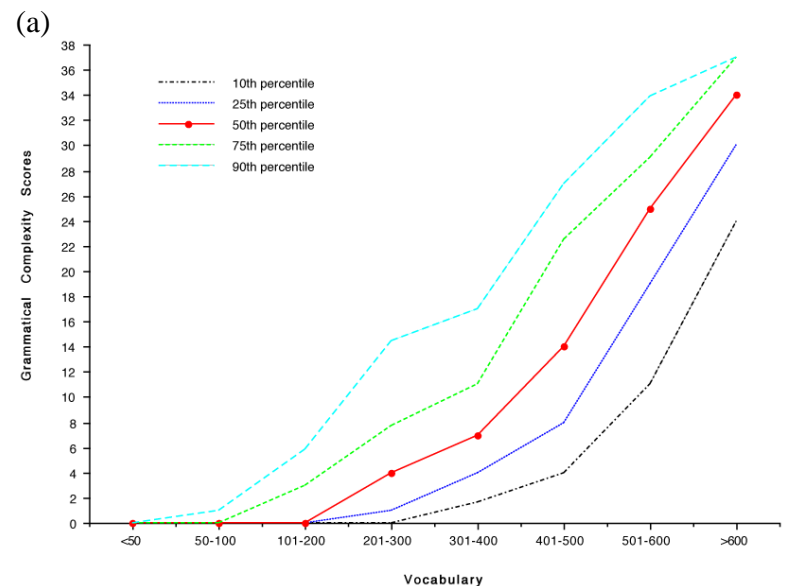

(b)

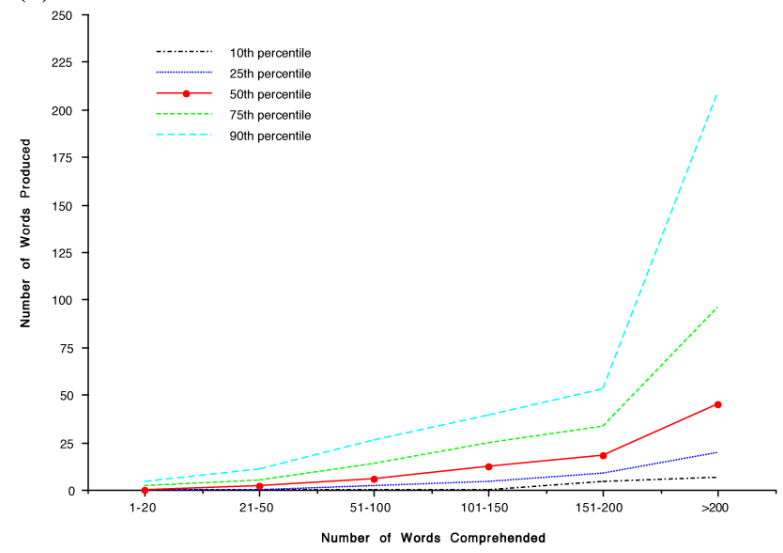

Figure 3. (a) Relationship between grammar and vocabulary size variation within each vocabulary level. (b) Variability in word production as a function of comprehension vocabulary size (redrawn from Fenson et al., 1994).

Both these points are clarified further if we compare the tight correlation between grammar and vocabulary with the clear dissociation between word comprehension and word production observed at an earlier point in language development. Figure $3 \mathrm{~b}$ displays the relation between expressive vocabulary (on the vertical axis) and receptive vocabulary (on the horizontal axis), collapsed over age in children between 8-16 months (redrawn from the MacArthur norming study, Fenson et al., 1994). Analogous to Figure 3a, Figure $3 b$ illustrates the relation between domains by plotting scores at the 90th, 75th, 50th, 25th and 10th percentile for word production within each comprehension group. What we see in Figure $3 \mathrm{~b}$ is a classic fan-shaped pattern of variation, including children who are still producing virtually no meaningful speech at all despite receptive vocabularies of more than 200 words. Hence this figure captures a phenomenon that is well attested in the child language literature: Comprehension and production can dissociate to a remarkable degree. A certain level of word comprehension is prerequisite for expressive language to get off the ground, but comprehension (though necessary) is apparently not sufficient. If the same thing were true for the relationship between vocabulary and grammar,

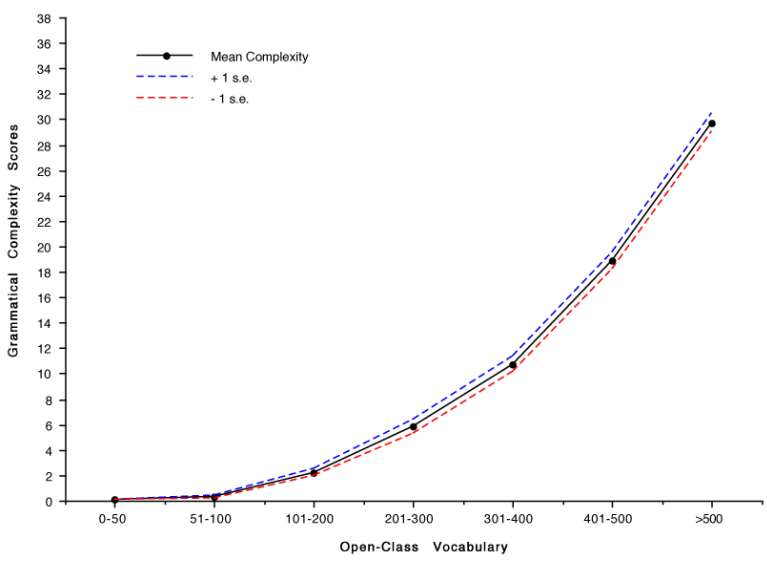

Figure 4. Grammatical complexity as a function of open-class vocabulary only.

we would expect the same kind of fan-shaped variance in Figure $3 a$. That is, we might expect vocabulary size to place a ceiling on grammatical development up to somewhere between 50-200 words (when most children make the passage into multiword speech). After that point, the variance should spread outward as the two domains decouple and grammar takes off on its own course. Instead, we find that grammar and vocabulary are tightly coupled across the 16-30-month age range.

To understand the relevance of this finding, it is important to keep in mind that normally developing children are able to produce most of the basic morphosyntactic structures of their language by 3-3.5 years of age, including passives, relative clauses and other complex forms (Bates \& Devescovi, 1989; Crain, 1991; Demuth, 1989; Marchman, Bates, Burkhardt, \& Good, 1991; Slobin, 1985, 1992, in press). Hence the function in Figure 2 follows children right into the very heart of grammatical development, when productive control over crucial morphological and syntactic structures is well underway (Brown, 1973). We also note that this powerful function is not an artifact of age, because it remains very strong when age is partialled out of the correlation (Fenson et al., 1994). Indeed, age is a surprisingly poor predictor of both vocabulary and grammar within this 16-30-month window, for this large sample of healthy English-speaking children. Taken together, age and vocabulary size account for $71.4 \%$ of the variance in grammatical complexity. When age is entered into the equation after vocabulary size is controlled, it adds a statistically reliable but exceedingly small $0.8 \%$ to the total variance accounted for. However, when vocabulary size is entered into the equation after age is controlled, it adds a reliable and robust $32.3 \%$ to the variance in grammar scores.

Given the power of this relationship, we might suspect that another kind of artifact is lurking beneath the surface. After all, the vocabulary checklist includes grammatical function words like prepositions, articles, auxiliary verbs, pronouns and conjunctions. Perhaps all that we really have in Figure 2 is a tautological relation 


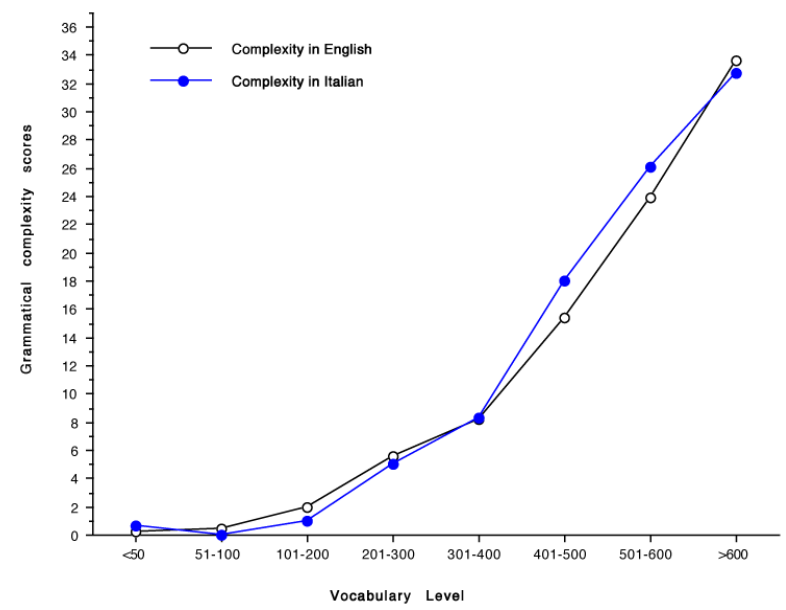

Figure 5. Sentence complexity as a function of vocabulary size for Italian and English toddlers (from Caselli, Casadio, \& Bates, 1997).

of grammar with itself! To control for this possibility, we recalculated total vocabulary size for the full MacArthur sample, subtracting out grammatical function words for each individual child. Figure 4 illustrates the relation between grammar and vocabulary that is observed when vocabulary counts are based entirely on the remaining content words. The nonlinear function that remains is, if anything, even more powerful than the original function where all words are included in the vocabulary total.

The data that we have reported so far are all based on English. More recently, Caselli and Casadio (1995) have developed and normed a version of the MacArthur CDI for Italian. Although the word checklist for Italian is equivalent to the English list in length, it is not a mere translation; instead, the words listed within each category were selected specifically for Italian, based on prior studies of lexical and grammatical development in this language. Similarly, because the grammar of Italian is quite dissimilar from that of English, Caselli and Casadio constructed a 37-item sentence complexity scale designed to tap those structures that are known to develop in Italian between 16-30 months of age (Bates, 1976; Caselli, 1995; Cresti \& Moneglia, 1993; Devescovi \& Pizzuto, 1995; Pizzuto \& Caselli, 1992; Volterra, 1976). Detailed cross-linguistic comparisons are provided elsewhere (Caselli et al., 1995; Caselli \& Bates, 1996; Pizzuto \& Caselli, 1994). For our purposes here, we note that the function linking grammar and vocabulary size is quite similar in English and Italian (Figure 5, from Caselli and Bates, 1996) - this despite striking differences between the two languages in the content of vocabulary and grammar.

Another possible objection to these findings revolves around the cross-sectional nature of the normative sample. Because the functions in Figures 1-5 are collapsed across different children at different age levels, we cannot assume that they represent patterns of growth for any individual child. In a more recent study



Figure 6. Grammatical complexity as a function of vocabulary level for the cross-sectional versus longitudinal samples.

(Goodman, 1995; Jahn-Samilo, 1995; Thal, Bates, Goodman, \& Jahn-Samilo, in press), we have used the MacArthur CDI to follow individual children longitudinally, with parents filling out the forms on a monthly basis from 8 to 30 months of age. From 1230 months, we also saw the children monthly in the laboratory, videotaping free speech and free play and administering structured measures of word comprehension, word production and comprehension of grammar. Thirty-four children enrolled in the study in the first few months, and 27 stayed with us through the 30-month end date. The sample was predominantly middle class, screened to exclude cases with serious medical complications (including mental retardation and prematurity). All children were growing up in homes in which English is the primary language spoken by both parents, although by the end of the study, three of the children had Spanish-speaking daycare providers.

The same high correlations between parent report and laboratory measures reported in other validation studies have appeared in our analyses to date (JahnSamilo, 1995). There are also striking similarities between this longitudinal sample and the large crosssectional sample from the MacArthur norming study in both the mean and the range of variation observed across age levels in word comprehension, word production and the development of grammar. The one compelling difference that we find between the longitudinal and cross-sectional samples rests in the fact that vocabulary growth functions are slightly (but reliably) elevated in the longitudinal group, from approximately 25 months of age through the rest of the study (Goodman, JahnSamilo, \& Bates, 1996). This may be an effect of repeated testing on the parents who are filling out the forms. It may also reflect an indirect effect on their children, insofar as parents may become more attuned to the linguistic structures that are likely to occur in this age range, noting those structures earlier and/or encouraging them more than we are likely to find in a 


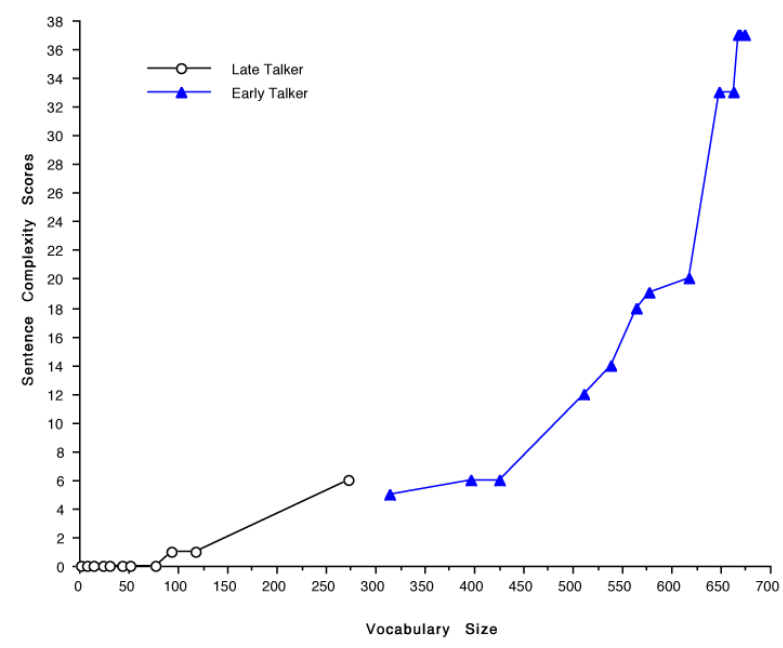

Figure 7. Relationship between grammatical complexity and vocabulary size for one late talker and one early talker.

"one shot" cross-sectional design. Of course this difference might also represent nothing more than the chance variations that are likely to occur when subsamples of 27 are drawn (randomly) from a larger population.

Because none of the parents were aware of our hypotheses or given feedback of any kind from month to month, it is quite unlikely that the repeated-testing design influenced the finding that is most important for our purposes here: the relationship between grammar and vocabulary in individual children followed across the 17-30-month period (that is, from the point at which we began to collect measures of grammatical abilities until the end of the study). Figure 6 compares the nonlinear function linking sentence complexity and vocabulary size in the respective cross-sectional and longitudinal samples. The two functions are remarkably similar, separated only by a very small lag (i.e., slightly lower complexity rates per vocabulary group in the longitudinal sample), well within the range of variation that we observe for the cross-sectional sample in Figures 2 and $3 a$.

Although this comparison does suggest that a common growth function is observed in both designs, we are still looking at group data in both cases (i.e., results collapsed over many different children at each data point). We might therefore ask whether the growth curves in the longitudinal study look similar for individual children, or whether the commonalities in Figure 6 represent group trends that mask sharp dissociations in at least some individual cases. To address this issue, we graphed the individual grammar-onvocabulary functions for all 27 children. Results suggest a remarkable degree of similarity between these individual growth curves and the range of curves (from the 10th to the 90th percentile) summarized at the group level in Figure 3a. To illustrate this point, we present the grammar-on-vocabulary functions for two individual children in Figure 7, for each session between 16 and 30 months. These children were selected to represent extremes in rate of vocabulary growth, including one very late talker and one very early talker. The contrast between these two cases is particularly interesting for our purposes here, because there is absolutely no overlap in their vocabulary size across the period from 17-30 months of age. Our late talker had a vocabulary of only 272 words on the CDI in the last session at 30 months. By contrast, our early talker already had a vocabulary of 315 words on the CDI at 17 months, when we began to administer the grammar scales. It is clear from Figure 7 that both children are making progress in grammar that is directly commensurate to their lexical abilities, even though they reach their respective grammar-on-vocabulary levels at widely different ages within this period of development.

We are convinced by these data that there is a powerful link between grammar and lexical growth in this age range, a nonlinear growth function that holds for both cross-sectional and longitudinal designs, at both the individual and the group level, and perhaps across languages as well (although two languages is a very small sample of the possibilities that the world has to offer). These results (even for individual children) are collapsed across a range of different grammatical structures. What does the relationship look like when we look at specific aspects of the grammar? Presumably, because we know that different grammatical structures come in at different points within this developmental window, we ought to expect individual forms to display different degrees and (perhaps) different types of "lexical dependence." For example, individual grammatical structures might require a different "critical mass" across the whole vocabulary, or they might require a critical number of lexical items within a specific class.

Some insights into this issue come from Marchman and Bates (1994), who used the MacArthur norming data to investigate the relationship between the number of verbs that children use and their progress on the verb morphology subscales on the CDI (i.e., the checklists of irregular, regular and overregularized forms noted above). This study was motivated by the ongoing controversy between the connectionist "single mechanism" approach to grammatical development (Elman et al., 1996, (Chapter 2); MacWhinney, 1989, 1993, in press; MacWhinney, Leinbach, Taraban, \& McDonald, 1989; Plunkett \& Marchman, 1991, 1993; Rumelhart \& McClelland, 1986) and the symbolic "rote vs. rule" approach (Brown, 1973; Marcus et al., 1992; Pinker, 1991, 1994). In connectionist simulations of the acquisition of past-tense morphology, it has been shown that a single mechanism can display the same sequence of behaviors that had long been used to justify a discontinuous shift from rote memorization to the use of grammatical rules. That is, a single mechanism may be responsible even though the content to which that mechanism is applied changes across development 
(a)

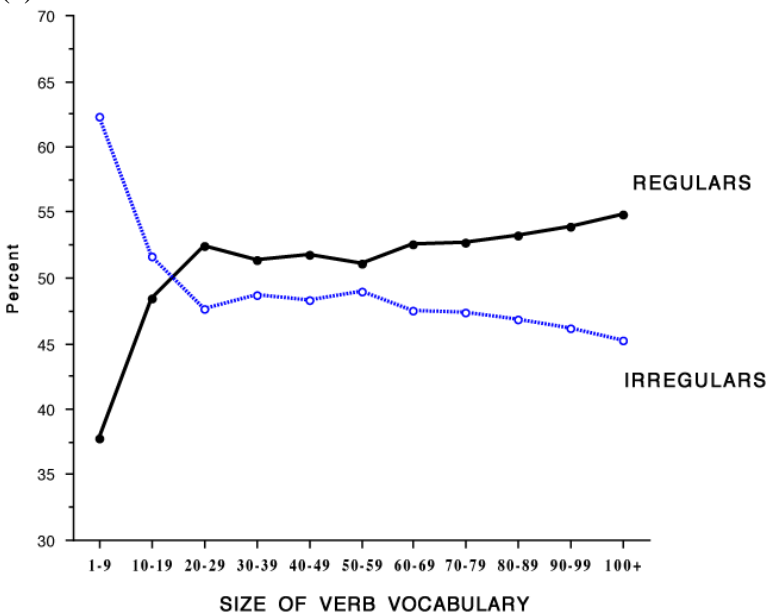

(b)



(Plaut, this volume). In this case, the changes include an initial stage in which the system produces highfrequency irregular past-tense forms correctly (e.g., CAME, WENT), a lengthy intermediate phase in which these correct forms coexist with occasional overregularizations (e.g., COMED, GOED), followed by an asymptotic convergence on the use of correct regulars and irregulars. Within these simulations, the passage from one stage to another is invariably linked to the size and composition of verb vocabulary (e.g., highfrequency irregulars tend to dominate in the early stages; the appearance of overregularizations correlates with an increase in the proportion of regulars to irregulars in the network's "vocabulary").

This account has had detractors. Using free-speech data from the Child Language Data Exchange System (MacWhinney, 1991), Marcus et al. (1992) report that there is no significant change in the proportion of regulars and irregulars in early child language, and that there is no correlation between vocabulary size and the appearance of overregularizations. On these and other grounds, they conclude that the connectionist account of past-tense learning is incorrect. However, as Marchman and Bates note, free-speech records do not yield a representative estimate of vocabulary growth in children (see (c)



Figure 8. (a) Relative distribution of regular and irregular verbs as a function of size of verb vocabulary. (b) Reported production of 16 irregular verbs as a function of verb vocabulary size. (c) Comparison of estimated and actual over-regularized verb types reported of estimated and actual over-regularized verb types reported (c) 1994 Cambridge University Press. Reprinted with the permission of Cambridge University Press.)

also Anglin, 1993). As we have seen, vocabulary size can be estimated reliably through parental report up to 30 months of age in normal children. Figure $8 \mathrm{a}$ from Marchman and Bates (1994) shows that there is indeed a cross-over across this period of development, from a period in which irregulars predominate to a period in which the majority of verb types in the child's vocabulary are regular forms (see Lindner \& Elsen, 1996, for similar results in German using parental diary data).

Furthermore, in real children and in the singlemechanism connectionist simulation, the onset of overregularization is linked to the size of verb vocabulary. Figure $8 \mathrm{~b}$ illustrates the relation between number of verbs in the child's vocabulary (based on the subset of verbs that are used in the vocabulary checklist and in the past-tense scale) and three forms of past-tense marking: zero stem (the child is reported to use the verb in the citation form only), correct irregulars, and incorrect overgeneralizations. This figure reveals a strong nonlinear relationship between verb vocabulary size and successive phases in the development of past-tense morphemes, similar to the relationship observed in connectionist simulations of this learning process. Thus, a single-mechanism learning model shows that same sort of relations between vocabulary size and grammatical development that has been traditionally explained using a dual-mechanism model.

It might be argued that the apparent link between verb errors and verb vocabulary is a statistical artifact, i.e., that there are simply more opportunities to observe verb errors in children who produce more verbs. Note, however, that this criticism relies on a critical assump- 
tion: that the probability of verb errors is a constant across this period of development. Marchman and Bates address this issue by comparing the overgeneralization rates reported by parents with the overgeneralization rates that we would expect for each child if a constant error rate accounted for their data. This comparison yields a linear function (the estimates obtained by applying a constant error rate) and a nonlinear function (the error rates that are actually reported for individual children with different verb repertoires). The difference (illustrated in Figure 8c) is statistically reliable, indicating that the nonlinear relation between vocabulary size and the appearance of overregularizations is not a statistical artifact.

This demonstration of a link between verb vocabulary and past-tense morphology is the only example we have right now of a link between specific grammatical structures and their requisite "critical mass" of lexical items. A great deal more work could be done in this area, to determine the lexical prerequisites (if any) for specific grammatical forms. Results of such investigations are likely to vary markedly within and across languages, despite the solid trends that we find by collapsing over lexical and grammatical types. For present purposes, we will stay at the higher (collapsed) level to ask a different kind of question: Are these relationships universal for anyone acquiring English, or can we find atypical populations in which dissociations between lexical and grammatical development are observed? This brings us to the next section.

\section{Grammatical development and the lexicon in atypical populations}

Although grammatical development invariably follows a stage in which single words are acquired, the findings reviewed so far suggest that, aside from this temporal lag, there is no dissociation between grammar and lexical development in normal children. In view of the claims that have been made about the dissociability of these domains in adults, it seemed important to us to determine whether there are any individual children or any specific pediatric populations who deviate from the function displayed in Figures 2-7.

In fact, the literature on older children with language disorders gives us reason to expect selective impairments in early grammar. Specific Language Impairment or SLI is defined as a delay in expressive language abilities that is at least 1 standard deviation below the mean for the child's chronological age, in the absence of mental retardation, frank neurological impairment, social-emotional disorders (e.g., autism), or any other serious biomedical risk factors that could account for the delay. Although the definition of SLI presupposes that language can be dissociated from the rest of cognition, the specificity of Specific Language Impairment is still controversial (Gopnik \& Crago, 1991; Johnston, in press; Leonard, in press; Rice, in press; Thal \& Katich, in press; van der Lely, 1994). Some investigators report that children with SLI score significantly below age-matched controls on at least some nonlinguistic measures. Candidates include mental imagery and mental rotation (Johnston, 1994), symbolic play (Thal \& Katich, in press), shifting attention (Townsend, Wulfeck, Nichols, \& Koch, 1995), and the ability to detect rapid temporal changes in auditory stimuli (Tallal et al., 1996; Tallal, Stark, \& Mellits, 1985). There is considerably more agreement about the nature of the language impairment in SLI. After 30 years of research looking for deviant patterns of language development, most investigators in this field have concluded the SLI represents a pattern of delay rather than deviance (for recent reviews, see Bishop, in press; Leonard, in press). That is, within every linguistic domain that has been studied to date, the expressive and/or receptive abilities of children with SLI are qualitatively similar to those of younger normal children. However, as Johnston and Schery pointed out some time ago (Johnston \& Schery, 1976), a specific kind of deviance can be detected if one looks across rather than within linguistic domains. In particular, grammatical morphology appears to be more delayed than any other area of language development. Thus much of the debate in this field concerning the nature and causes of SLI revolves around the disproportionate problems that children with SLI experience in this aspect of grammar, with some investigators arguing that the deficit is due to a problem that is strictly linguistic in nature (Clahsen, 1991; Levy, 1996; Rice, in press; Rice, Wexler, \& Cleave, 1995; van der Lely, 1994), while others argue that the morphological problems observed in SLI are secondary to a processing deficit that may transcend the boundaries of language (Bishop, in press; Leonard, in press; Tallal et al., 1996).

One of the most radical proposals concerning the possibility that SLI involves a grammar-specific deficit comes from Gopnik and her colleagues (Gopnik, 1990; Gopnik \& Crago, 1991; Pinker, 1991, 1994). These investigators described a family with what appears to be a congenital version of SLI, manifested in a specific dissociation between regular and irregular grammatical morphology, with relative sparing of irregular forms. They suggest that such a dissociation is possible because irregulars are mediated by the lexicon, while regulars are handled by a separate grammatical processor. However, a more comprehensive study of the same family by Vargha-Khadem, Watkins, Alcock, Fletcher, \& Passingham (1995) has shown that the affected members of this family are equally impaired on both regular and irregular morphemes, as well as on a host of other language and nonlanguage measures. Marchman, Wulfeck and Weismer (1995) have investigated the proposed regular/irregular past-tense dissociation in a large sample of children with SLI. They report significant impairments in past-tense morphology for SLI children compared with age-matched controls. 
However, they find no evidence whatsoever for a dissociation beween regular and irregular forms. The errors produced by children with SLI are quite similar to those of younger normal children.

Regardless of one's position on this question, we shall see later on that the selective vulnerability of grammatical morphology is not specific to SLI. It has been observed in a number of other child and adult populations, including children with Down Syndrome (Chapman, 1995; Contardi \& Vicari, 1994). Some possible explanations for this pattern will be discussed later. For present purposes, the point is that a certain degree of dissociability has already been observed between grammatical morphology and other aspects of language in older children and adults with language impairments. What we want to determine here is whether analogous patterns of dissociation are observed in the period when grammar first develops.

Late and early talkers. Within a larger program looking for patterns of association and dissociation within and across linguistic and cognitive domains, Thal and her colleagues have examined patterns of lexical and grammatical development in infants and preschool children at the extreme ends of the normal distribution. This includes "late talkers," defined as children in the bottom 10th percentile for expressive vocabulary between 18-24 months of age, in the absence of the same exclusionary factors that are used to diagnose SLI in older children (Bates, Dale, \& Thal, 1995; Thal, 1991; Thal et al., in press; Thal \& Katich, in press). It also includes "early talkers," defined as children in the top 10th percentile for expressive vocabulary between 12-24 months of age (Fletcher \& MacWhinney, 1995; Robinson, Dale, \& Landesman, 1990; Thal et al., in press; Thal et al., 1996). Much of this work has focussed on the stability of late- or early-talker status over time. For example, it is now clear that some late talkers do go on to qualify for a diagnosis of Specific Language Impairment or SLI, and that some early talkers maintain their precocity over many months or years (see also Dale, Robinson, \& Crain-Thoreson, 1992; Robinson et al., 1990). Thal and her colleagues have also concentrated on the factors that predict initial and continuing status as a late or early talker. For example, late talkers who remain delayed are more likely to have delays in both receptive and expressive language, with relatively low levels of communicative gesture; late talkers who eventually catch up with their agemates tend to start out with delays in expressive vocabulary only, manifesting ageappropriate levels of word comprehension and communicative gesture throughout this period.

For our purposes here, we are interested in the relationship between grammar and vocabulary in these extreme groups. If late talkers constitute an early variant of SLI, then we might expect to find that grammar lags behind vocabulary level, compared with children who reach the same vocabulary size closer to the normative age. Alternatively, we might find some late talkers who have managed to develop grammatical abilities well in advance of their lexical level. The same two extremes may also be observed among the early talkers: children whose grammatical abilities are still tied to chronological age, despite their lexical precocity, and children who are "grammar geniuses", attaining levels of sentence complexity that are even greater than their abilities in the lexical domain.

We see no evidence for such a dissociation in our longitudinal samples. Instead, grammatical development appears to be tied to lexical level even in children at the far ends of the continuum, in patterns similar to those displayed by the two extreme longitudinal cases in Figure 7. Among the children who start out as late talkers, those who remain delayed tend to stay delayed on both vocabulary and grammar, and those who move into the normal range end up normal in both these domains. If we restrict our attention to children with vocabularies under 400 words, then there is a tendency for some late talkers to produce more multiword utterances and a higher proportion of function words than we typically observe in younger children at the same vocabulary level (see also Bates et al., 1988; Bates, Marchman et al., 1994; Fenson et al., 1994). However, this tendency appears to reflect an overreliance on formulaic utterances like "Want dat" - a pattern that investigators in the child language literature refer to as "expressive style", "pronominal style," "holistic style" and/or "suprasegmental strategy" (Bates et al., 1988; Bates, Dale, \& Thal, 1995; Bloom et al., 1975; Peters, 1977, 1983; Shore, 1995). In fact, studies have shown that early use of closed-class morphemes around 20 months of age is either unrelated or (depending on how it is measured) negatively correlated with grammatical productivity eight months later (for a detailed discussion, see Bates, Dale, \& Thal, 1995). For example, Bates et al. (1988) calculated a ratio of function words to total vocabulary types at 20 and 28 months in their longitudinal sample, and discovered a significant negative correlation of the "same" measure with itself at these two points in time $(\mathrm{r}=-.41, \mathrm{p}<.05)$.

This finding suggests that the "same" measure is indexing very different processes at these two points in time. At 20 months of age, the grammatical morphemes that children use in their expressive language typically fail to meet criteria for morphological productivity (e.g., Brown, 1973); by the same criteria, most children display productive control over these morphemes around 28 months of age. For these reasons, Bates et al. conclude that the use of closed-class morphology at 20 months reflects the production of frozen forms that have not yet been analyzed for use within a flexible, productive grammatical system. In fact, continued use of these morphemes within frozen frames may be an obstacle to progress, enticing some children to postpone the inevitable day when those morphemes must be "broken out" for use in other 
contexts. Bates et al. speculate that some late talkers may produce a relatively high proportion of these rote, unanalyzed forms simply because they are older when they reach the point at which productive grammar must emerge. For example, they may have better auditory short-term memory and/or better articulatory abilities despite their relatively slow progress in both vocabulary and grammar, permitting them to get by with frozen or semiproductive forms for a longer period of time (see also Elman, 1993; Newport 1990).

Some further insights into this issue come from two case studies of children with extremely precocious language development (Thal \& Bates, 1988; Thal et al., 1996). In one of these children, grammar does appear to lag behind vocabulary level, suggesting some degree of dissociation. However, a detailed comparison of the free-speech data and parent report data reveals an unexpectedly strong association between vocabulary development and inflectional morphology for both these children, even though one of them has barely moved out of the single-word stage. Table 2 (from Thal et al., 1996) provides examples of the utterances produced by MW (17 months old with an expressive vocabulary of 596 words in the CDI) and SW (21 months old with an expressive vocabulary of 627 words on the CDI). With an MLU of 2.13, MW is right where we would expect her to be in grammar, given her vocabulary size (equivalent to performance by an average 28-30-monthold child in both domains). By contrast, SW has just begun to combine words (MLU 1.12) despite her huge vocabulary. In fact, her grammatical abilities are quite average for a 21-month-old child.

At first glance it appears that SW represents a striking dissociation between grammar and vocabulary. However, the examples in Table 2 reveal a very curious phenomenon: production of words with contrasting inflections (e.g., "falling....fell") in single-word utterances. This is a very odd phenomenon for children acquiring English, although it has been observed in children acquiring a highly inflected language such as Turkish (Slobin, 1985). Applying the criteria for morphological productivity developed by Brown (1973), Thal et al. discovered that both children have about as much control over English morphology as we would expect to find in a 2.5-year-old child. In fact, SW was actually more advanced than MW in grammatical morphology (i.e., productive control over more morphemes according to Brown's rules), although both children are well within the range that we would expect for children with more than 500 words (Marchman \& Bates, 1994).

If the difference between MW and SW does not represent a clear dissociation between grammar and vocabulary, how can we explain their striking differences in utterance length? Thal et al. note that SW produced carefully articulated single words. By contrast, MW was observed to use longer utterances that often appeared formulaic in nature. Her parents indicated that
TABLE 2

Examples of Language Production by Two Very Early Talkers (from Thal et al., in press)

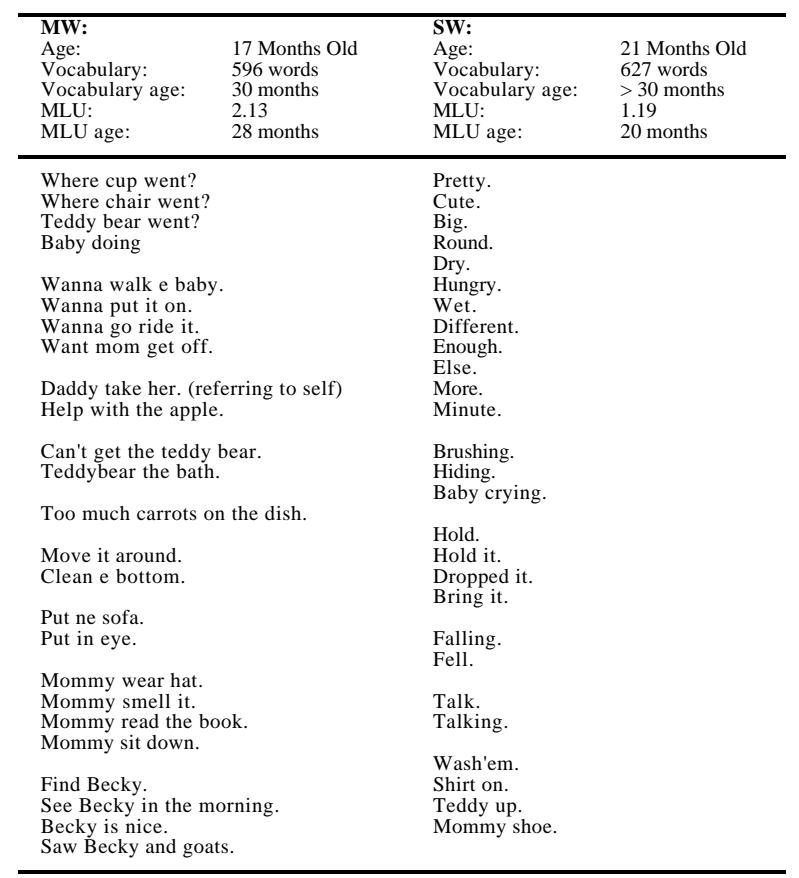

MW could remember and produce a number of songs and idiomatic expressions (e.g., "No way, José", or "You little monkey!"). An examination of the sample utterances for MW in Table 2 supports this idea. She appears to make use of partially analyzed formulae and "frame-slot" structures in her spontaneous speech (e.g., "Where went?"). In fact, to the surprise and amusement of her mother and the experimenter, MW produced a novel juxtaposition of two established formulae during one of the experimental sessions: "No way, you monkey!" One possible interpretation of this finding may be that MW is an example of the expressive, pronominal, formulaic or holistic style described above, while SW illustrates an alternative style that has been referred to in the child language literature as "referential style", "nominal style," "analytic style" and/or "segmental strategy" (cf. Bates et al., 1988; Nelson, 1973; Shore, 1995). However, Thal et al. note that both these children produce a large number of novel utterances (the hallmark of analytic style), and yet they have both adopted a slot-filler approach to combining words (the classical finding for holistic style). Indeed, the few two-word combinations that SW produced in these transcripts fall within the "pivot-open" category that is typically associated with expressive style (e.g., "hold it", "keep it", "pour it", and "hide it"). Hence the distinction between analytic and holistic style does not capture the difference between these cases any better than the distinction between grammar and single words. Thal et al. tentatively conclude that these two children differ primarily in the size of the unit that they are able to store in auditory memory, and/or the size of the unit 
that they are able to retrieve and reformulate in speech production (see also Peters, 1977). As we shall see shortly, this kind of processing account will prove useful in explaining the apparent dissociations observed in some clinical populations.

Early focal lesions. A different perspective on the relationship between earl y grammar and the lexicon comes from studies of infants and children with early focal brain lesions to the left or right hemisphere, usually due to pre- or perinatal stroke (Bates et al., in press; Marchman, Miller, \& Bates, 1991; Reilly, Bates, \& Marchman, in press; Thal et al., 1991). When cases with intractable seizures or other medical complications are excluded, most studies of this population report language abilities that are well within the normal range, regardless of lesion side, size or site (Bates, Vicari, \& Vargha-Khadem, in press; Eisele \& Aram, 1995; Feldman, Holland, Kemp, \& Janosky, 1992; Rasmussen \& Milner, 1977; Vargha-Khadem, Isaacs, \& Muter, 1994). As a group, children with unilateral brain damage tend to perform below normal controls, but few would qualify for a diagnosis of aphasia. This conclusion holds even for children whose injuries involve the perisylvian regions of the left hemisphere (i.e., the classical language zones), and for some children who have had the entire left hemisphere removed. In fact, many studies of older children with early lesion onset report no significant differences between cases with leftvs. right-hemisphere injury. When differences are reported, they tend to be very subtle, involving a handful of phonological, grammatical and/or semantic contrasts that are difficult even for children who are neurologically intact (Dennis \& Whitaker, 1976; Eisele \& Aram, 1995; Eisele, Aram, \& Lust, in press; Riva \& Cazzaniga, 1986).

In view of all this evidence for plasticity, what can children with focal brain injury tell us about the relationship between grammar and the lexicon? It is useful to compare the outcomes of early lesions at different sites to the outcomes faced by adults with lesions at comparable sites. The stereotypical view of aphasia in adults might lead one to expect that these children would provide evidence for a dissociation between grammar and the lexicon. Instead, we see a tight relationship between deficits observed in grammar and the lexicon during the years in which these skills develop, together with a number of very striking differences between children and adults in the relationship between language symptoms and lesion site (Bates et al., in press; Marchman, Miller, \& Bates, 1991; Reilly et al., in press; Stiles \& Thal, 1993; Thal et al., 1991). Some particularly relevant findings for our purposes here come from a series of studies by Bates et al. (in press) and Reilly et al. (in press), covering a period of development from 10 months to 12 years of age:

(1) Delays in word comprehension and communicative gesture during the first two years of life are actually more common with right-hemisphere injury - precisely the opposite of the patterns observed in brain-injured adults (where word comprehension and gestural deficits are more often associated with left-hemisphere damage).

(2) There are few global differences between children with left- vs right-hemisphere injuries on expressive language measures across this range of development, in sharp contrast with more than a hundred years of research on brain injury in adults.

(3) Differences in hemispheric specialization do emerge when one considers only those children who have injuries involving left temporal cortex, compared to children who have damage to any other sites in the right or left hemispheres. In particular, children with left temporal damage are selectively delayed in expressive language across the period from 10-60 months, on a succession of ageappropriate lexical and grammatical measures. This finding is surprising from the point of view of classical aphasiology, where lesions to left temporal cortex (the presumed site of Wernicke's area) are usually associated with fluent aphasia with mild to severe deficits in comprehension.

(4) What about Broca's area? Bates et al. and Reilly et al. find no selective effects of damage to left frontal cortex (the presumed site of Broca's area) at any point from 10 months to 12 years of age. Frontal damage does make a difference in the period between 19-31 months, a period that includes dramatic changes in both lexical and grammatical development (i.e. the vocabulary burst and the emergence of grammatical morphology). However, this frontal effect is bilaterally symmetrical. That is, children whose lesions included either left frontal or right frontal cortex are more delayed in vocabulary size and in grammatical complexity. Putting these lines of evidence together, Bates et al. conclude that the temporal regions of the left hemisphere appear to be specialized in some way from the beginning of language learning, but the frontal regions of the left hemisphere do not have a special status until some point much later in normal development.

(5) After 5-7 years of age, children with a history of early focal brain injury tend (as a group) to perform below their age-matched normal controls on a range of lexical, grammatical and discourse measures (Reilly et al., in press). However, there are no effects due to site of lesion. In other words, the specific effects of lesion site uncovered for younger children do not appear in older children with the same early-onset etiology, suggesting that a great deal of reorganization must have occurred in the intervening years.

In addition to these group data suggesting that lexical and grammatical abilities are affected equally by early focal brain injury, Bates et al. and Reilly et al. 


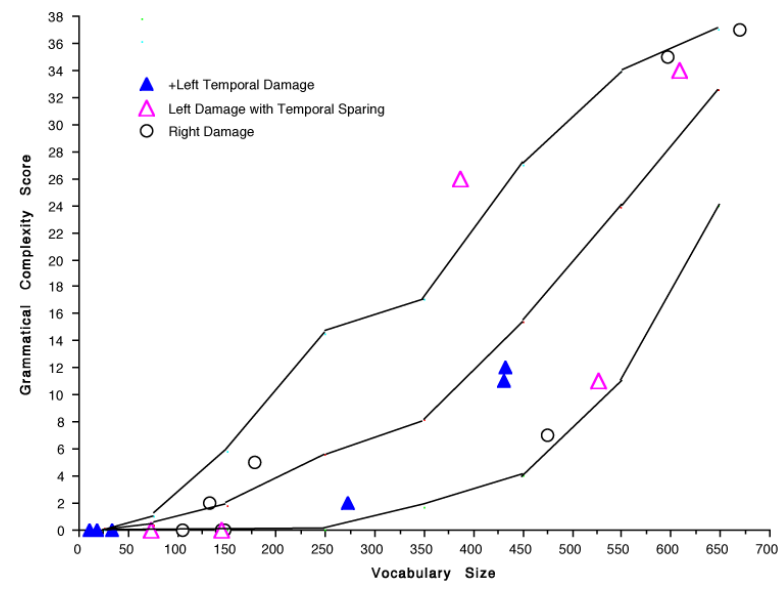

Figure 9. Grammar as a function of vocabulary size in children with focal brain injury (lines $=10$ th, 50th and 90th percentiles for normals).

studies found no evidence in individual children for a selective dissociation between grammar and lexical development. Children who are delayed on one tend to be delayed on the other, and children who progress at a normal rate show the normal relationship between these aspects of language. To illustrate this last point, Figure 9 shows the relationship between grammar and vocabulary for 19 individual children in the Bates et al. study, compared with the means for normal controls at different vocabulary levels between 19-31 months of age from the MacArthur CDI norming study (Fenson et al, 1994). We have plotted grammatical complexity against vocabulary size in this figure in a form that facilitates comparison between the focal lesion data and the other populations considered so far. ${ }^{3}$ Separate symbols are provided to distinguish cases with lefthemisphere injuries involving the temporal lobe, lefthemisphere injuries that spare the temporal lobe, and right-hemisphere damage. The three lines in Figure 9 represent the 10th, 50th and 90th percentiles for grammar as a function of vocabulary size in the Fenson et al. normative sample. It should be clear from this figure that children with focal brain injury display the normal nonlinear relationship between grammar and

${ }^{3}$ Bates et al. described the relation between vocabulary and grammar using the CDI subscale on which parents record the three longest utterances their children have produced in the last two weeks. Scores on the 37-item complexity scale were only available for children from 2 of the 3 research sites participating in that study. For our purposes here, we have used the 37-item complexity scale data, available only for the San Diego and New York populations. In addition, we excluded data for one child who was dropped from the focal lesion sample one year after the Bates et al. study, due to extraneous medical complications. Despite these differences, the results in Figure 9 for 19 children on the complexity scale are comparable to the results reported by Bates et al. for 30 children on the longest-utterance scale. vocabulary, even though some of them are markedly delayed on both (clustered in overlapping symbols in the bottom left quadrant). Of course there is some variance around this function, but the variance is no greater than we observe with normal children. 18 out of 19 focal-lesion cases fall within the 10-90 window for normal children, and one falls outside; we would expect between 1-4 cases to fall outside that window if we were drawing children randomly from the normal population. In short, there is no evidence for a dissociation between vocabulary and grammar in this phase of development, even in children who have suffered pre- or perinatal injuries to the classical language zones within the left hemisphere.

Williams Syndrome and Down Syndrome. Williams Syndrome (WMS) and Down Syndrome (DNS) are genetically based forms of mental retardation (Bellugi, Bihrle, Jernigan, Trauner, \& Doherty, 1990; Bellugi, Bihrle, Neville, Jernigan, \& Doherty, 1992; Bellugi, Marks, Bihrle, \& Sabo, 1988; Bellugi \& Morris, 1995; Bellugi, Sabo, \& Vaid, 1988; Bellugi, Wang, \& Jernigan, 1994; Contardi \& Vicari, 1994; Giannotti \& Vicari, 1994; Jernigan \& Bellugi, 1990; Mervis \& Bertrand, 1993; Miller, 1987; Reilly, Klima, \& Bellugi, 1991; Semel \& Rosner, in press; Wang, Doherty, Hesselink, \& Bellugi, 1992; Wang, Hesselink, Jernigan, Doherty, \& Bellugi, 1992). In both groups, mean IQs generally hover between 40-60, although a broader range of IQ scores can be observed at every stage from infancy through adulthood. People with WMS and DNS tend to end up in the same special classrooms and residential centers; some adults are able to hold down simple jobs, but they are rarely able to live independently. Despite these similarities in global IQ and life experience, recent studies have revealed sharp contrasts between the two groups. For our purposes here, we are particularly interested in the claim that WMS and DNS represent a double dissociation between language and nonlinguistic cognition, and between lexical and grammatical aspects of language processing.

Children with DNS are markedly delayed in the acquisition of language. More importantly, their language abilities at virtually every stage (including the adult steady state) fall below the levels that we would expect based upon their mental age (Chapman, 1995; Miller, 1987, in press a\&b). Furthermore, children and adults with DNS appear to be especially impaired in the production of bound and free grammatical morphemes, constituting a form of congenital agrammatism that is even more severe than the selective delays in grammatical morphology reported for children with Specific Language Impairment. The function word omissions and structural simplifications produced by older children with DNS are especially salient in a richly inflected language like Italian (Contardi \& Vicari, 1994), resulting in profiles that are qualitatively similar to much younger normal children, although rates of omission are actually higher in DNS than controls when mean length 
of utterance is controlled (Fabbretti, Pizzuto, Vicari, \& Volterra, in press).

By contrast, older children and adults with WMS display levels of linguistic knowledge and language use that are surprisingly good when they are compared with the low levels of performance that the same individuals show on most measures of visual-spatial cognition, problem solving and reasoning (Bellugi et al., 1992; Bihrle, Bellugi, Delis, \& Marks, 1989; Carey, Johnson, \& Levine, 1993; Karmiloff-Smith, Klima, Bellugi, Grant, \& Baron-Cohen, 1995; Mervis \& Bertrand, 1993). This does not mean that individuals with WMS are "language savants." Those studies that have used normal controls have shown that the linguistic performance of WMS falls invariably below their chronological age - which is, of course, not surprising for subjects with an IQ score around 50. When WMS are compared with younger normals matched for mental age, the picture is mixed. Some studies report performance above mental-age controls on a handful of measures, but most studies report performance close to mental age on tests of vocabulary comprehension, sentence comprehension, sentence repetition and spontaneous sentence production (Capirci, Sabbadini, \& Volterra, in press; Giannotti \& Vicari, 1994; Vicari, Brizzolara, Carlesimo, Pezzini, \& Volterra, in press; Volterra, Pezzini, Sabbadini, Capirci, \& Vicari, in press). The excitement that research on Williams Syndrome has engendered in recent years hinges not on absolute levels of performance, but on the striking profiles of sparing, deviance and delay that WMS display across different linguistic and nonlinguistic tasks - a profile that challenges many existing theories of the relationship between language and cognition, and raises interesting questions about the relation between grammar and the lexicon.

On some linguistic measures, performance by individuals with Williams is not only superior to mentalage controls, but qualitatively different from normals of any age. For example, on word fluency tasks (e.g., "Name all the animals you can think of") they tend to produce low-frequency items like "ibex" and "brontosaurus" that are never produced by normals or by other individuals with mental retardation. They are also reported to produce language that is prosodically and affectively very rich, peppered with devices like "You know what?", or "And then guess what happened!" designed to hold the attention of their audience (Reilly, Klima, \& Bellugi, 1991). In view of these findings, some of the earlier papers describing language in WMS suggested that grammar may be "spared" while semantics and pragmatics are deviant or "odd" (Bellugi, Wang, \& Jernigan, 1994; Reilly et al., 1991). Pinker (1991) has made the further suggestion that WMS may be particularly adept in the use of regular morphemes, resulting in overgeneralization errors on irregular forms (e.g., "goed" instead of "went").
However, more recent evidence suggests that grammar and lexical semantics are both abnormal in the WMS population. Rubba and Klima (1991) have shown that English-speaking WMS produce peculiar substitutions of prepositional forms. Karmiloff-Smith and Grant (1993) have provided evidence suggesting that French-speaking WMS find it difficult to generalize regular gender morphology to novel words - even though they are very good at repeating the same novel items. Comparative studies of WMS and DNS in Italian suggest that both groups are markedly impaired in the production of grammatical morphemes, including both regular and irregular forms. However, the two groups differ markedly in the kinds of errors they produce. As noted above, Italian speakers with DNS tend to err by omission and simplification, yielding profiles similar to those that are observed in Italian Broca's aphasics, Italians with SLI, and very young Italian-speaking normals. By contrast, Italian speakers with WMS have been shown to produce a range of morphological substitutions that are never observed in normals at any age, bearing a distant resemblance to the substitution errors observed in Italian Wernicke's aphasics (Bates, Friederici, \& Wulfeck, 1987a). The idea that WMS have "spared" language in the face of "impaired" cognition is compromised still further by event-related brain potentials studies showing that adults and adolescents with WMS display deviant patterns of brain activity in response to language stimuli (Neville, Mills, \& Bellugi, 1993).

The peculiar patterns of sparing and impairment that are observed within the language domain in WMS are complemented by equally interesting patterns of sparing and impairment outside of language. For example, although they show severe impairments on most visual-spatial tasks, WMS children are remarkably good at face recognition as early as this function can be measured (Bellugi, Wang, \& Jernigan, 1994; see also Bertrand, Mervis, Rice, \& Adamson, 1993; Giannotti \& Vicari, 1994). In fact, this is the only area where WMS perform reliably better than chronological age-matched controls. People with WMS and DNS also differ markedly in basic measures of information processing. WMS tend to be extremely sensitive to sound (i.e., hyperacusis), and they perform significantly better than IQ-matched individuals with DNS on tests of auditory short-term memory (Contardi \& Vicari, 1994; Vicari, Brizzolara, Carlesimo, Pezzini, \& Volterra, in press; Vicari, Pezzini, \& Brizzolara, 1994; Wang \& Bellugi, 1994). DNS is often associated with mild to moderate deficits in hearing, but DNS children show significantly better performance than age-matched WMS on gestural tasks, and DNS adults perform significantly better than WMS adults on measures of visual short-term memory. As we will point out in more detail later, these differences in processing modality may be relevant to the contrasting grammatical profiles observed in WMS and DNS. 
In view of the many contrasts observed in older children and adolescents, a number of studies have begun to explore the early stages of language development in WMS and DNS. When do these two groups separate? Is the language advantage in WMS present from the very beginning, or does it emerge only after some critical mental age is reached? In every study to date, children in both groups have proven to be significantly severely delayed on early language milestones (Mervis \& Bertrand, 1993; Thal, Bates, \& Bellugi, 1989). In other words, despite their ultimate proficiency with language, children with WMS are late talkers.

This conclusion is underscored in a recent study by Singer, Bellugi, Bates, Rossen, \& Jones (in press), who used the MacArthur CDI to obtain early language data from a large sample of children with WMS or DNS between one and six years of age. In the period of development covered by the infant scale (equivalent to normal children between 8-16 months), WMS and DNS were equally and severely delayed in both word comprehension and word production. The predicted separation between WMS and DNS did not emerge until the period of development covered by the toddler scale (equivalent to normal children between 16-30 months). Both groups were still delayed by approximately two years at this point, with no significant difference in overall vocabulary size. However, Singer et al. found striking differences in the emergence of grammar. Interestingly, this difference reflects a DNS disadvantage rather than a WMS advantage. To facilitate comparison across groups, we have plotted the data for individual WMS and DNS from Singer et al. in Figure 10, in the same format adapted throughout this paper. Within WMS, grammatical development appears to be paced by vocabulary size, in the normal fashion. In fact, when these children are compared with lexically matched normal controls from the CDI sample, the relationship between grammar and vocabulary size is identical, following the same nonlinear accelerating function described above for normals and for children with focal brain injury. In short, there is no evidence for a dissociation between grammatical and lexical development in WMS - at least not in this early phase of grammatical development. By contrast, the DNS sample provides our best evidence to date for a significant dissociation between grammar and the lexicon. In particular, DNS children scored significantly below the grammatical levels displayed by normal children and by WMS matched for vocabulary size (Figure 10).

Singer et al. conclude that lexical size is a necessary but not sufficient condition for the acquisition of grammatical function words, the onset of word combinations, and growth in sentence complexity. This finding is compatible with reports on the selective impairment of grammar displayed by older DNS, although the basis of the impairment is still unknown. Of course it could be due to impairment of some

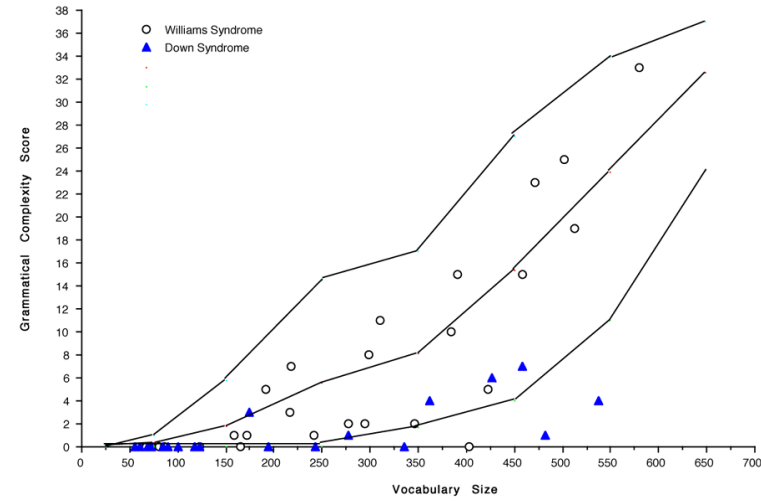

Figure 10. Grammar as a function of vocabulary size in children with Williams versus Down syndrome (lines $=10$ th, 50th and 90th percentiles for normals)

domain-specific grammatical processor (e.g., Pinker, 1991). Alternatively, it may derive from aspects of information processing that are only indirectly related to grammar. As we noted earlier, there is a double dissociation in these two groups between auditory shortterm memory (significantly better in WMS) and visual short-term memory (significantly better in DNS). It appears that DNS suffer from a selective impairment in one or more aspects of auditory processing, a deficit that is superimposed upon their more general cognitive delay. Under these circumstances, it is perhaps not surprising the DNS are selectively impaired in the ability to detect, store and/or retrieve those aspects of their linguistic input that are lowest in what Leonard et al. refer to as "phonological substance", or salience (Leonard, Bortolini, Caselli, McGregor, \& Sabbadini, 1992) and lowest in visual imagery (Goodglass \& Menn, 1985). This argument (which Leonard et al. apply to young children with SLI) is similar to one that Tallal and her colleagues have used to explain the selective grammatical deficits displayed by older children with SLI (Tallal, Stark, \& Mellits, 1985). We will return to this issue later on, after we survey the evidence for selective impairments of grammar in brain-injured adults.

Explaining the link. Why is the relationship between grammar and the lexicon so strong in this period of development? The same basic nonlinear relationship appears in longitudinal and cross-sectional data, in at least two dramatically different languages, in different domains of grammar, in children who are developing on a normal schedule and in children who are developing at an aberrant rate. So far, systematic evidence for a dissociation in this age range has appeared in only one population: children with Down Syndrome. In view of the many disabilities that co-occur with language delays in Down Syndrome, this group constitutes an unlikely candidate for the selective and modular impairment of grammar. In fact there are good reasons to believe that the selective impairment of grammatical morphemes in this group is the by-product 
of their limitations in auditory perception and/or auditory memory.

Whether or not this proves to be the case (and it is a testable hypothesis), we also note that the evidence for a dissociation appears to work in one direction only: Grammar can fall behind vocabulary size, but we have observed no case of a child who was able to stage productive grammar with a vocabulary of 100-300 words. There is no a priori reason why this had to be the case. For example, many adults who try to acquire a second language in the classroom find themselves in a situation in which their stock of grammatical rules outstrips their limited vocabulary. Although we do find children who try to get away with a repertoire of long formulae and rote expressions, this strategy does not seem to go very far - and may be negatively correlated with grammatical progress in the long run (Bates et al., 1988).

The dependence of early grammar on vocabulary size is so strong and the nonlinear shape of this function is so regular that it approaches the status of a psychological law, akin to the reliable psychophysical functions that have been observed in perception (e.g., Weber's Law, Fechner's Law). But explanation by legislation is not very satisfactory, and it is particularly unsatisfactory if better explanations are available. We can offer at least five reasons why grammar and vocabulary track each other so closely in this stage of language development. None of them are mutually exclusive.

(1) Perceptual bootstrapping. Nusbaum and Goodman (1994) and Nusbaum and Henly (1992) have proposed that efficient word perception requires a certain amount of top-down processing, permitting the listener to weed out inappropriate candidates from a large pool of items that overlap (at least partially) with the blurred word tokens that so often occur in fluent speech (see also Marslen-Wilson, 1987; McQueen, Cutler, Briscoe, \& Norris, 1995). To the extent that this is true, it is probably even more true for the perception of grammatical function words and bound inflections. For a variety of reasons, these units are particularly hard to perceive (Cutler, 1993; Goodglass \& Menn, 1985; Grosjean \& Gee, 1987; Hurlburt \& Goodman, 1992; Kean, 1977; Leonard, in press; Shillcock \& Bard, 1993). They tend to be short and low in stress even in speech that is produced slowly and deliberately. In informal and rapid speech, speakers have a tendency to exploit the frequency and predictability of function words and bound morphemes by giving them short shrift, deforming their phonetic structure and blurring the boundaries between these morphemes and the words that surround them. In fact, when grammatical function words are clipped out of connected speech and presented in isolation, adult native speakers can recognize them no more than $40-50 \%$ of the time (Herron \& Bates, in press). This is true of speech directed to children as well as speech directed to adults (Goodman, Nusbaum,
Lee, \& Broihier, 1990). Under these circumstances, we should not be surprised that young children are unable to acquire grammatical forms until they have a critical mass of content words, providing enough top-down structure to permit perception and learning of those closed-class items that occur to the right or left of "real words."

(2) Logical bootstrapping. Studies in several different languages have shown that verbs and adjectives are acquired later than nouns (Au, Dapretto, \& Song, 1994; Caselli et al., 1995; Gentner, 1982; Pae, 1993; for a dissenting view, see Gopnik \& Choi, 1990, 1995). Except for a few terms like "up" and "no" that can stand alone, function words tend to appear later still, well after the first verbs and adjectives appear (Bates, Marchman et al., 1994). Furthermore, many relatively early prepositions (e.g., "up") may not be used in the same way by children as by adults. Adults use them to specify a relation between objects or a location. Children on the other hand use them to refer to events (Tomasello \& Merriman, 1995) instead of using them as "grammatical glue." It has been suggested that this progression from names to predication to grammar is logically necessary, based on a simple assumption: Children cannot understand relational terms until they understand the things that these words relate. One can argue about the extent to which this assumption holds for individual structures, but it may provide a partial explanation for the dependence of grammar on lexical growth.

(3) Syntactic bootstrapping. The perceptual and logical bootstrapping accounts both presuppose that the causal link runs from lexical growth to grammar. However, studies from several different laboratories have shown that children between 1-3 years of age are able to exploit sentential information to learn about the meaning of a novel word (Goodman \& McDonough, 1996; Goodman, McDonough, \& Brown, 1996; Naigles, 1988, 1990; Naigles, Gleitman, \& Gleitman, 1993; Sethuraman, Goldberg, \& Goodman, 1996; Tomasello, 1992). Naigles et al. (1993) refer to this process as "syntactic bootstrapping", although it has been shown that children can use many different aspects of a sentence frame for this purpose, including sentence-level semantics, morphological cues, word order and prosody. It is therefore possible that the accelerating function in Figures 2-10 is due in part to the effect of the child's emerging grammar on lexical growth.

(4) Nonlinear dynamics of learning in a neural network. The above three accounts all support a link between lexical and grammatical development, but it is not obvious from these accounts why the function ought to take the nonlinear form that appears so reliably across populations and age levels. We noted earlier that the nonlinear functions governing the relation between verb vocabulary and the emergence of regular and irregular past-tense marking appear in a similar form in English-speaking children and in neural 
network simulations of past-tense learning (MacWhinney et al., 1989; Marchman \& Bates 1994; Plunkett \& Marchman, 1991, 1993). This is only one example of a more general point: Multilayered neural networks produce an array of nonlinear growth functions, reflecting the nonlinear dynamics of learning and change in these systems (Elman et al., 1996, Chapter 4). The kinds of critical-mass effects that we have proposed to underlie the relation between lexical and grammatical growth may be a special case of this more general approach to the nonlinear dynamics of learning (see also Port \& van Gelder, 1995; Smith \& Thelen, 1993; Thelen \& Smith, 1994; van Geert, 1994).

(5) Lexically based grammar. Finally, as we noted at the outset of this paper, the historical trend in modern linguistics has been to place in the lexicon more and more of the work that was previously carried out in a separate grammatical component. The powerful relation between grammatical and lexical development that we have observed here is precisely what we would expect if grammar is an inherent part of the lexicon.

Points 1-4 all pertain to learning. Point 5 is a stronger claim, extending to the relationship between grammar and the lexicon in the adult steady state. The data that we have reviewed so far may be relevant only to the early stages of language development, the period in which the fundamental properties of language-specific morphosyntax are laid down. It is entirely possible that a modular distinction between grammar and the lexicon may emerge at a later point in development, in accordance with the processes of "modularization" described by Karmiloff-Smith (1992); see also Bates et al., 1988; Friederici, 1990). This question is best addressed by looking at the literature on language disorders in older children and adults, where strong claims about the modularity of grammar and the lexicon have been made. But first, we indulge in a brief phylogenetic digression.

Nonhuman primates: a digression. Before we turn to the question of grammar vs. the lexicon in adults with language disorders, we indulge in a brief digression regarding the putative dissociation between grammar and vocabulary reported in reviews of the literature on chimpanzees exposed to languagelike symbolic systems (Gardner, Gardner, \& van Cantfort, 1989; Greenfield, 1991; Greenfield \& Savage-Rumbaugh, 1990, 1991; Savage-Rumbaugh, 1986; SavageRumbaugh, Brakke, \& Wilkinson, 1989; Savage-Rumbaugh et al., 1993; Seidenberg \& Petitto, 1979; Tomasello, 1992, 1994; Tomasello \& Call, in press; Tomasello \& Camaioni, in press). It is often argued that these animals are quite capable of lexical acquisition, picking up expressive vocabularies of up to 200 symbols or signs. However, the chimpanzees studied to date display minimal abilities in grammatical production, with deviant patterning (compared with normal children) in those combinations that are observed (Premack, 1971, 1976; Premack \& Premack, 1983;
Seidenberg \& Petitto, 1979; but compare Greenfield, 1991 and Savage-Rumbaugh, 1986, Savage-Rumbaugh et al., 1989). This difference between grammar and vocabulary is usually interpreted to reflect a qualitative difference in the language-learning abilities of nonhuman primates (i.e., they have lexical abilities, but they lack a "grammar acquisition device"). That may well be the case; after all, they are not human. However, the data that we have presented here suggest another interpretation: Because the animals studied to date apparently find it difficult to produce more than 200-300 words, symbols or signs (Tomasello, personal communication, May 1996), we should not be surprised to find that they also have very restricted abilities in expressive grammar. Consider the developmental relationship between grammar and vocabulary size that we have observed in human children (Figures 1-10). From these figures, it is clear that children with vocabularies under 300 words have very restricted grammatical abilities: some combinations, a few function words in the right places, the occasional bound morpheme, but little evidence for productive control over morphology or syntax. Viewed in this light, the difference between child and chimpanzee may lie not in the emergence of a separate grammar "module", but in the absolute level that they are able to attain in either of these domains. Chimpanzees do not attain the "critical mass" that is necessary for grammar in normal children; instead, they appear to be arrested at a point in lexical development when grammar is still at a very simple level in the human child. Hence the putative dissociation between lexical and grammatical abilities in nonhuman primates may be an illusion. In other words, it may be the case that chimpanzees are equally deficient in both aspects of language ${ }^{4}$

We are not deeply invested in this hypothesis. Our goal is to examine the relationship between grammar and the lexicon in human beings, and data on chimpanzees may not be relevant to this point. Nevertheless, our data for human children do provide a new way of thinking about the old problem of languagelike abilities in other species.

\footnotetext{
${ }^{4}$ Savage-Rumbaugh (personal communication, June 1996) has pointed out that the quantification of lexical vs. grammatical abilities in studies of chimpanzees is greatly complicated by the modalities used to assess these abilities. For example, the chimpanzees in her studies are taught to use symbols on a computerized lexigram board. The symbols themselves are quite limited in number, and there are relatively few connectives or other symbols analogous to grammatical function words in a natural language. A similar point could be made for chimpanzees exposed to gestural symbols, because their signed input is grammatically impoverished compared with the rich grammatical systems that characterize a true signed language. We would like to thank Sue Savage-Rumbaugh and Michael Tomasello for helpful discussion of this issue.
} 


\section{Grammar and the lexicon in adult language disorders}

When the basic aphasic syndromes were first outlined by Broca, Wernicke and their colleagues, differences among forms of linguistic breakdown were explained along sensorimotor lines, rooted in clear albeit rudimentary principles of neuroanatomy. For example, the symptoms associated with damage to a region called Broca's area were referred to collectively as motor aphasia: slow and effortful speech, with a reduction in grammatical complexity, despite the apparent preservation of speech comprehension at a clinical level. A motor definition of this syndrome made sense when we consider the fact that Broca's area lies near the motor strip. Conversely, the symptoms associated with damage to Wernicke's area were defined collectively as a sensory aphasia: fluent but empty speech, marked by moderate to severe word-finding problems, in patients with serious problems in speech comprehension. This characterization also made good neuroanatomical sense, because Wernicke's area lies at the interface between auditory cortex and the various association areas that were presumed to mediate or contain word meaning. Isolated problems with repetition were further ascribed to fibers that link Broca's and Wernicke's area; other syndromes involving the selective sparing or impairment of reading or writing were proposed, with speculations about the fibers that connect visual cortex with the classical language areas (for an influential and highly critical historical review, see Head, 1926).

In the period between 1960 and 1980, a radical revision of this sensorimotor account was proposed (summarized in Kean, 1985). Psychologists and linguists who were strongly influenced by generative grammar sought an account of language breakdown in aphasia that followed the componential analysis of the human language faculty proposed by Chomsky and his colleagues. This effort was fueled by the discovery that Broca's aphasics do indeed suffer from comprehension deficits (Caramazza \& Zurif, 1976; Heilman \& Scholes, 1976; Saffran \& Schwartz, 1988; Zurif \& Caramazza, 1976): Specifically, these patients display problems in the interpretation of sentences when they are forced to rely entirely on grammatical rather than semantic or pragmatic cues (e.g., they successfully interpret a sentence like "The apple was eaten by the girl", where semantic information is available in the knowledge that girls, but not apples, are capable of eating, but fail on a sentence like "The boy was pushed by the girl", where either noun can perform the action). Because those aspects of grammar that appear to be impaired in Broca's aphasia are precisely the same aspects that are impaired in the patients' expressive speech, the idea was put forth that Broca's aphasia may represent a selective impairment of grammar (in all modalities), in patients who still have spared comprehension and production of lexical and propositional semantics (Caramazza \& Berndt, 1985). Caramazza, Berndt, Basili and Koller
(1981, p. 348) state this position succinctly, as follows:

"Although it is possible that Broca patients may suffer from deficits in addition to this syntactic processing deficit, it should be the case that all patients classified as Broca's aphasics will produce evidence of a syntactic impairment in all modalities."

From this point of view, it also seemed possible to reinterpret the problems associated with Wernicke's aphasia as a selective impairment of semantics (resulting in comprehension breakdown and in word-finding deficits in expressive speech), accompanied by a selective sparing of grammar (evidenced by the patients' fluent but empty speech).

If grammar and lexical semantics can be doubly dissociated by forms of focal brain injury, then it seems fair to conclude that these two components of language are mediated by separate neural systems. It was never entirely obvious how or why the brain ought to be organized in just this way (e.g., why Broca's area, the supposed seat of grammar, ought to be located near the motor strip), but the lack of a compelling link between neurology and neurolinguistics was more than compensated for by the apparent isomorphism between aphasic syndromes and the components predicted by linguistic theory. ${ }^{5}$ The linguistic approach to aphasia was so successful in its initial stages that it captured the imagination of many neuroscientists, and it has worked its way into basic textbook accounts of language breakdown in aphasia (Newmeyer, 1988). It seemed fortunate indeed that Nature had provided such a cunning fit between the components described by linguists and the spatial representation of language in the brain.

In fact, evidence against the hypothesized double dissociation between grammar and the lexicon has been there all along (cf. Arnold Pick, below). Additional evidence has accumulated in the last 15 years that casts serious doubt on any first-order linguistic partitioning of the brain. While we cannot summarize all this evidence here, we want to make three related but somewhat different points:

(1) Deficits in word production are observed in all forms of aphasia, suggesting that grammar cannot be impaired in isolation.

(2) Deficits in expressive and receptive grammar can take several forms, but none of these forms are unique to agrammatic Broca's aphasia, or to any

\footnotetext{
${ }^{5}$ Lieberman (1985) has argued that grammar is parasitic upon the organizational structure of the motor system, and for this reason the cortical and subcortical areas that control motor output have come to play a major role in language as well. This is an interesting and plausible proposal, but in our view it rests on a radically different view of grammar from the one proposed within generative grammar, including the accounts of agrammatism put forward by neurolinguists working within the generative tradition.
} 
other single clinical group, and some of them can be induced in normals under adverse processing conditions.

(3) There are some interesting parallels between the specific lexical and grammatical deficits that we observe within groups, suggesting that common mechanisms may be responsible. Although most individual patients and patient groups display a mixture of symptoms within and across domains, it is possible to isolate three different patterns of impairment in language production that strike in a parallel fashion across grammar and the lexicon; each of these is the predominant "symptom complex" for more than one clinical group, as follows:

(a) A nonfluent pattern characterized by omission, including omission of function words (the predominant grammatical symptom) and a reduction in the number of content words, including many word-finding failures (the predominant lexical symptom); this complex is observed in Broca's aphasia, Down Syndrome, and some cases of Specific Language Impairment.

(b) A fluent and deviant pattern characterized by substitution, including substitution of inflections and function words (the predominant grammatical symptom) coupled with substitution of content words (i.e., semantic and/or phonological paraphasias, the predominant lexical symptom); this pattern is found in Wernicke's aphasia, and to a lesser extent in Williams Syndrome.

(c) Another fluent and less deviant pattern characterized by simplification, including avoidance of complex syntactic structures (the predominant grammatical symptom), and an over-reliance on pronouns and relatively empty lexical forms like "this guy here" (the predominant lexical symp-tom); this pattern is observed in Alzheimer's disease, some forms of mild anomic aphasia, and, to a lesser extent, in elderly normals.

Taken together, these lines of evidence have convinced us that grammar and the lexicon do not dissociate in adult aphasia. These two aspects of language tend to break down together. However, several different forms of lexical/grammatical "co-impairment" have been observed, suggesting that more than one causal mechanism may be responsible for disruptions to the unified lexicon that we have proposed here.

To assist the reader with this necessarily terse survey of lexical and grammatical impairments, a summary of the relevant deficits within and across populations is provided in Table 3 . This includes three kinds of word production deficits (omissions, or failures at word finding; substitutions, or paraphasias; empty speech with a heavy reliance on pronominal forms), three kinds of deficits in expressive grammar (morphological subsitution; morphological omission; syntactic simplification), together with two related but distinct deficits in receptive grammar (difficulty processing closed-class morphemes; difficulty with complex syntactic forms).

On the nonspecificity of deficits in word production. The term anomia refers to deficits in the ability to retrieve and produce words (Vaina, Goodglass, $\&$ Daltroy, 1995). Anomic symptoms can range from the temporary word-finding problems that are sometimes observed in young normals (i.e., the Tip-of-theTongue state-Brown \& McNeill, 1966; Levelt, 1989), the mild word-finding problems that accompany normal aging, the chronic naming deficits that are among the first signs of dementia (often accompanied by circumlocutions and "empty speech"), the moderate to severe word retrieval problems that are typically observed in fluent and nonfluent aphasics, all the way out to the debilitating lexical deficit referred to as jargon aphasia. The term anomic aphasia refers to a language deficit that is restricted entirely to problems in word retrieval, in the absence of other clinical symptoms (but see receptive agrammatism, below). When patients recover from more severe forms of fluent or nonfluent aphasia, they often end up with a diagnosis of persistent anomic aphasia, although some patients receive this diagnosis from the onset of their aphasic condition.

In addition to these variations in etiology and severity, interesting variations are sometimes observed among anomic patients in (a) the lexical categories that are most severely compromised, (b) the kinds of errors that are likely to occur within a given category (e.g., substitution vs. omission), and (c) the association or dissociation of these expressive errors with deficits in word comprehension. For example, proper names and common nouns are the first categories to suffer in most mild anomias, usually in production only. Some patients have a harder time naming actions, others show the reverse pattern (for reviews, see Chen \& Bates, in press; Hillis \& Caramazza, 1995; Zingeser \& Berndt, 1990). Some patients find it harder to name animate objects, while others show the opposite profiles (Devlin, Gonnerman, Andersen, \& Seidenberg, 1996; Gonnerman, Andersen, Devlin, Kempler, \& Seidenberg, in press; Warrington \& Shallice, 1984). Categoryspecific anomias have been reported for color words, body parts, household objects, and for fruits and vegetables, with variants of these patterns reported for both comprehension and production, separately and together (Goodglass, 1993). In other words, lexical processing can break down in a number of ways. Some investigators explain category-specific anomias by ascribing each category to a separate neuroanatomical and/or functional module, with separate modules for each modality (e.g., a verb comprehension module, a verb production module, and so forth - Hillis \& Caramazza, 
TABLE 3

Populations with Evidence for Deficits in Expressive or Receptive Grammar

\begin{tabular}{|c|c|c|c|c|c|c|c|c|}
\hline \multirow[b]{2}{*}{ POPULATION } & \multicolumn{3}{|c|}{ LEXICAL DEFICITS } & \multicolumn{3}{|c|}{ EXPRESSIVE GRAMMAR DEFICITS } & \multicolumn{2}{|c|}{ RECEPTIVE GRAMMAR DEFICITS } \\
\hline & $\begin{array}{l}\text { Omission } \\
\text { (word-finding } \\
\text { failure) }\end{array}$ & $\begin{array}{l}\text { Substitution } \\
\text { (paraphasia) }\end{array}$ & $\begin{array}{l}\text { Empty Speech } \\
\text { (heavy use of } \\
\text { proforms) }\end{array}$ & Omission & Substitution & $\begin{array}{l}\text { Reduction in } \\
\text { Syntactic } \\
\text { Complexity }\end{array}$ & $\begin{array}{c}\text { Difficulty } \\
\text { Processing } \\
\text { Closed-Class } \\
\text { Morphemes }\end{array}$ & $\begin{array}{c}\text { Difficulty } \\
\text { Processing } \\
\text { Complex Syntactic } \\
\text { Frames }\end{array}$ \\
\hline Broca's Aphasia & ++ & + & - & ++ & + & ++ & ++ & ++ \\
\hline Wernicke's Aphasia & + & ++ & ++ & + & ++ & + & ++ & ++ \\
\hline Anomic Aphasia & + to ++ & - to ++ & $\sim$ to ++ & - & - & $\sim$ & + & + \\
\hline Alzheimer's Dementia & + to ++ & - to $\sim$ & + to ++ & - & - & + & $\sim$ & + \\
\hline $\begin{array}{l}\text { Neurologically Intact } \\
\text { Deaf Speakers of an } \\
\text { Oral Language }\end{array}$ & - to + & - & $?$ & + & $\begin{array}{l}\text { substitutions } \\
\& \text { additions }\end{array}$ & - to & + & $\sim$ \\
\hline $\begin{array}{l}\text { College Students } \\
\text { under Noise or } \\
\text { Compression }\end{array}$ & $?$ & ? & $?$ & $?$ & $?$ & $?$ & $\sim$ & $\sim$ \\
\hline $\begin{array}{l}\text { College Students } \\
\text { under Dual-Task } \\
\text { Condition }\end{array}$ & $?$ & ? & $?$ & ? & ? & ? & $\sim$ & - \\
\hline $\begin{array}{l}\text { Elderly Controls \& } \\
\text { Non-Aphasic Patients }\end{array}$ & $\sim$ & - to & $\sim$ & - & - & $\sim$ & $\sim$ & $\sim$ \\
\hline $\begin{array}{l}\text { Specific Language } \\
\text { Impairment }\end{array}$ & $\sim$ to ++ & - & $?$ & ++ & $\sim$ & ++ & + & + \\
\hline Down Syndrome & $\sim$ to ++ & - & ? & ++ & $\sim$ & ++ & + & + \\
\hline Williams Syndrome & - to & + & $?$ & - to $\sim$ & + & $\sim$ & $\sim$ to + & $\sim$ to + \\
\hline
\end{tabular}

$-=$ no deficit (equivalent to normal to young adults, under normal conditions); = mild deficit (worse than normal young adults) $++=$ moderate deficit (worse than age- or IQ-matched normal controls; ++ = severe and characteristic deficit; ? = untested/unknown.

1995). Others have proposed instead that categoryspecific anomias are epiphenomena of differences in the modalities that underlie word meaning (e.g., tactile vs. visual; motor vs. visual-Damasio, Grabowski, Tranel, Hichwa, \& Damasio, 1996; Farah \& McClelland, 1991; Martin, Wiggs, Ungerleider, \& Haxby, 1996), the correlational structure of the categories in question (Devlin et al., 1996), and/or the kinds of processing that are required for different word types (Farah \& McClelland, 1991; Hinton \& Shallice, 1991; Plaut, 1994, 1995).

Although we acknowledge that a complete account of brain organization for language will have to handle these disparate facts, the literature converges on one uncontroversial conclusion that is crucial for our arguments about grammar and the lexicon: Anomia is the one symptom (or class of symptoms) that is present in every form of aphasia that has been documented to date. This fact sets an important lower limit on any claim about the dissociation of linguistic modules: We are unlikely to observe any form of aphasia in which grammar is impaired but lexical processing is completely intact - which means, in turn, that the relationship between grammar and the lexicon cannot constitute a full double dissociation. Any dissociations that we do find will have to be cast in terms of a relative dissociation, e.g., grammar is LESS impaired than lexical production in one case, grammar is MORE impaired than lexical production in another. As Shallice (1988) has discussed in some detail, this kind of weak dissociation is difficult to prove. This problem is compounded when we are dealing with lexical and grammatical structures that differ so much in size, shape, privileges of occurrence and the kinds of tasks that can be used to measure each one (see Bates, Marchman, Harris, Wulfeck, \& Kritchevsky (1995) for a discussion of this point).

On the nonspecificity of expressive agrammatism. We have just argued that grammar is never impaired in isolation in brain-injured adults. Grammatical impairments always co-occur with some form of anomia. Could it still be the case, however, that deficits in grammar are associated with a unique lesion site, e.g. with lesions to Broca's area? Several different lines of evidence have accumulated against the idea that expressive agrammatism is uniquely associated with Broca's aphasia, or (by extension) with the neural tissue surrounding Broca's area.

First, cross-linguistic studies have shown that the expressive symptoms displayed by nonfluent Broca's aphasics differ markedly from one language to another (Bates \& Wulfeck, 1989a\&b, 1991; Bates, Wulfeck, \& MacWhinney, 1991; Menn \& Obler, 1990). Detailed and specific cross-linguistic differences have been observed in the order in which words and morphemes are produced (even in severely nonfluent patients), the retention or omission of grammatical inflections and function words in contexts where those inflections are required, and in the production of language-specific features like tone in Chinese or pragmatic word order variations in Hungarian and Italian (Bates, 1991). These findings can only be explained if we assume that Broca's aphasics retain detailed knowledge of their native grammar.

Second, studies of speech production in richly inflected languages show that Wernicke's aphasics make grammatical errors that are similar in quantity and quality to the errors produced by Broca's aphasics. This 
point was first made by Arnold Pick (1913/1973), who originated the term "agrammatism." Based on his observations with German- and Czech-speaking patients, Pick noted that there are two forms of agrammatism: a nonfluent form, usually associated with frontal lesions, characterized by omission and reductions in complexity, and a fluent form, typically associated with posterior (temporal lobe) lesions, involving substitutions of one grammatical form for another (i.e., paragrammatism). In Pick's view, the fluent (temporal) form of agrammatism is actually the more interesting of the two:

“...Temporally determined expressive agrammatism is characterized by erroneous grammatical constructions (paragrammatisms), in contrast to the frontal type with its telegraphic style ... This temporally determined form is characterized, in pure cases, by disturbances in the use of auxiliary words, incorrect word inflections, and erroneous prefixes and suffixes ... In contrast to motor agrammatism, the tempo of speech is not retarded, tending rather to logorrhea with intact sentence pattern and intonation. Occasionally some motor (i.e. telegrammatic) phenomena are found, such as the dropping of inflections, with juxtaposition of the words which com-prise the skeleton of the sentence." (pp. 76-77, Pick 1913/1973; also cited in Bates et al., 1987a).

As we have noted in other reviews (Bates \& Wulfeck, 1989a\&b; Bates et al., 1991), English has such an impoverished system of grammatical morphology that substitutions are very rare; hence the paragrammatic errors associated with fluent aphasia are difficult to detect. This is not the case in languages like Italian, German, Turkish, Hungarian or Serbo-Croatian, where the substitution errors observed in Wernicke's aphasia are very obvious. In fact, it is probably not an accident that the effort to equate agrammatism with damage to anterior and semantic deficits to posterior regions of the left hemisphere both arose in research on language breakdown in English-speaking aphasics. When the language has a structure that permits morpheme substitutions to emerge, it becomes apparent that there are striking parallels in the lexical and grammatical errors produced by Wernicke's aphasics, i.e., a tendency to err by substitution, replacing the intended item with one that is a close semantic and/or phonological neighbor.

Based on the finding that Wernicke's aphasics do display problems in expressive grammar, some investigators have argued that Alzheimer's Disease actually constitutes a better example of grammatical sparing in a patient with lexical deficits (Kempler, Curtiss, \& Jackson, 1987; Ullman et al., 1993, 1994; Whitaker, 1976). It is true that word-finding deficits are an early indicator of Alzheimer's Disease, and these symptoms worsen across the course of the disease despite the fact that AD patients continue to produce fluent speech with

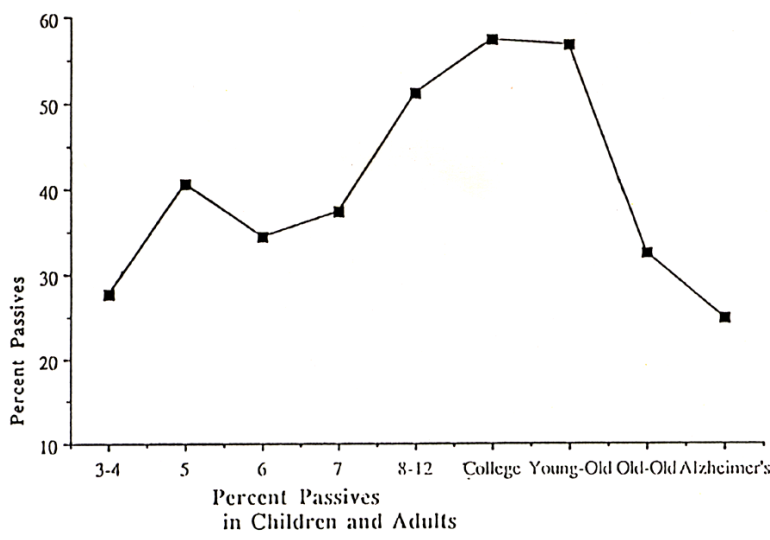

Figure 11. Rise and fall of passivization across the human life-span, as a percentage of passive-eliciting items on which a passive was produced.

little or no evidence for frank grammatical errors (i.e., no omission of function words or inflections in obligatory contexts, no evidence for grammatical substitutions). On the other hand, as Bates, Marchman et al. (1995) have noted, frank lexical errors are also rare in AD patients. That is, AD patients do not produce the kinds of paraphasias (blends and word substitutions) that are so common in the speech of Wernicke's aphasics. In that respect, the lexical and grammatical abilities of $\mathrm{AD}$ patients are parallel. The lexical deficits of $\mathrm{AD}$ patients can be characterized primarily as failures of word retrieval, resulting in frequent production of circumlocutions (e.g., "I can't remember how you say it....it goes like this...."), together with a higher than normal ratio of pronouns to nouns, and generic verbs like "make" or "do" in place of more explicit forms.

Given this characterization of the lexical problems observed in $\mathrm{AD}$, what should their grammatical deficits look like if grammar and the lexicon are breaking down in a parallel fashion? Bates et al. have argued that the syntactic simplifications observed in Alzheimer's disease and (to a lesser extent) in normal aging constitute a grammatical variant of anomia. They illustrate this point with results from a speech production task in which children, young adults, older adults and AD patients are asked to describe the same set of animated events. The film was designed to elicit transitives, intransitives, datives, and directional locatives; it includes compound events involving three protagonists and two repeated actions, encouraging the production of more complex syntactic frames. Subjects were first asked to describe these events freely, with no discourse constraints. Then they were asked to describe each event in response to a discourse probe that focussed on the passive recipient of an action-an "ecological niche" that results in high rates of passive voice descriptions in healthy young adults (see also Tannenbaum \& Williams, 1968).

Figure 11 puts together results from the adult study by Bates et al. and a developmental study by Marchman, Bates et al. (1991) using the same 
paradigm. This figure illustrates the rise and fall of passivization across the human life span. There is a monotonic increase in passive production from 3 years of age to adulthood. This is true even though the majority of 3-year-olds in the Marchman, Bates et al. study do produce at least one well-formed passive in this situation. That is, they "know" the passive but they apparently find it difficult to produce. Rates of passivization hold steady between 18 years (Young) and 65 years of age (Young-Old), but drop off markedly in healthy adults between 65-100 years of age (Old-Old). Results are even worse for AD patients, who produce very few passive constructions in this discourse situation (significantly fewer than the Old-Old). Instead, AD patients opt for alternative ways of topicalizing the recipient of the action, with structures that young children also use in this situation, e.g.,

\section{Experimenter: "What happened to the goat?" \\ Patient: "He was just sitting there and the horse bit him."}

This and other lines of evidence in the same study led Bates et al. to conclude that Alzheimer's patients suffer from a deficit in the ability to access and deploy complex, low-frequency syntactic forms in the appropriate discourse context - akin to their deficits at the lexical level (see also Wallesch \& Hundsalz, 1994).

So far we have described three different forms of grammatical impairment in expressive language: omission of inflections and function words (agrammatism), substitution of inflections and function words (paragrammatism), and syntactic simplification. As summarized in Table 3, all of these are observed in Broca's aphasia, but none of them are unique to Broca's aphasia. In fact, these three deficits in expressive grammar can be found in a wide variety of populations, as follows.

Omission of function words and inflections is a common symptom of Down Syndrome, SLI, and it is also a pattern that is often found in normal children during the first stages of language development. It is interesting and perhaps relevant that omission errors tend to prevail with the least fluent populations, suggesting commonalities across grammar and the lexicon in the factors that cause this profile.

Grammatical substitutions occur with even higher frequency in Wernicke's aphasia than they do in Broca's aphasia - although this fact is not apparent in a language like English, with relatively impoverished morphology. As we noted earlier, substitutions of this kind have also been observed in Italian speakers with Williams Syndrome. Again, it is interesting that grammatical substitutions (paragrammatism) are more common in groups that also produce lexical substitutions (paraphasias). Bates and Wulfeck (1989a \& b) and Kolk and Heeschen (1992) note that there may be a single continuum from omission to substitution across all aspects of language, and that a given speaker's position along that continuum is a by-product of processing speed. In other words, this may be a language-specific instantiation of the well-known speed-accuracy tradeoff, with parallel effects in grammar and the lexicon.

There is one population in which grammatical substitutions occur in the absence of lexical paraphasias. In particular, Volterra and her colleagues (Caselli, Volterra, Pagliari-Rampelli, \& Maragna, 1994) note that neurologically intact deaf adults often omit or substitute function words in oral and written Italian. In addition, Italian deaf speakers also have a tendency to add in function words in places where they should not occur (Volterra \& Bates, 1989). This symptom is rarely observed in hearing populations, and may reflect the absence of experience with prosodic cues that predict the occurrence of function words for hearing people (cf. Herron \& Bates, in press).

Finally, syntactic simplifications occur in a wide range of populations, including Broca's aphasia and Wernicke's aphasia, and they are the predominant grammatical symptom in Alzheimer's Disease and normal aging. They are also characteristic of the speech of young normal children, and a range of clinical populations including Down Syndrome, Specific Language Impairment (Clifford, Wulfeck, \& Powell, 1995; Wulfeck, Manning, \& Sklar, 1995), and focal brain injury (Reilly, 1995; Reilly \& Bates, 1995). It is interesting that lexical paraphasias are invariably absent in those populations for whom syntactic simplification is the most prominent grammatical symptom (e.g., Alzheimer's disease). However, syntactic simplification does have a parallel in the lexical domain, in the overreliance on pronouns and other high-frequency, empty forms (e.g., "this thing here").

Putting these lines of evidence together, we conclude that the various forms of expressive agrammatism observed in Broca's aphasia also occur in other populations, including individuals without any form of focal brain damage. In other words, expressive agrammatism appears to have no localizing value, and its presence or absence in specific syndromes does not permit us to conclude that these patients suffer from the loss of a grammar module. In addition, there are enough parallels between specific word-finding problems and specific problems in expressive grammar to suggest that common factors may be at work, although the correlation is not perfect.

On the nonspecificity of receptive agrammatism. Receptive agrammatism has been defined as a difficulty in the interpretation of sentences or phrases in the absence of converging information from nongrammatical sources (i.e., semantics, pragmatics, prosody, or the real-world situation). The term is also used by some investigators to refer to selective deficits in the processing of inflections and grammatical function words outside of a sentential or phrasal context. As we noted above, the idea that Broca's aphasics might suffer from some form of central agrammatism was prompted by the discovery that these patients do have a hard time understanding language if they are prevented from 
making use of nongrammatical information. Hence the apparent sparing that these patients evidence in language comprehension at bedside was presumed from the preservation of semantics and real-world knowledge. Although this proposal is compelling in its parsimony and explanatory power, it has fallen on hard times.

First, several studies have appeared documenting cases of Broca's aphasics with expressive agrammatism in the absence of deficits in receptive grammar (Miceli, Mazzucchi, Menn, \& Goodglass, 1983). This apparent dissociation between expressive and receptive grammar resembles the comprehension/production dissociations that have been observed within the lexicon in a range of different populations (e.g., Figure $3 b$ for normal infants).

Second, there are now a large number of studies showing that Broca's aphasics who meet the usual criteria for both receptive and expressive agrammatism are still able to recognize grammatical errors in someone else's speech (Devescovi et al., 1996; Linebarger, Schwartz, \& Saffran, 1983; Lukatela, Shankweiler, \& Crain, 1995; Shankweiler, Crain, Gorrell, \& Tuller, 1989; Wulfeck, 1988; Wulfeck, Bates, \& Capasso, 1991). These results are difficult to reconcile with the idea that grammatical knowledge is stored in or around Broca's area.

Finally, forms of receptive agrammatism such as those displayed by most Broca's aphasics have now been demonstrated in a wide range of patient groups. The receptive deficits in grammar that have been reported for Broca's aphasics involve at least two different kinds of breakdown: deficits in the processing of closed-class morphemes (even when they are presented out of context), and difficulty interpreting syntactic forms that involve nonstandard word order (e.g., passives like "John was pushed by Mary"; object relatives like "It was John that Mary pushed"). These correspond roughly to a morphological deficit, and a syntactic deficit. The nature and dissociability of these two grammatical deficits are still hotly debated in this field (Fromkin, 1995; Grodzinsky, 1993), and a detailed consideration of the literature would go well beyond our purview here. We would like to point out, however, that both these deficits have been observed outside of Broca's aphasia. Indeed, preliminary evidence suggests that these deficits can be induced (temporarily, of course) in normal adults forced to process linguistic stimuli under adverse conditions (Blackwell \& Bates, 1995; Kilborn, 1991).

In our own work, we have demonstrated selective deficits in the use of agreement morphology in Broca's aphasics who were native speakers of English, Italian, German, Spanish, Hindi and Serbo-Croatian (Bates, Friederici, \& Wulfeck, 1987b; Smith \& Bates, 1987; Smith \& Mimica, 1984; Vaid \& Pandit, 1991; Wulfeck, Juarez, Bates, \& Kilborn, 1986); selective deficits in the use of case cues to interpret sentences have also been shown in Broca's aphasics who were native speakers of Serbo-Croatian, Turkish or Hungarian (MacWhinney, Osmán-Sági, \& Slobin, 1991; Smith \& Bates, 1987; Smith \& Mimica, 1984). In all these groups, this selective impairment of morphology was observed even though most patients retained nearnormal use of canonical word order and/or semantic cues, compared with normal speakers of the same language. In related studies in which subjects were asked to detect grammatical errors, we also found that the ability to detect agreement errors was more impaired than the ability to detect errors involving illegal movement of words (Wulfeck \& Bates, 1991; Wulfeck et al., 1991).

These cross-linguistic findings would appear to provide prima facie evidence in favor of the closed-class theory of agrammatism, i.e., the proposal that the grammatical deficit observed in Broca's aphasia is restricted to grammatical morphology, with sparing of word order (Garrett, 1992; see chapters in Kean, 1985). However, two additional results mitigate that conclusion. First, there were significant cross-linguistic differences in the degree of control that Broca's aphasics retain over closed-class morphology, in the direction that we would predict if these patients retain languagespecific knowledge of morphology (e.g., greater use of agreement morphology and greater sensitivity to agreement errors in Italian Broca's aphasics compared with their English counterparts). Second, the selective vulnerability of grammatical morphology and selective sparing of word order has been observed in many other patient groups, including Wernicke's aphasics, anomic aphasics (who should, at least in principle, have no grammatical deficits at all), patients with right-hemisphere damage, even some patients with no neurological damage at all (e.g., a subset of patient controls from the orthopedic ward!).

This last finding led us to hypothesize that closedclass morphemes constitute a "weak link in the processing chain", subject to breakdown whenever the processor is placed under stress. To test this hypothesis, we have begun a series of experiments in which college students are asked to interpret sentences or to make grammaticality judgments (a) with stimuli that have been perceptually degraded, (b) with stimuli that have been compressed to half their normal length, and/or (c) in conjunction with another cognitive task that places heavy demands on memory and attention (Bates, Devescovi et al., 1994; Blackwell \& Bates, 1995; Kilborn, 1991; see also Miyake, Carpenter \& Just, 1994, 1995). Briefly summarized, these results confirm that virtually any severe stressor can disrupt the listener's ability to use closed-class morphology, while leaving the use of canonical word order essentially untouched. Indeed, the patterns that we observe with normal college students under stress bear a striking resemblance to the receptive language profiles observed in aphasic patients. 
More recently, we have used the same methodology to investigate processing of syntactic contrasts that do not depend on closed-class cues (Bates, Devescovi et al., 1994). This includes the contrast between subject and object relatives (e.g., "It's the horse that is biting the cow" vs. "It's the horse that the cow is biting"), two sentence types that vary only in word order. We have already noted that aphasic patients tend to retain control over the canonical word orders in their language (Subject-Verb-Object in English, Italian, German, Serbo-Croatian, Spanish, Chinese and Hindi; SubjectObject-Verb in Turkish, Hungarian and Japanese-Bates et al., 1987b; Chen, 1989; Hagiwara \& Caplan, 1990; MacWhinney \& Osmán-Sági, 1991; MacWhinney, Osmán-Sági, \& Slobin, 1991; Slobin, 1991; Vaid \& Pandit, 1991; Wulfeck et al., 1986). However, noncanonical orders seem to pose a special problem for Broca's aphasics. Our own work looking at comprehension of these structures suggests that these structures are also more difficult for Wernicke's aphasics, anomic patients (who should - at least in theory - have no problem with these structures), and elderly adults without dementia (Bates et al., 1991). College students show the same order of difficulty, although the difference only shows up in reaction time (i.e., errors of interpretation are very rare). When college students are forced to process these sentences under compression or perceptual degradation, the difference between subject and object relatives increases dramatically, becoming evident in error data as well as reaction times. Interestingly, however, our college students are apparently not affected by a cognitive overload in this task (see also Caplan \& Waters, 1995), even though cognitive overload did disrupt processing of grammatical morphology in other studies. This is our first evidence to date suggesting that morphology and syntax may be vulnerable to a different set of stressors, constituting potential evidence for a modular view. However, that fact that these patterns can be induced in healthy college students argues against a strong form of the modular view (i.e., a view that attributes selective deficits in behavior to selective damage at the neural level).

Table 3 summarizes the populations for whom we have evidence of selective impairment in the receptive processing of grammatical morphemes and/or selective difficulties in the processing of syntactic structures that involve noncanonical order (structures that are generated by movement rules in generative grammar - Grodzinsky, 1993). It is clear from the evidence in this table that receptive agrammatism (like expressive agrammatism) has little or no localizing value. The symptoms observed in agrammatic Broca's aphasics are observed in many other groups, including neurologically intact individuals who are forced to process sentences under stress. Even though certain aspects of grammar can be selectively impaired, these impairments do not yield persuasive evidence for a dissociation between grammar and the lexicon. Instead, they can be explained by differences in the processing characteristics of individual items - their perceptual salience, frequency, the demands they place on memory, and so forth.

The effects of brain injury appear to cut across traditional linguistic boundaries, and although there are indeed qualitative differences in the symptom patterns associated with particular aphasic syndromes (i.e., fluent Wernicke's aphasia and nonfluent Broca's aphasia), a characterization of the mental/neural mechanisms responsible for these patterns still eludes us. Aphasiologists are hard at work on alternative accounts of the different forms of language breakdown that have been observed to date. Some investigators postulate specific rather than general forms of processing cost, associated with damage to specific brain regions. Proposals that are currently on the table include the following:

(1) Anterior and posterior lesions differ in their effect on processing speed (i.e., anterior lesions have a greater effect on rapid processes - Friederici \& Kilborn, 1989; Swinney, Zurif, Rosenberg, \& $\mathrm{Nicol}$, in press) and/or types of working memory (e.g., anterior lesions result in a "degraded trace"-Ostrin \& Schwartz, 1986).

(2) Anterior lesions have a selective effect on automatic aspects of language processing, while posterior lesions have a greater impact on controlled processing (Milberg \& Blumstein, 1981; cf. Milberg, Blumstein, Katz, Gershberg, \& Brown, 1995; Shiffrin \& Schneider, 1977; but see Tyler, Ostrin, Cooke, \& Moss, 1995 for counterarguments).

(3) There is a differential anterior-posterior distribution in the basic components of attention (with differential effects on those aspects of language processing that are most dependent on anterior vs. posterior aspects of attention - Posner, Petersen, Fox, \& Raichle, 1988).

(4) Anterior lesions result in a selectively greater reduction of excitation while posterior lesions tend to reduce inhibition-an old proposal (e.g., Goldstein, 1948) that has taken on new meaning in an era of neural network models, combined with an increased understanding of neural transmitters, their differential distribution in the brain, and their differential consequences for computation.

Any of these proposed contrasts might result in qualitative differences in the performance deficits displayed by different patient groups, without contradicting the assumption that linguistic knowledge (competence) is broadly distributed in the brain and largely preserved in patients with focal brain injury (see also Friederici \& Kilborn, 1989; Linebarger, Schwartz, \& Saffran, 1983; Patterson, Seidenberg, \& McClelland, 1989). Some related ideas have emerged from the modular camp, including the proposal that each linguistic subsystem (e.g., syntax, phonology, the lexicon) makes use of a separate pool of processing resources; hence the gradual 
nature of linguistic symptoms is due to a degradation in one or more of these language-specific processors (cf. Caplan \& Waters, 1995; Miyake, Carpenter, \& Just, 1994, 1995). Other investigators still seek an account that honors the structural details of generative grammar, although their proposals take a much more subtle form compared with the original notion of "central agrammatism" (Caplan \& Hildebrandt, 1988; Grodzinsky, 1986). Finally, a few investigators who once pursued a linguistic account of aphasia have abandoned any effort to map aphasic syndromes onto specific brain regions, recommending the study of individual cases that may tell us something about the structure of the normal language processor even though they tell us nothing at all about the structure of the brain (Caramazza, 1986).

We are certainly not trying to suggest that the matter is settled. However, we believe that the evidence for a pathological dissociation between lexical and grammatical processing has been overstated. In the current state of affairs, evidence from aphasia is compatible with a strong lexicalist approach to grammar-although such an approach must be complemented with an account of how different aspects of this unified processor can be damaged in aphasia (for additional evidence showing that a unified processor can display apparent double dissociations, see Plaut, 1994, 1995, and this volume). This brings us to at last to a brief review of claims about the modularity of grammatical and lexical processing in real-time processing by normal adults.

\section{On the inseparability of grammar and the lexicon in normal language processing}

We end with a brief consideration of the case for modularity of grammatical and lexical processing in normal adults.

In the 1960s-1970s, efforts were made to develop real-time processing models of sentence comprehension and production (i.e., performance) that implemented the same modular structure proposed in various formulations of generative grammar (i.e., competence). (For reviews, see Fodor, Bever, \& Garrett, 1974; Garrett, 1980; Slobin, 1979). The comprehension variants had a kind of "assembly line" structure, with linguistic inputs passed in a serial fashion from one module to another (phonetic --> phonological --> grammatical --> semantic). Production models looked very similar, with arrows reversed (semantic --> grammatical --> phonological --> phonetic). From the 1970 s to the early 1980s, there was a veritable cottage industry of studies showing "top down" context effects on the early stages of comprehension, raising serious doubts about this fixed serial architecture. These included studies showing that sentence-level information can affect the accuracy and timing of word recognition, thus constituting evidence against a modular distinction between grammar and the lexicon.
In response to all these demonstrations of context effects, proponents of the modular view have countered with studies demonstrating temporal constraints on the use of top-down information during the word recognition process (Kintsch \& Mross, 1985; Onifer \& Swinney, 1981). An influential example comes from experiments in which ambiguous words like "bug" are presented within an auditory sentence context favoring only one of its two meanings (e.g., "bug" in an exterminator context). Shortly after the ambiguous word is presented, lexical decisions are required for word or nonword targets presented in the visual modality, including targets that are unrelated (e.g., MOP), related to the contextually inappropriate meaning (e.g., SPY), or related to the contextually appropriate meaning (e.g., ANT). If the prime and target are separated by at least 750 milliseconds, priming is observed only for the contextually appropriate meaning (i.e., selective access); however, if the prime and target are very close together in time (less than 250 milliseconds), priming is observed for both meanings of the ambiguous word (i.e., exhaustive access). These results were interpreted as support for a two-stage model of word recognition: a bottom-up stage that is unaffected by context, and a second post-lexical stage when contextual constraints can apply. The finding that both meanings of an ambiguous word are primed regardless of context under some temporal conditions provides much stronger evidence for modularity than studies showing an absence of context effects, because null effects can be obtained in a variety of uninteresting ways.

The theoretical basis for the notion of a modular lexicon has been challenged for many years (MarslenWilson \& Tyler, 1980), and although the exhaustiveaccess effect has been replicated in many different laboratories, its interpretation is still controversial (Ratcliff \& McKoon, 1994). For example, some investigators have shown that exhaustive access fails to appear on the second presentation of an ambiguous word (Simpson \& Kang, 1994), or in very strong contexts favoring the dominant meaning of the word (Tabossi \& Zardon, 1993). Van Petten and Kutas (1991) replicated the original finding using event-related brain potentials as well as RT; however, they went on to show that the two stages (exhaustive --> selective access) are preceded by an even earlier stage at which priming is only observed for the contextually appropriate target (selective --> exhaustive --> selective). Finally, Kawamoto (1989) has conducted simulations of lexical access in neural networks, showing that exhaustive access can occur under some circumstances even in a fully interactive model, depending on differences in the rise time and course of activation for different items under different timing conditions. In short, the literature on processing of lexically ambiguous words still does not provide clear evidence one way or another for a modular boundary between sentential and lexical priming effects. 
A recent study by Hernandez (1996) takes a different approach to the relation between sentence- and wordlevel priming, using unambiguous words (see also Hernandez \& Bates, 1994; Hernandez, Fennema-Notestine, Udell, \& Bates, 1995). Semantically related and unrelated word pairs were presented visually, with instructions to pronounce the second word in each word pair. Primes were presented for a very short time (100 or 200 milliseconds), and the interval between prime and target was also very short ( 0 or 100 milliseconds). Hence these lexical effects are in the temporal region that is usually associated with rapid, automatic, modular lexical effects. When these pairs were presented out of context, significant priming effects on naming times were observed that do not vary in magnitude across these temporal conditions. Having established that these materials do yield classical word-word priming, Hernandez conducted a series of studies in which the same word pairs were embedded in short discourse frames presented in the auditory modality. The prime and target were always located in a sentence-internal position, in either the penultimate or the final sentence. Contexts were designed so that the target word in each word pair was either an appropriate continuation, or a semantically inappropriate continuation. The prime words were also either appropriate continuations, or inappropriate. Hence a typical stimulus set would involve the following five possibilities:

\begin{tabular}{|c|c|c|}
\hline & $\underline{\text { PRIME }}$ & TARGET \\
\hline \multicolumn{3}{|l|}{ Target fits context: } \\
\hline Related pair & STREET & ROAD \\
\hline Unrelated pair & APPLE & ROAD \\
\hline \multicolumn{3}{|l|}{ Target doesn't fit context: } \\
\hline Related pair & APPLE & ORANGE \\
\hline Unrelated pair & STREET & ORANGE \\
\hline No relations at any level: & APPLE & CLOCK \\
\hline
\end{tabular}

This procedure permits the conjoint assessment of sentential context effects, lexical context effects, and any interactions that might occur between the two, across the same four temporal conditions described above for word pairs in isolation. (For any particular word pair, conditions were rotated over subjects, so that no subject saw the same word pair twice.) For our purposes here, the major findings were that (1) robust and reliable main effects of sentence priming are observed in every condition, at these very short time lags, ${ }^{6}$ and (2) word-word priming is much more fragile and variable, appearing only when the target cannot be integrated into the context, or at the longest time lag (200-millisecond exposure to the prime, 100-millisecond SOA). It seems clear that word- and sentence-

\footnotetext{
${ }^{6}$ Ancillary analyses showed that these sentential effects were independent of the presence or number of lexical associates in the sentence.
}

level priming are both early phenomena, and interactions between the two can be observed within a very short time window - clear evidence against a two-stage modular model.

This evidence for an interaction between sentenceand word-level semantics is only indirectly related to the relationship between lexical processing and grammar. Are the processes of word recognition and/or word retrieval directly affected by grammatical context, or does grammatical context exert its effect at a later, postlexical stage of integration? A number of early studies looking at grammatical priming in English obtained weak effects or no effects at all on measures of lexical access (Seidenberg, Waters, Sanders, \& Langer, 1984; Tyler \& Wessels, 1983; Wright \& Garrett, 1984). In a summary of the literature on priming in spoken-word recognition, Tanenhaus \& Lucas (1987) conclude that "On the basis of the evidence reviewed...it seems likely that syntactic context does not influence pre-lexical processing" (p. 223).

However, more recent studies in languages with rich morphological marking have obtained robust evidence for grammatical priming. This includes effects of gender priming on lexical decision and gating in French (Grosjean, Dommergues, Cornu, Guillelmon, \& Besson, 1994), on word repetition and gender classi-fication in Italian (Bates, Devescovi, Hernandez, \& Pizzamiglio, 1996), and on picture naming in Spanish (Reyes, 1995) and German (Hillert \& Bates, 1996; but see van Berkum, 1996, and Friederici \& Schriefers (1994) for reports indicating that gender priming may be relatively fragile in German and Dutch). Studies of lexical decision in Serbo-Croatian provide evidence for both gender and case priming, with real-word and nonword primes that carry morphological markings that are either congruent or incongruent with the target word (Gurjanov, Lukatela, Moskovljevic, \& Turvey, 1985; Lukatela, Kostic, Feldman, \& Turvey, 1983). Unpublished studies from our own laboratory show that repetition of Chinese nouns can be primed by noun classifiers (an abstract grammatical category in Chinese-Lu, Tzeng, \& Bates, research in progress). Returning to English, we have recently investigated the effects of very short syntactic frames like "I like the " or "I want to___" on word repetition (Liu, 1996) and picture naming (Federmeier \& Bates, 1996). Results include significant facilitation of targets that are congruent (object names/pictures in a noun context; action names/pictures in a verb context) and inhibition of targets that are incongruent (object names in a verb context; action names in a noun context), compared in all cases with neutral prime. Finally, we have uncovered very strong sentential priming effects for closed-class words that are difficult to recognize when they are spliced into a neutral context (Herron \& Bates, in press). In all of the studies within our laboratory, the interval between prime and target is very short (set at zero in most cases), and reaction times are in the same 
range that has been reported for word-word priming. Hence it appears that grammatical context can have a significant effect on lexical access within the very short temporal windows that are usually associated with automatic, nonstrategic priming effects. The fact that these priming results include facilitation as well as inhibition provides further evidence against the idea that grammatical priming is a strategic, postlexical integration process that only occurs after lexical access is complete (see Bates et al., 1996, for a detailed discussion of this point).

As Altmann and Steedman (1988) have pointed out, the demonstration that context effects operate very early can be used to argue against assembly line versions of the modularity argument (i.e., "strong modularity"). However, these demonstrations do not rule out a different form of modularity, in which distinct and tightly bounded processors work in parallel on the input stream (i.e., "weak modularity"). In other words, we cannot disprove the existence of a modular border between grammar and the lexicon. We can conclude, however, that grammatical and lexical processes interact very early, in intricate patterns of the sort that we would expect if they are taking place within a single, unified lexical system (Bates \& MacWhinney, 1989; Gaskell \& Marslen-Wilson, 1996; MacDonald et al., 1994; Marslen-Wilson \& Tyler, 1980).

This evidence for early interaction is complemented by a different line of evidence, indicating that the production of lexical items and the production of sentence frames follow the same processing constraints. For example, Bock (1986) has shown that phrase structure types like the passive or dative movement can be "primed", just like lexical items. For example, if a subject has just been exposed to a sentence with a ditransitive (e.g., "John gave Mary the book"), he is more likely to describe a subsequent picture using that phrase structure type (e.g., "The nurse showed the doctor the bill"), even though the "prime" and the "target" have no words in common. From a different point of view, Demuth (1989) has shown that passives are produced many years earlier by children exposed to an African language (Sesotho) in which passives are very frequent, compared with Indo-European languages (e.g., English) where passives are relatively rare. Bates and Devescovi (1989) report similar findings on the production of relative clauses, which are 3-5 times more common in Italian than English, and appear with high frequency in the speech of Italian children by three years of age. From yet another perspective, Bates, Friederici, Wulfeck and Juarez (1988) have shown that the retention of word order variations by Italian-speaking Broca's aphasics is directly related to the frequency of those word order types in informal discourse. Taken together, these findings suggest that the production of syntactic frames is subject to the same factors that are known to govern access and production of individual words - in this case, demonstrated effects of frequency and recency.

To summarize, grammatical and lexical structures interact very early in processing, and the access of grammatical and lexical structures is governed by common laws. To be sure, these structures differ markedly in size and function, and (perhaps most importantly) in the amount of phonetic specification that they entail (from fully specified word templates to phrase structure types like the object relative that have no terminal symbols). For these reasons, we should not be surprised to find, for example, that syntactic and lexical violations result in somewhat different patterns of cortical activity, including event-related brain potentials (Neville et al., 1991; Osterhout \& Holcomb, 1993; but see Kluender \& Kutas, 1993, in press), and positron emission tomography (Jaeger et al., in press; Mazoyer et al., 1993). Grammatical and lexical forms are not identical, and for that reason, deployment of these forms will necessarily involve "nonidentical brain systems" (Mills, Coffey-Corina, DiIulio, \& Neville, 1995). We have to configure our arm and hand differently to lift a pin, a book, or a ten-pound box of books. In the same fashion, the brain systems that are deployed during the activation of bound morphemes, root words, whole phrases and sentences will necessarily differ. The question we have addressed here is a different one: What evidence do we have to justify the conclusion that grammatical and lexical forms are processed by independent modules, each with its own maturational course, neural representation and processing profile? We think there is very little evidence for a claim of that sort, although there is firm evidence that "different things are processed differently."

If we assume that grammatical and lexical forms are handled by the same large and heterogeneous processing system, then we must commit ourselves to a theory of representation and learning that can handle both. What would such a theory look like? MacDonald et al. have argued that a unified lexical grammar will have to contain much of the descriptive machinery that linguists have used to describe phrase structure for decades (e.g., some equivalent to X-bar theory). That may well be the case. However, we would like to suggest that grammatical knowledge may take a much less explicit form, emerging from the process by which words and morphemes are activated in time.

A recent proposal by Elman (1990, 1993) offers some insights into the form that a unified lexical/ grammatical system might take, based on an interactiveactivation model of lexical access in a mechanism called a simple recurrent neural network. This is an artificial neural network that lives in time. On each time step, the system uses a combination of the current input and previous context to make a prediction about the linguistic element that will occur next (in this case, the next word). Based on the degree of mismatch between the predicted element and the element that actually 
occurs, the system modifies its internal state, and uses those modifications to make its next prediction. Elman has shown that a system of this sort is able to induce a phrase structure grammar from unlabelled strings of words that were generated by such a grammar. Under certain developmental conditions, such systems can even induce a grammar with multiple embeddings and long-distance dependencies (including agreement phenomena). The crucial point for our purposes here revolves around the nature of the underlying representations that make this performance possible. Words are represented as vectors in a high-dimensional space, and the outcome of learning is that words with similar grammatical privileges are grouped closely together within this ndimensional space. As it acquires the grammar of this artificial language, the system acquires (a) an appropriate spatial organization (with elements sent to live in the proper space), and (b) a set of weights that permit movement from one position to another in this space over time. Hence grammatical "knowledge" can be viewed as a set of probabilistic trajectories in a highdimensional vector space.

Figure 12 (from Bates, Elman, \& Li, 1994, and Bates, Devescovi et al., 1996) illustrates a 3-dimensional reduction of this hyperspace, based on the first principal components of the Elman simulation. Given a sentence beginning (for example) with the plural word DOGS, a system that has acquired this simple phrase structure grammar will make a prediction that constitutes (formally) a move in the direction of the verb sector of space, with a strong bias toward plural verbs associated with animate first nouns. The match or mismatch between predicted words and the word that actually occurs next is a dynamic and continuous variable, i.e., success is a matter of degree.

Applying the same logic to grammatical priming, we may view the effect of (for example) a gender-marked adjective on a subsequent noun as a trajectory in a similar multidimensional space. If the adjective causes a move closer to the noun that will subsequently appear, we have the equivalent of "facilitation"; if the adjective causes a move farther from the noun that is about to appear, then we would have the equivalent of "inhibition". Because this is a continuous multidimensional space where movements are always relative to some (arbitrary) position, there is no need to postulate a single, neutral starting point. Regardless of where the system stands at the point where processing begins, grammatical priming (like phonological and semantic priming) operates by moving the system toward or away from the position in multidimensional space that it will have to occupy when the target word is recognized.

These simulations of language learning in a simple recurrent network provide two important elements for the kind of unified lexicalist approach to grammar that we have proposed here. First, the distributed and timebased representations offered by recurrent nets help us to



Figure 12. Schematic representation of hidden-unit activation patterns as vectors in an $\mathrm{N}$-dimensional state space. Lexical items are points in space; different regions correspond to grammatical categories or semantic features (Reproduced, with permission, from Bates et al., 1996).

understand how grammatical knowledge might be encoded implicitly within the lexicon, without specifying a set of symbolic templates with nonterminal symbols as the format for that knowledge. Second, the idea of language processing as movement through a hyperdimensional space provides a very different approach to priming effects, eliminating the need to set boundaries between "prelexical" and "postlexical" stages. The latter approach has served its purpose in psycholinguistics, but it has become increasingly difficult on empirical grounds to justify a "magic moment" when lexical items are accessed, prior to integration into a contextual frame [Balota, 1989; Grosjean, 1980]. A number of proposals along the lines proposed by Elman are now available within psycho-linguistics (e.g., Gaskell \& Marslen-Wilson, 1996; Hare, Elman, \& Daugherty, 1995; MacWhinney, in press). It remains to be seen whether such models can be modified to account for the complex patterns of dissociation that have been observed in adults and children with language disorders, although some encouraging efforts in this direction are underway (Devlin et al., 1996; Martin, Dell, Saffran, \& Schwartz, 1994; Plaut, 1994, 1995 and this volume).

In conclusion, we have presented evidence from language development, language disorders and real-time language processing in support of a unified lexicalist approach to grammar. This approach is compatible with current trends in linguistic theory, including functionalist approaches like Construction Grammar (Fillmore et al., 1988; Goldberg, 1995), and Cognitive Grammar (Langacker, 1987), and some formal alternatives such as Head-Drive Phrase Structure Grammar (Pollard \& Sag, 1994). The distributed representations and dynamic principles that underlie our claims are also 
compatible with simulations of language learning and language processing in simple recurrent networks (Elman, 1990, 1993; Elman et al., 1996). We do not pretend for a moment that we have countered all claims in favor of a modular contrast between grammar and the lexicon. We have not, for example, dealt with some of the linguistic details that motivate recent proposals in generative grammar, including the phenomena associated with pronominal co-reference and Wh-movement in language processing (Swinney, 1991), language development (Borer \& Wexler, 1987; Roeper, 1988) and language disorders (Grodzinsky, 1990, 1993; Rice, in press). It is possible that a more restricted modular account of grammar can be built around these issues, untouched by the findings that we have presented here. We do believe, however, that broader claims about an independent mental organ for grammar are difficult to defend against all this new evidence for the interdependence of grammar and the lexicon in language development, language breakdown and language processing. One can never disprove the existence of a modular border (e.g., "weak autonomy" - Altmann \& Steedman, 1988), but we believe that such a border is not required to explain the evidence at hand.

\section{REFERENCES}

Altmann, G.T.M., \& Steedman, M. (1988). Interaction with context during human sentence processing. Cognition, 30, 191-238.

Anglin, J.M. (1993). Vocabulary development: A morphological analysis. Monographs for the Society for Research in Child Development, 58 (10, Serial No. 238).

Aslin, R.N., Jusczyk, P.W., \& Pisoni, D.B. (in press). Speech and auditory processing during infancy: Constraints on and precursors to language. In W. Damon (Series Ed.) \& D. Kuhn \& R. Siegler (Vol. Eds.), Handbook of child psychology: Vol. 5. Cognition, perception \& language (5th ed.) New York: Wiley.

Au, T.K.F., Dapretto, M., \& Song, Y.K. (1994). Input vs constraints: Early word acquisition in Korean and English. Journal of Memory and Language, 33(5), 567-582.

Balota, D.A. (1989). The role of meaning in word recognition. In D.A. Balota, G.B. Flores d'Arcais, \& K. Rayner (Eds.), Comprehension processes in reading. Hillsdale, $\mathrm{NJ}$ : Erlbaum.

Bates, E. (1976). Language and context: Studies in the acquisition of pragmatics. New York: Academic Press.

Bates, E. (Ed.) (1991). Special issue: Cross-linguistic studies of aphasia. Brain and Language, 41(2).

Bates, E., Bretherton, I., \& Snyder, L. (1988). From first words to grammar: Individual differences and dissociable mechanisms. New York: Cambridge University Press.
Bates, E., Dale, P., \& Thal, D. (1995). Individual differences and their implications for theories of language development. In $\mathrm{P}$. Fletcher \& $\mathrm{B}$. MacWhinney (Eds.), Handbook of child language (pp. 96-151). Oxford: Basil Blackwell.

Bates, E., \& Devescovi, A. (1989). A cross-linguistic approach to sentence production. In B. MacWhinney \& E. Bates (Eds.), The cross-linguistic study of sentence processing (pp. 225-256). New York: Cambridge University Press.

Bates, E., Devescovi, A., Dronkers, N., Pizzamiglio, L., Wulfeck, B., Hernandez, A., Juarez, L., \& Marangolo, P. (1994). Grammatical deficits in patients without agrammatism: Sentence interpretation under stress in English and Italian. Abstracts from the Academy of Aphasia 1994 Annual Meeting. Special issue, Brain and Language, 47(3), 400-402.

Bates, E., Devescovi, A., Hernandez, A., \& Pizzamiglio, L. (1996). Gender priming in Italian. Perception \& Psychophysics, 58(7), 992-1004.

Bates, E., Elman, J., \& Li, P. (1994). Language in, on, and about time. In M. Haith, J. Benson, R. Roberts \& B. Pennington, (Eds.), The development of future-oriented processes (pp. 293-321). Chicago: The University of Chicago Press.

Bates, E., Friederici, A., \& Wulfeck, B. (1987a). Grammatical morphology in aphasia: Evidence from three languages. Cortex, 23, 545-574.

Bates, E., Friederici, A., \& Wulfeck, B. (1987b). Comprehension in aphasia: A crosslinguistic study. Brain and Language, 32, 19-67.

Bates, E., Friederici, A., Wulfeck, B., \& Juarez, L. (1988). On the preservation of word order in aphasia: Cross-linguistic evidence. Brain and Language, 33, 323-364.

Bates, E., \& MacWhinney, B. (1989). Functionalism and the competition model. In B. MacWhinney \& E. Bates (Eds.), The crosslinguistic study of sentence processing (pp. 3-76). New York: Cambridge University Press.

Bates, E., \& Marchman, V. (1988). What is and is not universal in language acquisition. In F. Plum (Ed.), Language, communication and the brain (pp. 1938). New York: Raven Press.

Bates, E., Marchman, V., Harris, C., Wulfeck, B., \& Kritchevsky, M. (1995). Production of complex syntax in normal ageing and Alzheimer's Disease. Language and Cognitive Processes, 11(5), 487-539.

Bates, E., Marchman, V., Thal, D., Fenson, L., Dale, P., Reznick, S., Reilly, J., \& Hartung, J. (1994). Developmental and stylistic variation in the composition of early vocabulary. Journal of Child Language, 21(1), 85-124. (Reprinted in K. Perera, Ed., Growing points in child language. Cambridge: Cambridge University Press, in press).

Bates, E., Thal, D., Aram, D., Eisele, J., Nass, R., \& Trauner, D. (in press). From first words to 
grammar in children with focal brain injury. In D. Thal \& J. Reilly, (Eds.), Special issue on Origins of Communication Disorders, Developmental Neuropsychology.

Bates, E., Vicari, S., \& Vargha-Khadem, F. (in press). Neural mediation of language development: Perspectives from lesion studies of infants and children. Language and Cognitive Processes.

Bates, E., \& Wulfeck, B. (1989a). Comparative aphasiology: A cross-linguistic approach to language breakdown. Aphasiology, 3, 111-142 and 161-168.

Bates, E., \& Wulfeck, B. (1989b). Crosslinguistic studies of aphasia. In B. MacWhinney \& E. Bates (Eds.), The crosslinguistic study of sentence processing (pp. 328-374). New York: Cambridge University Press.

Bates, E., \& Wulfeck, B. (1991). Differential sensitivity to errors of agreement and word order in Broca's aphasia. Journal of Cognitive Neuroscience, 3, 258-272.

Bates, E., Wulfeck, B., \& MacWhinney, B. (1991). Crosslinguistic research in aphasia: An overview. Brain and Language, 41, 123-148.

Bellugi, U., Bihrle, A., Jernigan, T., Trauner, D., \& Doherty, S. (1990). Neuropsychological, neurological and neuroanatomical profile of Williams Syndrome children. American Journal of Medical Genetics, 6, 115-125.

Bellugi, U., Bihrle, A., Neville, H., Jernigan, T., \& Doherty, S. (1992). Language, cognition, and brain organization in a neurodevelopmental disorder. In M. Gunnar \& C. Nelson (Eds.), Developmental Behavioral neuroscience (pp. 201-232). Hillsdale, NJ: Erlbaum.

Bellugi, U., Marks, S., Bihrle, A.M., \& Sabo, H. (1988). Dissociation between language and social functions in Williams Syndrome. In K. Mogford \& D. Bishop (Eds.), Language development in exceptional circumstances. (pp. 177-189). New York: Churchill Livingstone Inc.

Bellugi, U., \& Morris, C.A. (Eds.). (1995). Williams Syndrome: From cognition to gene. Abstracts from the Williams Syndrome Association Professional Conference. Special Issue, Genetic Counseling, 6(1), 131-192.

Bellugi, U., Sabo, H., \& Vaid, J. (1988). Spatial deficits in children with Williams Syndrome: Brain bases and development. Hillsdale, NJ: Erlbaum.

Bellugi, U., Wang, P.P., \& Jernigan, T.L. (1994). Williams Syndrome: An unusual neuropsychological profile. In S. Broman \& J. Grafman (Eds.)., Atypical cognitive deficits in developmental disorders: Implications for brain function. Hillsdale, NJ: Erlbaum.

Bertrand, J., Mervis, C.B., Rice, C.E., \& Adamson, L. (1993, March). Development of joint attention by a toddler with Williams Syndrome. Paper presented at the Gatlinburg Conference on Research and Theory in Mental Retardation and Developmental Disabilities, Gatlinburg, TN.

Bickerton, D. (1984). The language bioprogram hypothesis. The Behavioral and Brain Sciences, 7, 173187.

Bihrle, A.M., Bellugi, U., Delis, M., \& Marks, S. (1989). Seeing either the forest or the trees: Dissociation in visuospatial processing. Brain and Cognition, 11, 37-49.

Bishop, D.V.M. (in press). Uncommon understanding: Development and disorders of comprehension in children. Hove, UK: Psychology Press/Erlbaum (UK), Taylor \& Francis.

Blackwell, A., \& Bates, E. (1995). Inducing agrammatic profiles in normals: Evidence for the selective vulnerability of morphology under cognitive resource limitation. Journal of Cognitive Neuroscience, 7:2, 228-257.

Bloom, L. (1991). Language development from two to three. New York: Cambridge University Press.

Bloom, L., Lightbown, L., \& Hood, L. (1975). Structure and variation in child language. Monographs of the Society for Research in Child Development, 40, \#160.

Bock, K. (1986). Syntactic persistence in language production. Cognitive Psychology, 18, 355-387.

Borer, H., \& Wexler, K. (1987). The maturation of syntax. In T. Roeper \& E. Williams (Eds.), Parameter setting (pp. 123-172). Dordrecht: Reidel.

Botha, R.P. (1989). Challenging Chomsky: The generative garden game. Oxford, UK; New York: Basil Blackwell.

Braine, M.D.S. (1976). Children's first word combinations. With commentary by Melissa Bowerman. Monographs of the Society for Research in Child Development, 41, Serial \# 164.

Bretherton, I., McNew, S., Snyder, L., \& Bates, E. (1983). Individual differences at 20 months. Journal of Child Language, 10, 293-320.

Bresnan, J. (Ed.). (1982). The mental representation of grammatical relations. Cambridge, MA: MIT Press.

Bresnan, J. (1996). Lexical functional syntax. Manuscript submitted for publication.

Brown, R. (1973). A first language: The early stages. Cambridge, MA: Harvard University Press.

Brown, R., \& McNeill, D. (1966). The tip of the tongue phenomenon. Journal of Verbal Learning and Verbal Behavior, 5, 325-327.

Capirci, O., Sabbadini, L., \& Volterra, V. (in press). Language development in Williams syndrome: A case study. Cognitive Neuropsychology.

Caplan, D., \& Hildebrandt, N. (1988). Disorders of syntactic comprehension. Cambridge, MA: MIT Press.

Caplan, D., \& Waters, G.S. (1995). Aphasic disorders of syntactic comprehension and working memory 
capacity. Cognitive Neuropsychology, 12(6), 637649.

Caramazza, A. (1986). On drawing inferences about the structure of normal cognitive systems from the analysis of patterns of impaired performance: The case for single-patient studies. Brain and Cognition, 5, 41-66.

Caramazza, A., \& Berndt, R. (1985). A multicomponent view of agrammatic Broca's aphasia. In M.-L. Kean (Ed.), Agrammatism (pp. 27-63). Orlando: Academic Press.

Caramazza, A., Berndt, R.S., Basili, A.G., \& Koller, J.J. (1981). Syntactic processing deficits in aphasia. Cortex, 17, 333-348.

Caramazza, A., \& Zurif, E. (1976). Dissociation of algorithmic and heuristic processes in language comprehension: Evidence from aphasia. Brain and Language, 3, 572-582.

Carey, S., Johnson, S., \& Levine, K. (1993, March). Conceptual structure of adults/adolescents with Williams syndrome. Poster presented at the 60th Annual Meeting of the Society for Research in Child Development, New Orleans, LA.

Caselli, M.C. (1995). Il primo sviluppo lessicale [Early lexical development]. In G. Sabbadini (Ed.), Manuale di neuropsicologia dell' età evolutiva [Handbook of developmental neuropsychology] (pp. 242-258). Bologna: Zanichelli.

Caselli, M.C., \& Bates, E. (1996). A cross-linguistic study of the transition from first words to grammar. Manuscript, Institute of Psychology, National Council of Research, Rome.

Caselli, M.C., Bates, E., Casadio, P., Fenson, L., Fenson, J., Sanderl, L., \& Weir, J. (1995). A cross-linguistic study of early lexical development. Cognitive Development, 10, 159-199.

Caselli, M.C., \& Casadio, P. (1995). Il primo vocabolario del bambino: Guida all'uso del questionario MacArthur per la valutazione della comunicazione e del linguaggio nei primi anni di vita [The child's first words: Guide to the use of the MacArthur questionnaire for the assessment of communication and language in the first years of life] (pp. 94-100). Milan: FrancoAngeli.

Caselli, M.C., Maragna, S., Pagliari-Rampelli, L., \& Volterra, V. (1994). Linguaggio e sordità: Parole e segni nell'educazione dei sordi [Language and deafness: Words and signs in the education of the deaf]. Florence: La Nuova Italia.

Chapman, R.S. (1995). Language development in children and adolescents with Down Syndrome. In Paul Fletcher \& Brian MacWhinney (Eds.), The handbook of child language (pp. 664-689). Oxford: Basil Blackwell.

Chen, S. (1989, April). On grammatical deficits in Chinese aphasia. Abstracts of the 18th Annual Linguistics Symposium. University of Wisconsin, Milwaukee.
Chen, S., \& Bates, E. (in press). The dissociation between nouns and verbs in Broca's and Wernicke's aphasia: Evidence from Chinese. Special issue on Chinese aphasia, Aphasiology.

Chomsky, N. (1957). Syntactic structures. The Hague: Mouton.

Chomsky, N. (1965). Aspects of the theory of syntax. Cambridge, MA: MIT Press.

Chomsky, N. (1981). Lectures on government and binding. New York: Foris.

Chomsky, N. (1995). The minimalist program. Cambridge, MA: MIT Press.

Clahsen, H. (1991). Child language and developmental dysphasia: Linguistic studies of the acquisition of German. Amsterdam: Benjamins.

Clifford, J.M., Wulfeck, B., \& Powell, T.A. (1995). Frog, where are you? Narratives from children with specific language impairment. Society for Research in Child Development Abstracts, 10, 200.

Contardi, A., \& Vicari, S. (Eds.). (1994). Le persone Down: Aspetti neuropsicologici, educativi $e$ sociali. Milano: FrancoAngeli.

Crain, S. (1991). Language acquisition in the absence of experience. Behavioral and Brain Sciences, 14, 597-611.

Cresti, E., \& Moneglia, M. (1995). Ricerche sull'acquisizione dell'italiano [Research on the acquisition of Italian]. Rome: Bulzoni.

Cutler, A. (1993). Phonological cues to open- and closed-class words in the processing of spoken sentences. Special Issue: Sentence processing: III. Journal of Psycholinguistic Research, 22(2), 109131.

Dale, P.S. (1991). The validity of a parent report measure of vocabulary and syntax at 24 months. Journal of Speech and Hearing Sciences, 34, 565571.

Dale, P.S., Bates, E., Reznick, S., \& Morisset, C. (1989). The validity of a parent report instrument of child language at 20 months. Journal of Child Language, 16, 239-249.

Dale, P. S., Robinson, N.M., \& Crain-Thoreson, C. (1992). Linguistic precocity and the development of reading: The role of extralinguistic factors. Applied Psycholinguistics, 16(2), 173-187.

Damasio, H., Grabowski, T.J., Tranel, D., Hichwa, R.D., \& Damasio, A.R. (1996). A neural basis for lexical retrieval. Nature, 380(11), 499-505.

Demuth, K. (1989). Subject, topic and Sesotho passive. Journal of Child Language, 17, 67-84.

Dennis, M., \& Whitaker, H. (1976). Language acquisition following hemidecortication: Linguistic superiority of the left over the right hemisphere. Brain and Language, 3, 404-433.

Devescovi, A., Bates, E., D’Amico, S., Hernandez, A., Marangolo, P., Pizzamiglio, L., \& Razzano, C. (1996). An on-line study of grammaticality judgments in patients with and without expressive 
agrammatism. In L. Menn (Ed.), Special issue on cross-linguistic aphasia. Aphasiology.

Devescovi, A., \& Pizzuto, E. (1995). Lo sviluppo grammaticale [Grammatical development]. In G. Sabbadini (Ed.), Manuale di neuropsicologia dell' età evolutiva [Handbook of developmental neuropsychology] (pp. 242-258). Bologna: Zanichelli.

Devlin, J.T., Gonnerman, L.M., Andersen, E.S., \& Seidenberg, M.S. (1996). Category-specific semantic deficits in focal and widespread brain damage: A computational account. Manuscript submitted for publication.

Eisele, J., \& Aram, D. (1995). Lexical and grammatical development in children with early hemisphere damage: A cross-sectional view from birth to adolescence. In Paul Fletcher \& Brian MacWhinney (Eds.), The handbook of child language (pp. 664-689). Oxford: Basil Blackwell.

Eisele, J., Aram, D., Lust, B. (in press). Presuppositions and implications of truth: Linguistic deficits following early brain lesions. In M. Dennis (Ed.), Special issue, Discourse in children with anomalous brain development or acquired brain injury. Brain and Language.

Elman, J. (1990). Finding structure in time. Cognitive Science, 14, 179-211.

Elman, J.L. (1993). Learning and development in neural networks: The importance of starting small. Cognition, 48, 71-99.

Elman, J., Bates, E., Johnson, M., Karmiloff-Smith, A., Parisi, D., \& Plunkett, K. (1996). Rethinking innateness: A connectionist perspective on development. Cambridge, MA: MIT Press/Bradford Books.

Fabbretti, D., Pizzuto, E., Vicari, S., \& Volterra, V. (in press). A story description task in children with Down Syndrome: Lexical and morphosyntactic abilities. Journal of Intellectual Disability Research.

Farah, M.J., \& McClelland, J. (1991). A computational model of semantic memory impairment: Modality specificity and emergent category specificity. Journal of Experimental Psychology: General, 120, 339-357.

Federmeier, K., \& Bates, E. (1996, March). Effects of grammatical context on naming actions and objects. Poster presented at the 3rd Annual Meeting of the Cognitive Neuroscience Society, San Francisco.

Feldman, H., Holland, A., Kemp, S., \& Janosky, J. (1992). Language development after unilateral brain injury. Brain and Language, 42, 89-102.

Fenson, L., Dale, P., Reznick, J.S., Thal, D., Bates, E., Hartung, J., Pethick, S., \& Reilly, J. (1993). The MacArthur Communicative Development Inventories: User's guide and technical manual. San Diego: Singular Press.
Fenson, L., Dale, P., Reznick, J., Bates, E., Thal, D., \& Pethick, S. (1994). Variability in early communicative development. Monographs of the Society for Research in Child Development, Serial No. 242, Vol. 59, No. 5.

Fillmore, C.J., Kay, P., \& O'Connor, C. (1988). Regularity and idiomaticity in grammatical constructions: The case of Let Alone. Language, 64, 501-538.

Fletcher, P., \& MacWhinney, B. (Eds.) (1995). Handbook of child language. Oxford: Basil Blackwell.

Fodor, J.A. (1983). The modularity of mind: An essay on faculty psychology. Cambridge, MA: MIT Press.

Fodor, J.A., Bever, T.G., \& Garrett, M.F. (1974). The psychology of language: An introduction to psycholinguistics and generative grammar. New York, McGraw-Hill.

Friederici, A.D. (1990). On the properties of cognitive modules. Psychological Research, 52, 175-180.

Friederici, A.A., \& Kilborn, K. (1989). Temporal constraints on language processing in Broca's aphasia. Journal of Cognitive Neuroscience, 1, 262-272.

Friederici, A.D., \& Schriefers, H. (1994). The nature of semantic and morphosyntactic context effects on word recognition in young healthy and aphasic adults. Linguistische Berichte, Special Issue, 6, 932.

Fromkin, V.A. (1995). Special issues: Linguistic representational and processing analyses of agrammatism. Brain and Language, 50(1,2,3).

Gardner, A.R., Gardner, B.T., \& van Cantfort, T.E. (Eds.). (1989). Teaching sign language to chimpanzees. Albany: State University of New York Press.

Garrett, M. (1980). Levels of processing in sentence production. In B. Butterworth (Ed.), Language production: Vol. 1. Speech and talk. New York/London: Academic.

Garrett, M. (1992). Disorders of lexical selection. Cognition, 42, 143-180.

Gaskell, M.G., \& Marslen-Wilson, W.D. (1996). Integrating form and meaning: A distributed model of speech. Manuscript submitted for publication.

Gentner, D. (1982). Why are nouns learned before verbs: Linguistic relativity versus natural partitioning. In S.A. Kuczaj II (Ed.), Language development, Vol. 2: Language, thought and culture. Hillsdale, NJ: Erlbaum.

Giannotti, A., \& Vicari, S. (Eds.) (1994). Il bambino con sindrome di Williams. Milan: FrancoAngeli.

Goldberg, A.E. (1995). Constructions: A construction grammar approach to argument structure. Chicago: University of Chicago Press.

Goldstein, K. (1948). Language and language disturbances: Aphasic symptom complexes and 
their significance for medicine and theory of language. New York: Grune \& Stratton.

Gonnerman, L., Andersen, E., Devlin, J., Kempler, D., \& Seidenberg, M. (in press). Double dissociation of semantic categories in Alzheimer's disease. Brain and Language.

Goodglass, H. (1993). Understanding aphasia. San Diego: Academic Press.

Goodglass, H., \& Menn, L. (1985). Is agrammatism a unitary phenomenon? In M.-L. Kean (Ed.), Agrammatism. Orlando: Academic Press.

Goodman, J.C. (1995). The shape of change: Longitudinal evidence about language development. Society for Research in Child Development Abstracts, 10, 111.

Goodman, J.C., Jahn-Samilo, J., \& Bates, E. (1996). Patterns of vocabulary acquisition: Evidence from a longitudinal study. Manuscript in preparation.

Goodman, J.C., \& McDonough, L. (1996). The role of context in the acquisition of novel verbs. Manuscript submitted for publication.

Goodman, J.C., McDonough, L., \& Brown, T. (1996). Lexical bootstrapping: Toddlers' acquisition of new words heard in sentence contexts. Manuscript submitted for publication.

Goodman, J.C., \& Nusbaum, H.C. (Eds.). (1994). The development of speech perception: Transitions from speech sounds to spoken words. Cambridge, MA: MIT Press.

Goodman, J.C., Nusbaum, H.C., Lee, L., \& Broihier, K. (1990). The effects of syntactic and discourse variables on the segmental intelligibility of speech. The Proceedings of the 1990 International Conference on Spoken Language Processing (pp. 393396). Kobe, Japan: The Acoustical Society of Japan.

Gopnik, M. (1990). Feature-blind grammar and dysphasia. Nature, 344(6268), 715.

Gopnik, A., \& Choi, S. (1990). Do linguistic differences lead to cognitive differences? A crosslinguistic study of semantic and cognitive development. First Language, 10, 199-215.

Gopnik, A., \& Choi, S. (1995). Names, relational words, and cognitive development in English- and Korean-speakers: Nouns are not always learned before verbs. In M. Tomasello \& W. Merriman (Eds.), Beyond names for things: Young children's acquisition of verbs. Hillsdale, NJ: Lawrence Erlbaum.

Gopnik, M., \& Crago, M.B. (1991). Familial aggregation of a developmental language disorder. Cognition, 39, 1-50.

Greenfield, P.M. (1991). Language, tools and brain: The ontogeny and phylogeny of hierarchically organized sequential behavior. Behavioral and Brain Sciences, 14, 531-550.

Greenfield, P.M., \& Savage-Rumbaugh, E.S. (1990). Grammatical combination in Pan paniscus: Pro- cesses of learning and invention in the evolution and development of language. In S.T. Parker \& K.R. Gibson (Eds.), "Language" and intelligence in monkeys and apes (pp. 540-578). Cambridge, UK: Cambridge University Press.

Greenfield, P.M., \& Savage-Rumbaugh, E.S. (1991). Imitation, grammatical development, and the invention of protogrammar by an ape. In N.A. Krasnegor, D.M. Rumbaugh, R.L. Schiefelbusch \& M. Studdert-Kennedy (Eds.), Biological and behavioral determinants of language development (pp. 235-258). Hillsdale, NJ: Lawrence Erlbaum.

Grodzinsky, Y. (1986). Language deficits and the theory of syntax. Brain and Language, 27, 135159.

Grodzinsky, Y. (1990). Theoretical perspectives on language deficits. Cambridge, MA: MIT Press.

Grodzinsky, Y. (Ed.). (1993). Special issue: Grammatical investigations of aphasia. Brain and Language, 45(3).

Grosjean, F. (1980). Spoken word recognition processes and the gating paradigm. Perception \& Psychophysics, 28, 267-283.

Grosjean, F., Dommergues, J.-Y., Cornu, E., Guillelmon, D., \& Besson, C. (1994). The gender-marking effect in spoken word recognition. Perception \& Psychophysics, 56, 590-598.

Grosjean, F., Gee, J.P. (1987). Prosodic structure and spoken word recognition. In U. Frauenfelder \& L.K. Tyler, (Eds.), Spoken word recognition (Cognition special issue) pp. 135-155. Cambridge, MA: MIT Press.

Gurjanov, M., Lukatela, G., Moskovljevic, J., \& Turvey, M.T. (1985). Grammatical priming of inflected nouns by inflected adjectives. Cognition, $19,55-71$.

Hagiwara, H., \& Caplan, D. (1990). Syntactic comprehension in Japanese aphasics: Effects of category and thematic role order. Brain and Language, 38(1), 159-170.

Hare, M.L., Elman, J.L., \& Daugherty, K.G. (1995). Default categorization in connectionist networks. Language and Cognitive Processes, 10(6), 601-630.

Harris, R.A. (1993). The linguistics wars. New York: Oxford University Press.

Head, H. (1926). Aphasia and kindred disorders of speech. Cambridge: Cambridge University Press.

Heilman, K.M., \& Scholes, R.J. (1976). The nature of comprehension errors in Broca's, conduction and Wernicke's aphasics. Cortex, 12, 258-265.

Hernandez, A. (1996). Lexical and sentential priming in monolinguals and bilinguals: how things come together without colliding. Unpublished doctoral dissertation, University of California, San Diego.

Hernandez, A., \& Bates, E. (1994). Interactive activation in normal and brain-damaged individuals: can context penetrate the lexical "module"? In D. Hillert (Ed.), Linguistics and cognitive science. 
Special issue of Linguistische Berichte, 6, 145167.

Hernandez, A.E., Fennema-Notestine, C., Udell, C., \& Bates, E. (1995, March). Interactions of sentential and word contexts: Evidence against a two-process theory of semantic priming. Poster presented at the Eighth Annual CUNY Conference on Human Sentence Processing, Tucson, AZ.

Herron, D., \& Bates, E. (in press). Grammatical and acoustic factors in the recognition of open- and closed-class words. Journal of Memory and Language.

Hillert, D., \& Bates, E. (1996). Morphological constraints on lexical access: Gender priming in German (Tech. Rep. No. 9601). La Jolla: University of California, San Diego, Center for Research in Language.

Hillis, A., \& Caramazza, A. (1995). Cognitive and neural mechanisms underlying visual and semantic processing: Implications from optic aphasia Journal of Cognitive Neuroscience, 7(4), 457-478.

Hinton, G.E., \& Shallice, T. (1991). Lesioning a connectionist network: Investigations of acquired dyslexia. Psychological Review, 98, 74-95.

Horgan, D. (1978). How to answer questions when you've got nothing to say. Journal of Child Language, 5, 159-165.

Horgan, D. (1979, May). Nouns: Love 'em or leave 'em. Address to the New York Academy of Sciences.

Horgan, D. (1981). Rate of language acquisition and noun emphasis. Journal of Psycholinguistic Research, 10, 629-640.

Hurlburt, M.S., \& Goodman, J.C. (1992). The development of lexical effects on children's phoneme identifications. In J.J. Ohala, T.M. Nearey, B.L. Derwing, M.M. Hodge, \& G.E. Wiebe, (Eds.) ICSLP 92 Proceedings: 1992 International Conference on Spoken Language Processing (pp. 337340). Banff, Alberta, Canada: University of Alberta.

Jaeger, J.J., Lockwood, A.H., Kemmerer, D.L., Van Valin, R.D., Murphy, B.W., \& Khalak, H.G. (in press). A positron emission tomographic study of regular and irregular verb morphology in English. Language.

Jahn-Samilo, J. (1995). Language comprehension and production in children from 8 to 30 months of age: A comparison of parent report and laboratory measures from a longitudinal study. Society for Research in Child Development Abstracts, 10, 112.

Jakobson, R. (1968). Child language aphasia and phonological universals. Paris: Mouton.

Jernigan, T., \& Bellugi, U. (1990). Anomalous brain morphology on magnetic resonance images in Williams Syndrome and Down Syndrome. Archives of Neurology, 47, 429-533.
Johnston, J.R. (1994). Cognitive abilities of languageimpaired children. In R. Watkins \& M. Rice (Eds.), Specific language impairments in children: Current directions in research and intervention. Baltimore: Paul Brookes.

Johnston, J.R. (in press). Specific language impairment, cognition and the biological basis of language. In M. Gopnik (Ed.), The biological basis of language. New York: Oxford University Press.

Johnston, J.R., \& Schery, T.K. (1976). The use of grammatical morphemes by children with communication disorders. In D.M. Morehead \& A.E. Morehead (Eds.), Normal and deficient child language. Baltimore, MD: University Park Press.

Karmiloff-Smith, A. (1992). Beyond modularity: A developmental perspective on cognitive science. Cambridge, MA: MIT Press.

Karmiloff-Smith, A., \& Grant, J. (1993, March). Within-domain dissociations in Williams syndrome: A window on the normal mind. Poster presented at the 60th Annual Meeting of the Society for Research in Child Development, New Orleans, LA.

Karmiloff-Smith, A., Klima, E.S., Bellugi, U., Grant, J., \& Baron-Cohen, S. (1995). Is there a social module? Language, face processing, and theory of mind in subjects with Williams Syndrome. Journal of Cognitive Neuroscience, 7(2), 196-208.

Katz, J.J., \& Postal, P.M. (1964). An integrated theory of linguistic descriptions. Cambridge, MA: MIT Press.

Kawamoto, A.H. (1993). Nonlinear dynamics in the resolution of lexical ambiguity: A parallel distributed processing account. Journal of Memory and Language, 32, 474-516.

Kean, M.-L. (1977). Linguistic interpretation of aphasia syndromes. Cognition, 5, 9-46.

Kean, M.-L. (Ed.) (1985). Agrammatism. Orlando: Academic Press.

Kempler, D., Curtiss, S., \& Jackson, C. (1987). Syntactic preservation in Alzheimer's Disease. Journal of Speech and Hearing Research, 30, 343350.

Kilborn, K. (1991). Selective impairment of grammatical morphology due to induced stress in normal listeners: Implications for aphasia. Brain and Language, 41, 275-288.

Kintsch, W., \& Mross, E.F. (1985). Context effects in word identification. Journal of Memory and Language, 24(3), 336-349.

Kluender, R., \& Kutas, M. (1993). Bridging the gap: Evidence from ERPs on the processing of unbounded dependencies. Journal of Cognitive Neuroscience, 5(2), 196-214.

Kluender, R., \& Kutas, M. (in press). Interaction of lexical and syntactic effects in the processing of unbounded dependencies. Language and Cognitive Processes. 
Kolk, H., \& Heeschen, C. (1992). Agrammatism, paragrammatism and the management of language. Language and Cognitive Processes, 7(2), 89-129.

Kuhl, P.K. (1991). Perception, cognition, and the ontogenetic and phylogenetic emergence of human speech. In S. Brauth, W. Hall, \& R. Dooling (Eds.), Plasticity of development. Cambridge, MA: MIT/Bradford Books.

Langacker, R. (1987). Foundations of cognitive grammar. Stanford: Stanford University Press.

Leonard, L.B. (in press). Specific language impairment. Cambridge, MA: MIT Press.

Leonard, L.B., Bortolini, U., Caselli, M.C., McGregor, K., \& Sabbadini, L. (1992). Morphological deficits in children with specific language impairment: The status of features in the underlying grammar. Language Acquisition, 2(2), 151-179.

Leonard, L.B., Newhoff, M., \& Mesalam, L. (1980). Individual differences in early child phonology. Applied Psycholinguistics, 1, 7-30.

Levelt, W.J.M. (1989). Speaking: From intention to articulation. Cambridge, MA: MIT Press.

Levy, Y. (1996). Modularity reconsidered. Brain and Language, 55(2), 240-263.

Lieberman, P. (1985). On the evolution of human syntactic ability. Its pre-adaptive bases. Journal of Human Evolution, 14, 657-668.

Lindner, K., \& Elsen, H. (1996, February). 'Critical mass' and overgeneralization: The case of German data. Paper presented at the 7th International Morphology Meeting Workshop 'The acquisition of morphology in L1', Vienna.

Linebarger, M., Schwartz, M., \& Saffran, E. (1983). Sensitivity to grammatical structure in so-called agrammatic aphasics. Cognition, 13, 361-392.

Liu, H. (1996). Lexical access and differential processing in nouns and verbs in a second language. Doctoral dissertation, University of California, San Diego.

Locke, J.L. (1983). Phonological acquisition and change. New York: Academic Press.

Locke, J.L. (in press). A theory of neurolinguistic development. Brain and Language.

Lukatela, G., Kostic, A., Feldman, L.B., \& Turvey, M.T. (1983). Grammatical priming of inflected nouns. Memory \& Cognition, 11(1), 59-63.

Lukatela, K., Shankweiler, D., \& Crain, S. (1995). Syntactic processing in agrammatic aphasia by speakers of a Slavic language. Brain and Language, 49(1), 50-76.

MacDonald, M.C., Pearlmutter, N.J., \& Seidenberg, M.S. (1994). Lexical nature of syntactic ambiguity resolution. Psychological Review, 101(4), 676-703.

MacWhinney, B. (1989). Competition and connectionism. In B. MacWhinney \& E. Bates (Eds.), The crosslinguistic study of sentence processing (pp. 422-457). New York: Cambridge University Press.

MacWhinney, B. (1991). The CHILDES project: Tools for analyzing talk. Hillsdale, NJ: Erlbaum.

MacWhinney, B. (1993). Connections and symbols: Closing the gap. Cognition, 49(3), 291-296.

MacWhinney, B. (in press). Lexical connectionism. In P. Broeder (Ed.), Cognitive approaches to language learning. Cambridge, MA: MIT Press.

MacWhinney, B., \& Bates, E. (Eds.). (1989). The crosslinguistic study of sentence processing. New York: Cambridge University Press.

MacWhinney, B., Leinbach, J., Taraban, R., \& McDonald, J. (1989). Language learning: Cues or rules? Journal of Memory and Language, 28, 255277.

MacWhinney, B., \& Osmán-Sági, J. (1991). Inflectional marking in Hungarian aphasics. Brain and Language, 41, 165-183.

MacWhinney, B., Osmán-Sági, J., \& Slobin, D.I. (1991). Sentence comprehension in aphasia in two clear case-marking languages. Brain and Language, 41, 234-249.

Marchman, V., \& Bates, E. (1994). Continuity in lexical and morphological development: A test of the critical mass hypothesis. Journal of Child Language, 21, 339-366.

Marchman, V., Bates, E., Burkhardt, A., \& Good, A. (1991). Functional constraints on the acquisition of the passive: Toward a model of the competence to perform. First Language, 11, 65-92.

Marchman, V., Miller, R., \& Bates, E. (1991). Babble and first words in children with focal brain injury. Applied Psycholinguistics, 12, 1-22.

Marchman, V., Wulfeck, B., \& Weismer, S.E. (1995). Productive use of English past-tense morphology in children with SLI and normal language (Tech. Rep. No. CND-9514). La Jolla: University of California, San Diego, Center for Research in Language, Project in Cognitive and Neural Development.

Marcus, G., Pinker, S., Ullman, M., Hollander, M., Rosen, T.J., \& Xu, F. (1992). Overregularization in language acquisition. Monographs of the Society for Research in Child Development, 57.

Marslen-Wilson, W. (1987). Functional parallelism in spoken word recognition. In U. Frauenfelder \& L.K. Tyler (Eds.), Spoken word recognition (Cognition special issue) pp. 71-102. Cambridge, MA: MIT Press.

Marslen-Wilson, W., \& Tyler, L. (1980). The temporal structure of spoken language understanding. Cognition, 8, 1-71.

Martin, A., Wiggs, C.L., Ungerleider, L.G., \& Haxby, J.V. (1996). Neural correlates of category-specific knowledge. Nature, 379, 649-652.

Martin, N., Dell, G.S., Saffran, E.M., \& Schwartz, M.F. (1994). Origins of paraphasias in deep 
dysphasia: Testing the consequences of a decay impairment to an interactive spreading activation model of lexical retrieval. Brain and Language, 47(1), 52-88.

Mazoyer, B.M., Tzourio, N., Frak, V., Syrota, A., Murayama, N., Levrier, O., Salamon, G., Dehaene, S., Cohen, L., \& Mehler, J. (1993). The cortical representation of speech. Journal of Cognitive Neuroscience, 5(4), 467-479.

McQueen, J.M., Cutler, A., Briscoe, T., \& Norris D. (1995). Models of continuous speech recognition and the contents of the vocabulary. Language and Cognitive Processes, 10(3), 309-331.

Menn, L. (1985). Phonological development: Learning sounds and sound patterns. In J. Berko Gleason (Ed.), The development of language. Columbus, $\mathrm{OH}$ : Charles E. Merrill.

Menn, L., \& Obler, L.K. (Eds.). (1990). Agrammatic aphasia: Cross-language narrative sourcebook. Amsterdam/Philadelphia: John Benjamins.

Mervis, C.B., \& Bertrand, J. (1993, March). Early language and cognitive development: Implications of research with children who have Williams syndrome or Down syndrome. Paper presented at the 60th Anniversary Meeting of the Society for Research in Child Development, New Orleans, LA.

Miceli, C., Mazzucchi, A., Menn, L., \& Goodglass, H. (1983). Contrasting cases of Italian agrammatic aphasia without comprehension disorder. Brain and Language, 19, 65-97.

Milberg, W., \& Blumstein, S. (1981). Lexical decision and aphasia: Evidence for semantic processing. Brain and Language, 14, 371-385.

Milberg, W., Blumstein, S.E., Katz, D., Gershberg, F., \& Brown, T. (1995). Semantic facilitation in aphasia: Effects of time and expectance. Journal of Cognitive Neuroscience, 7(1), 33-50.

Miller, J. (1987). Language and communication characteristics of children with Down Syndrome. In S. Pueschel, C. Tingey, J. Rynders, A. Crocker \& D. Crutcher (Eds.), New perspectives on Down Syndrome (pp. 233-262). Baltimore: Brooks Publishing Co.

Miller, J. (in press-a). Lexical acquisition in children with Down Syndrome. In R.S. Chapman (Ed.), Child talk: Advances in language acquisition. Year Book Medical Publishers, Inc.

Miller, J. (in press-b). The development of speech and language in children with Down Syndrome. In E. McCoy \& I. Lott (Eds.) Clinical care for persons with Down Syndrome. Academic Press.

Mills, D., Coffey-Corina, S., DiIulio, L., \& Neville, H. (1995). The development of cerebral specialization for different lexical items in normal infants and infants with focal brain lesions (Tech. Rep. CND-9507). La Jolla: University of California, San Diego, Center for Research in Language, Project in Cognitive and Neural Development.
Miyake, A., Carpenter, P.A., \& Just, M.A. (1994). A capacity approach to syntactic comprehension disorders: Making normal adults perform like aphasic patients. Cognitive Neuropsychology, 11(6), 671717.

Miyake, A., Carpenter, P. A., \& Just, M.A. (1995). Reduced resources and specific impairments in normal and aphasic sentence comprehension. Cognitive Neuropsychology, 12(6), 651-679.

Naigles, L. (1988). Syntactic bootstrapping as a procedure for verb learning. Dissertation Abstracts International, 49(6-B), 2396.

Naigles, L. (1990). Children use syntax to learn verb meanings. Journal of Child Language, 17, 357374.

Naigles, L., Gleitman, H., \& Gleitman, L.R. (1993). Children acquire word meaning components from syntactic evidence. In E. Dromi (Ed.), Language and cognition: A developmental perspective ( $\mathrm{pp}$. 104-140). Norwood, NJ: Ablex.

Nelson, K. (1973). Structure and strategy in learning to talk. Monographs of the Society for Research in Child Development, 38, ( 1 \& 2, Serial \#149).

Neville, H.J., Mills, D.L., \& Bellugi, U. (1993). Effects of altered auditory sensitivity and age of language acquisition on the development of language-relevant neural systems: Preliminary studies of Williams Syndrome. In S. Broman \& J. Grafman (Eds.), Atypical cognitive deficits in developmental disorders: Implications for brain function (pp. 67-83). Hillsdale, NJ: Lawrence Erlbaum Associates.

Neville, H.J., Nicol, J., Barss, A., Forster, K., \& Garrett, M. (1991). Syntactically based sentenceprocessing classes: Evidence from event-related brain potentials. Journal of Cognitive Neuroscience, 3, 155-170.

Newmeyer, F.J. (Ed.) (1988). Linguistics: The Cambridge Survey. Cambridge: Cambridge University Press.

Newport, E.L. (1990). Maturational constraints on language learning. Cognitive Science, 14, 11-28.

Nusbaum, H.C., \& Goodman, J.C. (1994). Learning to hear speech as spoken language. In J.C. Goodman \& H.C. Nusbaum (Eds.), The development of speech perception: The transition from speech sounds to spoken words (pp. 299-338). Cambridge, MA: The MIT Press.

Nusbaum, H.C., \& Henly, A.S. (1992). Listening to speech through an adaptive window of analysis. In B. Schouten (Ed.), The processing of speech: From the auditory periphery to word recognition. Berlin: Mouton-De Gruyter.

Onifer, W., \& Swinney, D. (1981). Accessing lexical ambiguities during sentence comprehension: Effects of frequency of meaning and contextual bias. Memory \& Cognition, 9, 225-236. 
Osterhout, L., \& Holcomb, P.J. (1993). Event-related potentials and syntactic anomaly: Evidence of anomaly detection during the perception of continuous speech. Language and Cognitive Processes, 8(4), 413-437.

Ostrin, R., \& Schwartz, M. (1986). Reconstructing from a degraded trace: A study of sentence repetition in agrammatism. Brain and Language, 28, 328345.

Pae, S. (1993). Early vocabulary in Korean: Are nouns easier to learn than verbs? Unpublished doctoral dissertation, University of Kansas.

Patterson, K., Seidenberg, M.S., \& McClelland, J.L. (1989). Connections and disconnections: Acquired dyslexia in a computational model of reading processes. In R.G.M. Morris (Ed.), Parallel distributed processing: Implications for psychology and neurobiology (pp. 131-181). Oxford: Clarendon Press/Oxford University Press.

Peters, A. (1977). Language-learning strategies: Does the whole equal the sum of the parts? Language, $53,560-573$.

Peters, A. (1983). The units of language acquisition. Cambridge: Cambridge University Press.

Pick, A. (1913/1973). Aphasia. (J. Brown, Trans., \& Ed.) Springfield, IL: Charles C. Thomas. (Original work published 1913).

Pinker, S. (1991). Rules of language. Science, 253, 530-535.

Pinker, S. (1994). The language instinct: How the mind creates language. New York: William Morrow.

Pizzuto, E., \& Caselli, M.C. (1992). The acquisition of Italian morphology: Implications for models of language development. Child Language, 19, 491557.

Pizzuto, E., \& Caselli, M.C. (1994). The acquisition of Italian verb morphology in a cross-linguistic perspective. In Y. Levi (Ed.), Other children, other languages (pp. 137-187). Hillsdale, NJ: Lawrence Erlbaum.

Plaut, D.C. (1994). Parallel distributed processing challenges the strong modularity hypothesis, not the locality assumption. Behavioral and Brain Sciences, 17(1), 77-78.

Plaut, D.C. (1995). Double dissociation without modularity: Evidence from connectionist neuropsychology. Journal of Clinical and Experimental Neuropsychology, 17(2), 291-321.

Plunkett, K., \& Marchman, V. (1991). U-shaped learning and frequency effects in a multi-layered perceptron: Implications for child language acquisition. Cognition, 38, 43-102.

Plunkett, K., \& Marchman, V. (1993). From rote learning to system building: Acquiring verb morphology in children and connectionist nets. Cognition, 48, 21-69.
Pollard, C., \& Sag, I., (1994). Head-drive phrase structure grammar. Center for the Study of Language and Information, Report \# CSLI-88-132. University of Chicago.

Port, R., \& van Gelder, T. (1995). Mind as motion: Dynamical perspectives on behavior and cognition. Cambridge, MA: MIT Press.

Posner, M., Petersen, S., Fox, P., \& Raichle, M. (1988). Localization of cognitive operations in the human brain. Science, 240, 1627-1631.

Premack, D. (1971). Language in chimpanzee? Science, 172, 808-822.

Premack, D. (1976). Intelligence in ape and man. Hillsdale, NJ: Erlbaum.

Premack, A., \& Premack, D. (1983). The mind of an ape. New York: Norton.

Rasmussen, T., \& Milner, B. (1977). The role of early left brain injury in determining lateralization of cerebral speech functions. Annals of the New York Academy of Sciences, 229, 355-369.

Ratcliff, R., \& McKoon, G. (1994). Retrieving information from memory: Spreading-activation theories versus compound-cue theories. Psychological Review, 101(1), 177-184.

Reilly, J. (1995). Frog, where are you? Narratives from atypical populations. Society for Research in Child Development Abstracts, 10, 200.

Reilly, J., \& Bates, E. (1995). Frog, where are you? Narratives from children with early focal brain damage. Society for Research in Child Development Abstracts, 10, 200.

Reilly, J., Bates, E., \& Marchman, V. (in press). Narrative discourse in children with early focal brain injury. M. Dennis (Ed.), Special issue, Discourse in children with anomalous brain development or acquired brain injury. Brain and Language.

Reilly, J., Klima, E.S., \& Bellugi, U. (1991). Once more with feeling: Affect and language in atypical populations. Development and Psychopathology, 2, 367-391.

Reyes, I. (1995). Interaction of sentential and gender context in bilingual and monolingual Spanish speakers. Unpublished manuscript, University of California, San Diego.

Rice, M. (Ed.). (in press). Towards a genetics of language. Hillsdale, NJ: Erlbaum.

Rice, M., Wexler, K., \& Cleave, P. (1995) Specific language impairments as a period of extended optional infinitive. Journal of Speech and Hearing Research, 38, 850-863.

Riva, D., \& Cazzaniga, L. (1986). Late effects of unilateral brain lesions before and after the first year of life. Neuropsychologia, 24, 423-428.

Robinson, N.M., Dale, P.S., \& Landesman, S. (1990). Validity of Stanford-Binet IV with linguistically precocious toddlers. Intelligence, 14, 173-186. 
Roeper, T. (1988). Grammatical principles of first language acquisition: Theory and evidence. In F.J. Newmeyer (Ed.), Linguistics: The Cambridge Survey: Vol. II. Linguistic theory: Extensions and implications. Cambridge: Cambridge University Press.

Rubba, J., \& Klima, E.S. (1991). Preposition use in a speaker with Williams Syndrome: Some cognitive grammar proposals. Center for Research in Language Newsletter Vol. 6, No. 1. University of California, San Diego.

Rumelhart, D., \& McClelland, J.L. (Eds.). (1986). Parallel distributed processing: Explorations in the microstructure of cognition. Cambridge, MA: MIT Press.

Saffran, E.M., \& Schwartz, M.F. (1988). 'Agrammatic' comprehension it's not: Alternatives and implications. Aphasiology, 2, 389-394.

Savage-Rumbaugh, E.S. (1986). Ape language: From conditioned response to symbol. New York: Columbia University Press.

Savage-Rumbaugh, S., Brakke, K., \& Wilkinson, K. (1989). Tool use in monkeys. Behavioral and Brain Sciences, 12(3), 605.

Savage-Rumbaugh, S., Murphy, J., Sevcik, R., Brakke, K., Williams, S., \& Rumbaugh, D. (1993). Language comprehension in ape and child. Monographs of the Society for Research in Child Development, Serial \#233, Volume 58, 3-4, 222242.

Schwartz, R. (1978). Words, objects and actions in early lexical acquisition. Unpublished doctoral dissertation, Memphis State University.

Seidenberg, M.S., \& Petitto, L.A. (1979). Signing behavior in apes: A critical review. Cognition, 7, 177-215.

Seidenberg, M.S., Waters, G.S., Sanders, M., \& Langer, P. (1984). Pre- and post-lexical loci of contextual effects on word recognition. Memory \& Cognition, 12, 315-328.

Semel, E., \& Rosner, S.R. (in press). Williams Syndrome: Behavior patterns and interventions. Mahwah, NJ: Erlbaum.

Sethuraman, N., Goldberg, A.E., \& Goodman, J.C. (1996, April). Using the semantics associated with syntactic frames for interpretation without the aid of non-linguistic context. Poster presented at 28th Child Language Research Forum, Stanford, CA.

Shallice, T. (1988). From neuropsychology to mental structure. New York: Cambridge University Press.

Shankweiler, D., Crain, S., Gorrell, P., \& Tuller, B. (1989). Reception of language in Broca's aphasia. Language and Cognitive Processes, 4(1), 1-33.

Shiffrin, R.M., \& Schneider, W. (1977). Controlled and automatic human information processing: II. Perceptual learning, automatic attending and a general theory. Psychological Review, 84, 127-190.
Shillcock, R.C., \& Bard, E.G. (1993). Modularity and the processing of closed class words. In G.T.M. Altmann \& R.C. Shillcock (Eds.), Cognitive models of speech processing: The Second Sperlonga Meeting (pp. 163-183). Hove, U.K.: Erlbaum.

Shore, C.M. (1986). Combinatorial play: Conceptual development and early multiword speech. Developmental Psychology, 22, 184-190.

Shore, C.M. (1995). Individual differences in language development. Thousand Oaks, CA: Sage Publications, Inc.

Shore, C.M., O'Connell, C., \& Bates, E. (1984). First sentences in language and symbolic play. Developmental Psychology, 20, 872-880.

Simpson, G.B., \& Kang, H.W. (1994). Inhibitory processes in the recognition of homograph meanings. In D. Dagenbach \& T.H. Carr (Eds.), Inhibitory processes in attention, memory, and language (pp. 359-381). San Diego: Academic Press.

Singer, N., Bellugi, U., Bates, E., Rossen, M., \& Jones, W. (in press). Emerging language in two genetically based neurodevelopmental disorders. In D. Thal \& J. Reilly, (Eds.), Special issue on Origins of Communication Disorders, Developmental Neuropsychology.

Slobin, D. (1979). Psycholinguistics (2d ed.). Glenview, IL: Scott, Foresman.

Slobin, D. (Ed.). (1985). The crosslinguistic study of language acquisition (Vols. 1 \& 2). Hillsdale, NJ: Erlbaum.

Slobin, D. (1991). Aphasia in Turkish: Speech production in Broca's and Wernicke's patients. Brain and Language, 41, 149-164.

Slobin, D. (Ed.). (1992). The crosslinguistic study of language acquisition (Vol. 3). Hillsdale, NJ: Erlbaum.

Slobin, D. (Ed.). (in press). The crosslinguistic study of language acquisition (Vol. 4). Hillsdale, NJ: Erlbaum.

Smith, L.B., \& Thelen, E. (Eds.). (1993). A dynamic systems approach to development: Applications. Cambridge, MA: MIT Press.

Smith, S., \& Bates, E. (1987). Accessibility of case and gender contrasts for agent-object assignment in Broca's aphasics and fluent anomics. Brain and Language, 30, 8-32.

Smith, S., \& Mimica, I. (1984). Agrammatism in a case-inflected language: Comprehension of agentobject relations. Brain and Language, 21, 274-290.

Snyder, L., Bates, E., \& Bretherton, I. (1981). Content and context in early lexical development. Journal of Child Language, 8, 565-582.

Stiles, J., \& Thal, D. (1993). Linguistic and spatial cognitive development following early focal brain injury: Patterns of deficit and recovery. In $\mathrm{M}$. Johnson (Ed.), Brain development and cognition: A 
reader (pp. 643-664). Oxford: Blackwell Publishers.

Swinney, D. (1991). The resolution of indeterminacy during language comprehension: Perspectives on modularity in lexical, structural and pragmatic processing. In G.B Simpson (Ed.), Understanding word and sentence (pp. 367-385). Elsevier Science Publishers B.V. (North Holland).

Swinney, D., Zurif, E., Rosenberg, B., \& Nicol, J. (in press). Modularity and information access in the lexicon: Evidence from aphasia. Journal of Cognitive Neuroscience.

Tabossi, P., \& Zardon, F. (1993). Processing ambiguous words in context. Journal of Memory and Language, 32, 359-372.

Tallal, P., Miller, G., Bedi, G., Byma, G., Jenkins, W.M., Wang, X., Nagarajan, S.S., \& Merzenich, M.M. (1996). Language comprehension in language-learning-impaired children improved with acoustically modified speech. Science, 271 (5245), 81-84.

Tallal, P., Stark, R., \& Mellits, D. (1985). Identification of language-impaired children on the basis of rapid perception and production skills. Brain and Language, 25, 314-322.

Tanenhaus, M.K., \& Lucas, M.M. (1987). Context effects in lexical processing. Cognition, 25, 213234.

Tannenbaum, P., \& Williams, F. (1968). Generation of active and passive sentences as a function of subject or object focus. Journal of Verbal Learning and Verbal Behavior, 7, 246-250.

Thal, D. (1991). Language and cognition in latetalking toddlers. Topics in Language Disorders, $11,33-42$.

Thal, D., \& Bates, E. (1988). Language and gesture in late talkers. Journal of Speech and Hearing Research, 31,115-123.

Thal, D., Bates, E., \& Bellugi, U. (1989). Language and cognition in two children with Williams Syndrome. Journal of Speech and Hearing Research, 3, 489-500.

Thal, D., Bates, E., Goodman, J., \& Jahn-Samilo, J. (in press). Continuity of language abilities in lateand early-talking toddlers. To appear in D. Thal \& J. Reilly Eds.), Special issue on Origins of Communication Disorders, Developmental Neuropsychology.

Thal, D., Bates, E., Zappia, M.J., \& Oroz, M. (1996). Ties between lexical and grammatical development: Evidence from early talkers. Journal of Child Language, 23(2), 349-368.

Thal, D., \& Katich, J. (in press). Does the early bird always catch the worm? Predicaments in early identification of specific language impairment. In K. Cole, P. Dale, \& D. Thal (Eds.), The measurement of communication and language: Vol. 6. Assessment. Baltimore: Brookes.
Thal, D., Marchman, V., Stiles, J., Aram, D., Trauner, D., Nass, R., \& Bates, E. (1991). Early lexical development in children with focal brain injury. Brain and Language, 40, 491-527.

Thal, D., \& Reilly, J. (Eds.) (in press). Special issue on Origins of Communication Disorders, Developmental Neuropsychology.

Thelen, E., \& Smith, L.B. (1994). A dynamic systems approach to the development of cognition and action. Cambridge, MA: MIT Press.

Tomasello, M. (1992). First verbs: A case study of early grammatical development. Cambridge, UK ; New York: Cambridge University Press.

Tomasello, M. (1994). Can an ape understand a sentence? [Review of the book Language comprehension in ape and child]. Language and Communication, 14, 377-390.

Tomasello, M., \& Call, J. (in press). Primate cognition. New York: Oxford University Press.

Tomasello, M., \& Camaioni, L. (in press). A comparison of the gestural communication of apes and human infants. Human Development.

Tomasello, M., \& Merriman, W. (Eds.) (1995). Beyond names for things: Young children's acquisition of verbs. Hillsdale, NJ: Lawrence Erlbaum.

Townsend, J., Wulfeck, B., Nichols, S., \& Koch, L. (1995). Attentional deficits in children with developmental language disorder (Tech. Rep. No. CND-9503). La Jolla: University of California, San Diego, Center for Research in Language, Project in Cognitive and Neural Development.

Tyler, L.K., Ostrin, R.K., Cooke, M., \& Moss, H.E. (1995). Automatic access of lexical information in Broca's aphasics: Against the automaticity hypothesis. Brain and Language, 48(2), 131-162.

Tyler, L., \& Wessels, J. (1983). Quantifying contextual contributions to word recognition processes. Perception \& Psychophysics, 34, 409-420.

Ullman, M., Corkin, S., Pinker, S., Coppola, M., Locascio, J., \& Growdon, J.H. (1993). Neural modularity in language: Evidence from Alzheimer's and Parkinson's diseases. Society for Neuroscience Abstracts, 19(3), 1806.

Ullman, M., Corkin, S., Pinker, S., Coppola, M., Growdon, J.H., \& Locascio, J. (1994, March). The neural structures subserving language: Evidence from inflectional morphology. Poster presented at the Cognitive Neuroscience Society Inaugural Meeting, San Francisco.

Vaid, J., \& Pandit, R. (1991). Sentence interpretation in normal and aphasic Hindi speakers. Brain and Language, 41, 250-274.

Vaina, L.M., Goodglass, H., \& Daltroy, L. (1995). Inference of object use from pantomimed actions by aphasics and patients with right hemisphere lesions. Synthese, 104(1), 43-57. 
Van Berkum, J.J.A. (1996). The psycholinguistics of grammatical gender: Studies in language comprehension and production. Doctoral dissertation, Max Planck Institute for Psycholinguistics, Nijmegen, Netherlands.

Van der Lely, H.K.J. (1994). Canonical linking rules: Forward versus reverse linking in normally developing and specifically language-impaired children. Cognition, 51(1), 29-72.

Van Petten, C., \& Kutas, M. (1991). Electrophysiological evidence for the flexibility of lexical processing. In G.B. Simpson, Ed., Understanding word and sentence. Amsterdam: Elsevier.

Van Geert, P. (1994). Dynamic systems of development: Change between complexity and chaos. New York/London: Harvester Wheatsheaf.

Vargha-Khadem, F., Isaacs, E., \& Muter, V. (1994). A review of cognitive outcome after unilateral lesions sustained during childhood. Journal of Child Neurology, 9(Suppl.), 2S67-2S73.

Vargha-Khadem, F., Watkins, K., Alcock, K., Fletcher, P., \& Passingham (1995). Praxic and nonverbal cognitive deficits in a large family with a genetically transmitted speech and language disorder. Proceedings of the National Academy of Sciences USA, 92, 930-933.

Vicari, S., Brizzolara, D., Carlesimo, G.A., Pezzini, G., \& Volterra, V. (in press). Memory abilities in children with Williams syndrome. Cortex, 32(3).

Vicari, S., Pezzini, G., \& Brizzolara, D. (1994). La memoria. In A. Giannotti \& S. Vicari (Eds.), Il bambino con sindrome di Williams. Milan: FrancoAngeli.

Vihman, M., Ferguson, C., \& Elbert, M. (1986). Phonological development from babbling to speech: Common tendencies and individual differences. Applied Psycholinguistics, 7, 3-40.

Vihman, M., \& Greenlee, M. (1987). Individual differences in phonological development: Age one and age three. Journal of Speech and Hearing Research, 30, 503-528.

Vihman, M., Macken, M.A., Miller, R., Simmons, H., \& Miller, J. (1985). From babbling to speech: A reassessment of the continuity issue. Language, $61,397-445$.

Volterra, V. (1976). A few remarks on the use of the past participle in child language. Italian Linguistics, 2, 149-157.

Volterra, V., \& Bates, E. (1989). Selective impairment of Italian grammatical morphology in the congenitally deaf: A case study. Cognitive Neuropsychology, 6, 273-308.

Volterra, V., Pezzini, G., Sabbadini, L., Capirci, O., \& Vicari, S. (in press). Linguistic abilities in Italian children with Williams syndrome. Cortex.

Volterra, V., Sabbadini, L., Capirci, O., Pezzini, G., \& Osella, T. (1995). Language development in
Italian children with Williams Syndrome. Journal of Genetic Counseling, 6(1), 137-138.

Wallesch, C.-W., \& Hundsalz, A. (1994). Language function in delirium: A comparison of single word processing in acute confusional states and probable Alzheimer's Disease. Brain and Language, 46(4), 592-606.

Wang, P.P., \& Bellugi, U. (1994). Evidence from two genetic syndromes for a dissociation between verbal and visual short-term memory. Journal of Clinical and Experimental Neuropsychology, 16(2), 317322.

Wang, P.P., Doherty, S., Hesselink, J.H., \& Bellugi, U. (1992). Callosal morphology concurs with neurobehavioral and neuropathological findings in two neurodevelopmental disorders. Archives of Neurology, 49, 407-411.

Wang, P.P., Hesselink, J.H., Jernigan, T., Doherty, S., \& Bellugi, U. (1992). Specific neurobehavioral profile of Williams syndrome is associated with neocerebellar hemispheric preservation. Neurology, 42, 1999-2002.

Warrington, E., \& Shallice, T. (1984). Categoryspecific semantic impairments. Brain, 107, 829853.

Werker, J.F. (1994). Cross-language speech perception: Developmental change does not involve loss. In J.C. Goodman \& H.C. Nusbaum (Eds.), The development of speech perception: The transition from speech sounds to spoken words (pp. 93-120). Cambridge, MA: The MIT Press.

Werker, J., \& Tees, R. (1984). Cross-language speech perception: Evidence for perceptual reorganization during the first year of life. Infant Behavior and Development, 7, 49-63.

Whitaker, H. (1976). A case of the isolation of the language function. In H. \& H.A. Whitaker (Eds.), Studies in neurolinguistics. (Vol. II ). New York: Academic Press.

Wright, B., \& Garrett, M. (1984). Lexical decision in sentences. Memory \& Cognition, 12, 31-45.

Wulfeck, B. (1988). Grammaticality judgments and sentence comprehension in agrammatic aphasia. Journal of Speech and Hearing Research, 31, 72-81.

Wulfeck, B., Bates, E. (1991). Differential sensitivity to errors of agreement and word order in Broca's aphasia. Journal of Cognitive Neuroscience, 3, 258-272.

Wulfeck, B., Bates, E., \& Capasso, R. (1991). A crosslinguistic study of grammaticality judgments in Broca's aphasia. Brain and Language, 41, 311336.

Wulfeck, B., Juarez, L., Bates, E., \& Kilborn, K. (1986). Sentence interpretation strategies in healthy and aphasic bilingual adults. In J. Vaid (Ed.), Language processing in bilinguals: Psycholinguistic and neuropsychological perspectives (pp. 199-219). Hillsdale, NJ: Erlbaum. 
Wulfeck, B., Manning, T., \& Sklar, A. (1995). The temporal processing of narratives. Society for Research in Child Development Abstracts, 10, 201.

Zingeser, L.B., \& Berndt, R.S. (1990). Retrieval of nouns and verbs in agrammatism and anomia. Brain and Language, 39(1), 14-32.

Zurif, E., \& Caramazza, A. (1976). Psycholinguistic structures in aphasia: Studies in syntax and semantics. In H. \& H.A. Whitaker (Eds.), Studies in neurolinguistics (Vol. I). New York: Academic Press. 
